\title{
Radiative energy balance of Venus based on improved models of the middle and lower atmosphere
}

\author{
R. Haus ${ }^{a^{*}}$, D. Kappel ${ }^{\text {b }}$, S. Tellmann ${ }^{\text {c }}$, G. Arnold ${ }^{\text {b }}$, G. Piccioni ${ }^{\text {d }}$, P. Drossart ${ }^{\mathrm{e}}$, B. Häusler ${ }^{\mathrm{f}}$ \\ a'University of Münster (WWU), Institute for Planetology, Wilhelm-Klemm-Str.10, 48149 \\ Münster, Germany, rainer.haus@gmx.de \\ ${ }^{\mathrm{b}}$ German Aerospace Center (DLR), Institute of Planetary Research, Rutherfordstrasse 2, \\ 12489 Berlin, Germany, dkappel@gmx.net, gabriele.arnold@dlr.de \\ ${ }^{c}$ Rhenish Institute for Environmental Research at the University of Cologne, Department for \\ Planetary Reaearch, Aachener Str. 209, 50931 Köln, Germany, silvia.tellmann@ uni-koeln.de \\ ${ }^{\mathrm{d}}$ Istituto Nazionale di Astrofisica, (INAF-IAPS), Via Fosso del Cavaliere 100, 00133 Roma, \\ Italy, giuseppe.piccioni@iaps.inaf.it \\ ${ }^{\text {e}}$ Observatoire de Paris, Section de Meudon, Laboratoire d'Études Spatiales et \\ d'Instrumentation en Astrophysique (LESIA), 5 place Jules Janssen, 92195 Meudon, Cedex, \\ France, pierre.drossart@obspm.fr \\ ${ }^{\mathrm{f}}$ Bundeswehr University Munich, Institute of Space Technology and Space Applications, \\ Werner-Heisenberg-Weg 39, 85577 Neubiberg, Germany, b.haeusler@unibw.de
}

\begin{abstract}
The distribution of sources and sinks of radiative energy forces the atmospheric dynamics. The radiative transfer simulation model described by Haus et al. (2015b) is applied to calculate fluxes and temperature change rates in the middle and lower atmosphere of Venus $(0-100 \mathrm{~km})$ covering the energetic significant spectral range $0.125-1000 \mu \mathrm{m}$. The calculations rely on improved models of atmospheric parameters (temperature profiles, cloud parameters, trace gas abundances) retrieved from Venus Express (VEX) data (mainly VIRTIS-M-IR, but also VeRa and SPICAV/SOIR with respect to temperature results). The earlier observed pronounced sensitivity of the radiative energy balance of Venus to atmospheric parameter variations is confirmed, but present detailed comparative analyses of possible influence quantities ensure unprecedented insights into radiative forcing on Venus by contrast with former studies.

Thermal radiation induced atmospheric cooling rates strongly depend on temperature structure and cloud composition, while heating rates are mainly sensitive to insolation conditions and UV absorber distribution. Cooling and heating rate responses to trace gas variations and cloud mode 1 abundance changes are small, but observed variations of cloud mode 2 abundances and altitude profiles reduce cooling at altitudes $65-80 \mathrm{~km}$ poleward of $50^{\circ} \mathrm{S}$ by up to $30 \%$ compared to the neglect of cloud parameter changes. Cooling rate variations with local time below $80 \mathrm{~km}$ are in the same order of magnitude.

Radiative effects of the unknown UV absorber are modeled considering a proxy that is based on a suitable parameterization of optical properties, not on a specific chemical composition, and that is independent of the used cloud model. The UV absorber doubles equatorial heating near $68 \mathrm{~km}$. Global average radiative equilibrium at the top of atmosphere (TOA) is characterized by the net flux balance of $156 \mathrm{~W} / \mathrm{m}^{2}$, the Bond albedo of 0.76 , and the effective planetary emission temperature of $228.5 \mathrm{~K}$ in accordance with earlier results. TOA radiative equilibrium can be achieved by slight adjustments of either UV absorber or cloud mode abundances. Ratios of synthetic spectral albedo values at $0.36 \mu \mathrm{m}$ calculated for different abundance factors of the UV absorber are suggested to provide a possible tool to interpret observed VMC/VEX brightness variations with respect to actual absorber abundances.
\end{abstract}


Atmospheric net heating dominates the low and mid latitudes above $82 \mathrm{~km}$, while net cooling prevails at high latitudes at all mesospheric altitudes $(60-100 \mathrm{~km})$. This radiative forcing field has to be balanced by dynamical processes to maintain the observed thermal structure. A similar but much smaller meridional gradient is also observed at altitudes between 62 and 72 $\mathrm{km}$ where the unknown UV absorber provides additional heating. At these altitudes, equatorial net heating dominates net cooling from about 7:30 h until 16:30 h local time. Intermediate altitudes $(72-82 \mathrm{~km})$ are characterized by net cooling at all latitudes in case of VIRTIS temperature data. This planet-wide net cooling region is not observed when calculations are based on VeRa temperatures, and low latitudes are then characterized by small net heating. When a warm atmospheric layer as detected by SPICAV/SOIR around 100 $\mathrm{km}$ is considered, strong global average net cooling occurs above $90 \mathrm{~km}$ that is far away from radiative equilibrium. A weak net cooling layer (1-2 K/day) exists at altitudes between 55 and $60 \mathrm{~km}$, while very weak net heating (0.1-0.5 K/day) takes place near the cloud base $(48 \mathrm{~km})$. Almost zero net heating prevails in the deep atmosphere below $44 \mathrm{~km}$. On global average, the entire atmosphere of Venus at altitudes between 0 and $90 \mathrm{~km}$ is not far away from radiative equilibrium (usually within $\pm 2 \mathrm{~K} /$ day).

Maximum temperature change rate deviations from mean values at each altitude and latitude are defined based on retrieved atmospheric parameter single standard deviations using VIRTIS data. This is an important prerequisite to investigate parameterization approaches for the calculation of atmospheric temperature change rates that can be used in Global Circulation Models. This will be a major topic of future studies on radiative energy balance of Venus' atmosphere.

\section{Introduction}

Physical processes in a planetary atmosphere are based on three fundamental influence quantities, the input of solar energy including spatial and temporal variations due to both the planet's movement around its sun and its axial rotation, the release of energy by heated bodies, and the forces that result from planetary gravitation and rotation. Radiative energy conversion stimulates dynamical processes at all atmospheric levels and determines climate and weather in the lower atmosphere via a number of coupling effects. One of the main mysteries in our solar system is the atmospheric superrotation that is present on Venus and on Saturn's moon Titan. The origin of this phenomenon and the driving forces for the winds that blow faster than the bodies rotate are not well understood yet. To improve insights into atmospheric dynamics especially on Venus, detailed radiative energy balance studies are necessary. They will provide input parameters for General Circulation Models (GCMs) that are used to simulate and explain observed dynamical properties (e.g. Lebonnois et al., 2010).

Calculation of the radiative budget at each level of the atmosphere that is determined by absorption and scattering of solar radiation as well as thermal emissions requires precise knowledge of the thermal state, gaseous and particulate constituent distributions, and specific interaction processes between radiation and matter considering spatial and temporal variations of atmospheric parameters.

Early orbital and lander missions to Venus (Mariner 2, 5, 10; Venera 4-16; Pioneer Venus 1+2; Vega 1+2; Magellan) and space experiments during the Venus flybys of Galileo/NIMS and Cassini/VIMS revealed basic information about pressure and temperature conditions on the surface, chemical composition, thermal structure and cloud composition of the atmosphere, largescale atmospheric circulation features as well as surface topography (Arnold et al., 2012). But in spite of the many successful measurements, some fundamental problems 
in the physics of the planet remained unsolved. In particular, a systematic and long-term survey of the atmosphere was missing (Titov et al., 2008a).

Former analyses of radiative processes in the atmosphere of Venus were mainly based on Pioneer Venus and Venera-15 data (e.g. Pollack et al., 1980; Schofield and Taylor, 1982; 1983; Tomasko et al., 1985; Crisp, 1986, 1989; Haus and Goering, 1990; Titov, 1995). Summaries of knowledge about the planetary energy balance characteristics and of open issues were given by Crisp and Titov (1997), Taylor (2006), and Titov et al. (2006, 2007, 2013). These investigations already revealed a strong sensitivity of radiative energy balance to atmospheric parameter variations like changes of temperature structure, cloud microphysical properties, and vertical distributions of individual cloud mode abundances. However, all these parameters were not strongly constrained by measurements before Venus Express with its great planetary mapping potential. Moreover, early analyses were hampered by computational constraints during that time, and the use of band models for gaseous absorbers was mostly unavoidable.

The latest mission to Venus (ESA's Venus Express, VEX) has carried the most powerful remote sensing suite of instruments ever flown to Earth's sister planet. Together with the other instruments (VMC, SPICAV/SOIR, VeRa, ASPERA, MAG), the Visible and Infrared Thermal Imaging Spectrometer VIRTIS has enabled for the first time a long-time study of the structure, composition, chemistry, and dynamics of the atmosphere and the cloud system, as well as investigations of the thermal and compositional characteristics of the planetary surface. VIRTIS (Piccioni et al., 2007a; Drossart et al., 2007; Arnold et al., 2012) provided an enormous amount of new data and a four-dimensional picture of the planet Venus (2D imaging, spectral dimension, temporal variations) on global scales. The spectral dimension permits a sounding of atmospheric properties at different altitude levels. VIRTIS-M-IR measurements during eight Venus solar days between April 2006 and October 2008 have been used by Haus et al. $(2013,2014,2015 a)$ to retrieve information on mesospheric nightside thermal structure and cloud features and on trace gas distributions in the lower atmosphere using new methodical approaches. Resulting maps for the southern hemisphere have covered parameter variations with altitude, latitude, local time, and mission time.

Temperature profile and cloud top altitude retrieval results using VIRTIS-M-IR spectra were also reported by Grassi et al. (2010, 2014). Tellmann et al. (2009) used VeRa data to determine temperature profiles at altitudes between 45 and $90 \mathrm{~km}$, while SPICAV/SOIR occultation measurements provided profiles at 90-140 / 80-170 km (Piccialli et al., 2014; Mahieux et al., 2012). Altimetry of the Venus cloud top based on VIRTIS, VMC, and VeRa data was also investigated by Titov et al. (2008b), Ignatiev et al. (2009), and Lee et al. (2012). Trace gas distributions below the cloud bottom based on VIRTIS-M-IR and - $\mathrm{H}$ measurements were studied by Tsang et al. (2008, 2009, 2010), Marcq et al. (2008), Bézard et al. (2009). The only recent two-dimensional analysis (altitude-latitude) of both radiative cooling and radiative heating in the atmosphere of Venus that considers atmospheric parameters retrieved from VEX instrument data (VeRa temperatures, VIRTIS-M-IR cloud parameters) was performed by Lee et al. (2015).

It is the main goal of the present paper to investigate atmospheric radiation fluxes $(F)$ and temperature change rates $(\mathrm{Q})$ in the middle and lower atmosphere of Venus $(0-$ $100 \mathrm{~km}$ ) that are mainly based on improved three-dimensional atmospheric models (altitude-latitude-local time) retrieved from VIRTIS-M-IR data. An additional focus is the response of $\mathrm{Q}$ to the replacement of VIRTIS temperature profiles by VeRa data. The used approach is premised on the recently published precursor work of Haus et al. (2015b) where the mathematical and computational tools have been 
comprehensively outlined. Moreover, detailed studies of $F$ and $Q$ variability for possible atmospheric parameter variations based on initial atmospheric standard models have been performed there. $\mathrm{F}$ and $\mathrm{Q}$ responses to spectroscopic model changes have been also analyzed. These results enabled many new and improved insights into radiative cooling and heating characteristics. They now serve as reference for present investigations.

A summary of methodical approaches and recent modeling results to investigate the radiative energy balance of Venus is provided in retrospect in Section 2. Section 3 gives an overview of atmospheric parameter retrieval results obtained from VIRTIS-M-IR measurements by some of the present authors. Section 4 describes the used model of the unknown UV absorber in Venus' mesosphere. Section 5 presents detailed results on radiative temperature change rates that are based on these improved models of the middle and lower atmosphere and compares the recalculated quantities with previous results obtained for an atmospheric standard model. Section 6 contains additional discussions on the role of the UV absorber, the Q variability based on VIRTIS data, comparisons of calculated $Q$ profiles for VIRTIS temperature data with those determined from VeRa and SPICAV/SOIR temperature data, and comparisons of $\mathrm{Q}$ with recent results from the literature. The main results are summarized in Section 7.

\section{Retrospect}

This section recites the main methodical approaches and modeling results on Venus' radiative energy balance from the recently published paper by Haus et al. (2015b). Calculated responses of radiative fluxes and temperature change rates to atmospheric and spectroscopic parameter variations were based on distinct variations of initial (standard) model data sets rather than using actual retrieval results especially with respect to cloud feature changes with latitude.
A radiative transfer simulation model (RTM) that includes the discrete ordinate package DISORT (Discrete Ordinates Radiative Transfer, Stamnes et al., 1988) was applied to calculate thermal and solar radiance and flux spectra in the atmosphere of Venus. The solar irradiance spectrum of Kurucz (2011) was selected as standard insolation model. The RTM considers absorption, emission, and multiple scattering by gaseous and particulate constituents over the broad spectral range $0.125-1000 \mu \mathrm{m}$. The individual contributions of these constituents at infrared (0.7-1000 $\mu \mathrm{m})$, visible (0.4-0.7 $\mu \mathrm{m})$, and ultraviolet (0.1-0.4 $\mu \mathrm{m})$ wavelengths as well as infrared continuum absorption and molecular Rayleigh scattering were addressed. Look-up tables of quasimonochromatic absorption cross-sections of gaseous constituents were used in the infrared and visible spectral ranges that were calculated on the basis of a line-by-line procedure for a variety of temperature and pressure values being representative for Venus' atmosphere at altitude levels between the surface and $140 \mathrm{~km}$. These tables were generated for different sets of spectroscopic parameters including very fine spectral sampling steps, different spectral line catalogs, and variations of line shapes with respect to line cut and sub-Lorentz structure.

The atmospheric models required for RTM operation encompass altitude profiles of temperature and pressure, gas abundances, and cloud mode particle densities as well as cloud mode composition. Initial standard models were selected so far. The thermal structure of Venus' atmosphere was described by latitude-dependent temperature altitude profiles that were merged from the VIRA-1 (Seiff et al., 1985) and VIRA-2 (Zasova et al., 2006) data sets assuming identical thermal regimes on the nightside and dayside of the planet up to $95 \mathrm{~km}$. A characteristic dayside profile was considered above $95 \mathrm{~km}$ (Keating et al., 1985). The standard model of minor constituent altitude distributions was similar to that described by Tsang et al. (2008). The used standard model of cloud mode altitude profiles (Haus et al., 2013) facilitates analytical descriptions of 
four-modal particle altitude distributions (modes 1, 2, 2', 3) where all modes are assumed to consist of spherical $\mathrm{H}_{2} \mathrm{SO}_{4}$ aerosols at $75 \mathrm{wt} \%$ solution. Mie scattering theory (Wiscombe, 1980) was applied to derive wavelength-dependent microphysical parameters (absorption, scattering, and extinction cross-sections, single scattering albedo, asymmetry parameter, phase function moments) of each mode. Lognormal particle radius distributions were used for all four modes with modal radii of $0.3, \quad 1.0, \quad 1.4, \quad 3.65 \mu \mathrm{m}$ and unitless dispersions of $1.56,1.29,1.23,1.28$, respectively (Pollack et al., 1993). Refractive index data were taken from Palmer and Williams (1975) $(0.36-25 \mu \mathrm{m})$ and Jones (1976) $(20-50 \mu \mathrm{m})$, respectively. To bridge the gap in the Palmer-Williams imaginary index data between 1.8 and $2.9 \mu \mathrm{m}$, measurements of Carlson and Anderson (2011) were integrated into a new complete refractive index database for $\mathrm{H}_{2} \mathrm{SO}_{4}$ aerosols.

Using available measurements of Venus' spectral Bond albedo (summarized by Moroz, 1981 and Moroz et al., 1985), a new model for the unknown UV absorber was developed. This species being located at altitudes between 57 and $70 \mathrm{~km}$ was required to fit the observations shortward of $0.8 \mu \mathrm{m}$ down to $0.32 \mu \mathrm{m}$, while $\mathrm{SO}_{2} \mathrm{UV}$ absorption provided sufficient opacity at shorter wavelengths. The calculations also included $\mathrm{UV}$ absorptions by $\mathrm{CO}_{2}, \mathrm{H}_{2} \mathrm{O}, \mathrm{OCS}$, and $\mathrm{HCl}$ shortward of $0.3 \mu \mathrm{m}$. They were identified to be dominated by carbon dioxide. Laboratory data on UV absorption cross-sections were taken from various literature sources (see Haus et al., 2015b for details). The new UV absorber model, which will be also used in present studies, is not directly linked to cloud particle modes 1 or 2 (contrary to previous models provided by Pollack et al., 1980 and Crisp, 1986), and thus, permits an investigation of its radiative effects regardless of chemical composition and independently of the used cloud model. By analogy with a previously proposed model of Crisp (1986), two different altitude distributions were assumed. Based on these profiles, altitude-independent absorption cross-section spectra were calculated ('retrieved') that yielded good fits of the Bond albedo spectrum presented by Moroz (1981). Both models provided a globally averaged Bond albedo of 0.763 in excellent agreement with Moroz et al. (1985).

Downward and upward directed radiation fluxes inside the atmosphere as well as resulting net fluxes and net flux divergences with respect to altitude were calculated based on quasi-monochromatic absorption and scattering properties of all atmospheric constituents and based on the mentioned atmospheric standard models. These calculations were performed separately for thermal $\left(1.67-1000 \mu \mathrm{m}, 10-6000 \mathrm{~cm}^{-1}\right)$ and solar $\left(0.125-1000 \mu \mathrm{m}, 10-80000 \mathrm{~cm}^{-1}\right)$ flux components. Wavelength-integrated quantities and diurnal averages were then used to determine temperature change rates at each altitude in terms of thermal cooling rates and solar heating rates. Contributions of individual atmospheric constituents as well as contributions of different $\mathrm{CO}_{2}$ absorption bands to the total temperature change rates were investigated.

On global average (GA) and for the used atmospheric standard models, half of the solar flux received at TOA (the top of atmosphere, $F^{\mathrm{TOA}-\mathrm{GA}}=667 \mathrm{~W} / \mathrm{m}^{2}$ ) is either absorbed or redistributed by $\mathrm{CO}_{2}$ and cloud mode 1 and 2 particles at altitudes above 74 $\mathrm{km}$. The sum of direct and diffuse downward solar fluxes attains the 50\% level of TOA flux at $55 \mathrm{~km}$ where the unknown UV absorber has made a major contribution of about 15\%. Considering both globally averaged downward and upward solar flux components (that is, the solar net flux), half of the solar flux deposited on the planet at TOA altitude $(140 \mathrm{~km})$ is absorbed by atmospheric constituents at altitudes above $63 \mathrm{~km}$. Less than $5 \%$ of solar TOA flux (30 $\mathrm{W} / \mathrm{m}^{2}$ ) reaches the surface. The thermal downward flux near the surface is 16.5 $\mathrm{kW} / \mathrm{m}^{2}$. The globally averaged solar flux deposited on the planet (the solar net flux at TOA) and the outgoing thermal net flux for the used atmospheric standard models differ by about $1.5 \mathrm{~W} / \mathrm{m}^{2}$ around the mean value of 
$159 \mathrm{~W} / \mathrm{m}^{2}$, which very well corresponds to the calculated value of $(157 \pm 6) \mathrm{W} / \mathrm{m}^{2}$ reported by Titov et al. (2007). Considering the uncertainties in both TOA values, this discrepancy was not interpreted as an indication of global radiative imbalance. Exact TOA global radiative equilibrium was achieved by moderate adjustments of cloud mode and UV absorber abundances. There is a general trend of decreasing solar flux with increasing distance from equator, while the outgoing thermal flux shows a peculiarity of Venus compared with Earth and Mars. It only weakly decreases between $30^{\circ}$ and $60^{\circ}$, but then increases again toward the poles. These results were in good agreement with those obtained by Schofield and Taylor (1982).

The responses of net fluxes and temperature change rates to variations of spectroscopic parameters were studied in great detail to provide estimates of their uncertainties with respect to individual parameters. These results remain valid for any atmospheric parameter model. The use of $\mathrm{CO}_{2}$ absorption cross-section databases at a spectral wavenumber grid step (called point distance PD) of $0.01 \mathrm{~cm}^{-1}$ was found to be sufficiently accurate. Differences compared with higher resolution databases are usually less than $0.01 \mathrm{~K} /$ day at altitudes below $90 \mathrm{~km}$ and do not exceed $0.3 \mathrm{~K} /$ day at $100 \mathrm{~km}$. Based on a careful separation of spectral ranges that are dominated by more or less strong gaseous absorption bands, an optimum PD grid was developed that considerably accelerates the time expensive monochromatic flux calculations without introducing significant accuracy losses. Individual spectral ranges outside the strong absorption bands can be modeled by using coarser PD grids of 0.1 , 1.0 and even $10 \mathrm{~cm}^{-1}$. Maximum deviations of cooling rates as well as heating rates at the subsolar point obtained for the optimum and the reference grid $\left(0.01 \mathrm{~cm}^{-1}\right)$ are smaller than $0.1 \mathrm{~K} /$ day below $85 \mathrm{~km}$. At $100 \mathrm{~km}$, solar heating rate deviations may reach 2.3 $\mathrm{K} /$ day, but the uncertainties of diurnally averaged heating rates are much smaller. Using the optimum PD grid and precalculated absorption cross-sections, the
RTM run over either the thermal or solar spectral range for one latitude (and one solar zenith angle in case of heating) takes about six minutes on current desktop hardware.

Largest uncertainties of temperature change rates were identified when different spectral line catalogs were used. Compared with the default dataset HITRAN 2008 (Rothman et al., 2009), HITEMP 2010 (Rothman et al., 2010) for example would produce $3 \mathrm{~K} /$ day less heating and $0.3 \mathrm{~K} /$ day more cooling at $100 \mathrm{~km}$, while the deviations with respect to net heating would partly compensate between 70 and $90 \mathrm{~km}$. The use of different sub-Lorentz line shapes and line cut conditions did not significantly alter cooling and heating results above $50 \mathrm{~km}$, but for accurate thermal flux and cooling rate calculations in the region of the cloud base $(48 \mathrm{~km})$, the use of a line cut condition $v_{\mathrm{c}}$ of at least $250 \mathrm{~cm}^{-1}$ was recommended. This way, continuum absorption due to distant spectral line wings is considered sufficiently accurate. Present investigations even use $v_{c}=$ $350 \mathrm{~cm}^{-1}$. The deep atmosphere $\mathrm{CO}_{2}$ high pressure-induced continuum absorption, which plays an important role in the deep atmosphere of Venus below about $45 \mathrm{~km}$, was found to be completely negligible in energy balance calculations. Its consideration was very important, however, when lower atmosphere and surface features (cloud parameters, trace gas abundances, surface emissivity) were retrieved from measured radiance spectra (Haus et al., 2013, 2014, 2015b; Kappel et al., 2015, 2016). It was concluded that the calculated cooling and heating rates are very reliable at altitudes below $85 \mathrm{~km}$ with maximum uncertainties of about $0.25 \mathrm{~K} /$ day. Cooling uncertainties did not increase between 85 and $95 \mathrm{~km}$, but heating uncertainties could reach 3-5 K/day at $100 \mathrm{~km}$. It was stated that the use of equivalent Planck radiation as solar insolation source in place of measured solar spectra should be avoided, since it seriously overestimates solar heating shortward of 0.4 $\mu \mathrm{m}$. On the other hand, there is no significant difference with respect to heating rates when the Kurucz solar insolation spectrum 
(Kurucz, 2011) is replaced by ASTM Standard E490-00a (2006).

There is a strong response of cooling rates to variations of atmospheric thermal structure, while heating rates are less sensitive. Except for observed episodic strong $\mathrm{SO}_{2}$ abundance boosts, the overall response of the radiative energy balance to trace gas variations is rather small in the mesosphere, but trace gas variations (especially $\mathrm{H}_{2} \mathrm{O}$ and $\mathrm{SO}_{2}$ ) near the cloud base may become more important. The influence of mode 1 cloud particles was found to be comparatively small. When their column abundance was halved, both cooling and heating responses did not exceed 0.12 $\mathrm{K} /$ day at $70 \mathrm{~km}$ with decreasing tendency toward higher and lower altitudes. On the other hand, changes of mode 2, 2', and 3 parameters (cloud top and base altitudes, total mode abundances, upper scale height) may significantly alter radiative temperature change rates up to $50 \%$ in Venus' lower mesosphere and upper troposphere. The new nominal model for the unknown UV absorber provides a doubling of heating near $70 \mathrm{~km}$ at equatorial latitudes compared with a neglect of this opacity source.

Preliminary results on globally averaged heating and cooling rates revealed basic conformity with earlier results from the literature (Crisp, 1986; Crisp, 1989; Tomasko et al., 1985; Haus and Goering, 1990; Lee and Richardson, 2011), although some details were different. This was explained by the fact that each of these investigations used different atmospheric and spectroscopic model parameters. The sensitivity studies performed by Haus et al. (2015b) did not yet consider variations of cloud features with latitude that may result in significant changes of calculated temperature change rates. According to these preliminary results, a broad net cooling region was identified between 70 and $80 \mathrm{~km}$ with a strong increase of cooling toward the poles. A latitudinal net rate gradient was also observed at $65 \mathrm{~km}$ where heating prevailed at low latitudes. At altitudes above $80 \mathrm{~km}$, net heating dominated the low and mid latitudes, while net cooling prevailed at high latitudes leading to a dominant global average net heating. It was concluded that the observed thermal structure in the Venus mesosphere can only be maintained by dynamical processes.

\section{Atmospheric parameter retrieval results based on VIRTIS measurements}

New methodical approaches for selfconsistent temperature profile and cloud parameter retrievals from VIRTIS-M-IR nightside radiation measurements were applied to investigate both the thermal structure and cloud features of Venus' atmosphere on the northern and southern hemisphere (Haus et al., 2013, 2014). VIRTIS-M-IR was the mapper optical subsystem of the VIRTIS instrument at moderate spectral resolution (FWHM $\sim 17$ $\mathrm{nm}$ ) in the infrared spectral range from 1.0 to $5.1 \mu \mathrm{m}$. Temperature and cloud influences on measured spectra were carefully separated to allow for explicit cloud parameter studies. A data selection strategy was developed that is especially useful for statistical exploration of massive data sets. Combined radiative transfer and multi-window retrieval techniques (MWR) were used for a simultaneous processing of information from different spectral ranges of an individual spectrum. Mesospheric temperature altitude profiles were determined from $4.3 \mu \mathrm{m} \mathrm{CO}_{2}$ absorption band signatures, using Smith's relaxation method (Smith, 1970) and a prescribed initial temperature model that was based on the Venus International Reference Atmosphere (VIRA). Specific parts of the $4.3 \mu \mathrm{m}$ band wings as well as of the deep atmosphere transparency window at $2.3 \mu \mathrm{m}$ were utilized to derive cloud parameters (cloud top altitude, mode abundance factors, opacity).

\subsection{Thermal structure}

The $4.3 \mu \mathrm{m}$ band sounds the altitude range of about $60-95 \mathrm{~km}$. Outside these bounds, the temperature weighting functions become very small, and retrieved temperatures tend 
to follow the initial profiles. The proper specification of initial profiles is very important, therefore, since radiation flux calculations extend over the entire altitude range from the surface up to $140 \mathrm{~km}$ including ranges where temperature retrievals from IR and other measurements are not possible and other than VIRA profiles are not available.

The initial (or 'standard') model of Venus' atmospheric thermal structure was described by Haus et al. (2013, 2014) by latitudedependent (zonally averaged) temperature altitude profiles that were merged from the VIRA-1 (Seiff et al., 1985) and VIRA-2 (Zasova et al., 2006) data sets assuming identical thermal regimes on the nightside (N) and dayside (D) of the planet up to 95 $\mathrm{km}$. The notation VIRA-2 was originally introduced by Moroz and Zasova (1997). It was maintained in previous publications by the present authors and is also used here. VIRA-1 was compiled in 1982-1983 and published in 1985. It considers data from early US and USSR Venus missions and (for that time) latest results from the Pioneer Venus mission 1978. VIRA-2 summarizes measurement results from missions that had been completed after the early work on VIRA-1. It includes results from infrared thermal soundings performed by Venera-15 (1983), the Vega 2 entry probes (1985), and Galileo NIMS (1990) as well as radio occultation profiles from Venera-15/16 and Magellan (1990) data. VIRA-2 provides latitude and solar longitude-dependent temperature profiles at altitudes between 50 and $100 \mathrm{~km}$. To construct the pure latitudedependent standard model, these data have been averaged over solar longitude (local time) at first. Below $40 \mathrm{~km}$, the VIRA-1 profiles are used, which are local time independent models from the outset. Profiles between 40 and $50 \mathrm{~km}$ are obtained by linear interpolation between both models. Standard profiles above $90 \mathrm{~km}$ result from a linear interpolation between the latitude-dependent VIRA-2 temperatures at $90 \mathrm{~km}$ and a fixed value of $165 \mathrm{~K}$ at $100 \mathrm{~km}$. A latitudeindependent linear profile then extends to $140 \mathrm{~K}$ at $140 \mathrm{~km}$ altitude. This is the so- called 'VIRA-N' standard temperature distribution model for the Venus nightside as presented by Haus et al. (2013). These authors have assumed that atmospheric temperatures at fixed latitude and averaged over local time below about $95 \mathrm{~km}$ are not expected to be very different on the day- and nightside of Venus as it was measured by the Pioneer Venus probes in 1978 (Seiff and Kirk, 1982) and confirmed by 2006 radiooccultation data (VeRa, Tellmann et al., 2009). Individual local time dependent profiles, however, may show significant deviations from averaged ones. Pressure profiles for the standard VIRA-N model are determined by integrating the hydrostatic equation and using a surface pressure of 92.1 bar at zero elevation.

The temperatures on the day- and nightside of Venus start to diverge at altitudes above $95 \mathrm{~km}$. At this altitude, VIRA-1, VIRA-2, and VIRA-N profiles below $95 \mathrm{~km}$ converge to about $170 \mathrm{~K}$. For present flux calculations, the top of the atmosphere (TOA) is set to an altitude of $140 \mathrm{~km}$ to avoid discontinuities at $100 \mathrm{~km}$ (the assumed upper boundary of Venus' mesosphere). A latitude-independent dayside temperature profile is used between 100 and $140 \mathrm{~km}$ (Keating et al., 1985). Linear interpolations connect the VIRA-N nightside model at $95 \mathrm{~km}$ with this data set to construct the day time profile (VIRA-D).

Temperature field retrievals from VIRTIS measurements were only performed using nightside data, since it is very difficult to discriminate between thermal radiation, scattered sunlight and $\mathrm{CO}_{2}$ non-LTE emission features at VIRTIS wavelengths on the dayside. Due to instrumental noise in the main center of the $4.3 \mu \mathrm{m}$ band, the effective upper sounding altitude of VIRTIS-M-IR reduces to $84 \mathrm{~km}$. Retrieved temperature profiles above $84 \mathrm{~km}$ were modified by a linear interpolation between 84 and $90 \mathrm{~km}$ where the $90 \mathrm{~km}$ temperatures correspond to the initial (standard) values. On the other hand, retrievals work also well at altitudes below the lower sounding level $(\sim 60 \mathrm{~km})$ by constraining them to fit the latitude- 
dependent initial temperature profiles at 56 km (Haus et al., 2013).

Fig. 1 shows retrieved zonally averaged mean temperature profiles $\mathrm{T}(\mathrm{z})$ between 50 and $100 \mathrm{~km}$ altitude at seven latitudes in the southern hemisphere of Venus. The notation 'mean' used here and always later on refers

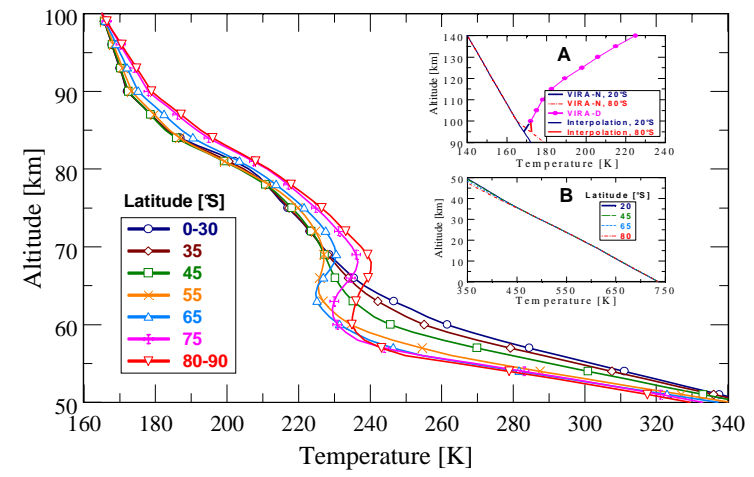

Fig. 1. Zonally averaged mean temperature altitude profiles at selected latitudes based on retrieved values from VIRTIS nightside measurements and VIRA-N initial profiles. Inset A: Extended range 90-140 km for nightside and dayside. Inset B: Extended range 0$50 \mathrm{~km}$. See text for more details.

to the mean state of atmospheric parameters (and resulting radiative quantities) that was determined from retrieval results for many individual (and statistically representative) VIRTIS measurements at each grid point of a local time and latitude space grid. Southern hemisphere results are based on VIRTIS-MIR mapping data where the number of used spectra varied in dependence on latitude and local time. Maximum numbers occurred at mid latitudes near midnight. For completeness, the two insets illustrate the atmospheric thermal structure above $90 \mathrm{~km}$ (A) and below $50 \mathrm{~km}$ (B) that is used in present energy balance calculations. Inset A visualizes nightside and dayside profiles that are assumed to be latitude-independent at altitudes above $100 \mathrm{~km}$.

Fig. 2 shows the retrieved zonally averaged mean nightside temperature field (display A) and the corresponding temperature variability (standard deviation $\sigma_{\mathrm{T}}$, display $\mathrm{B}$ ) as functions of latitude and altitude. $\sigma_{\mathrm{T}}$ values were calculated using all spectra that were processed at a certain latitude and for each local time. Temperature values between
0 and $10^{\circ} \mathrm{S}$ and also poleward of $85^{\circ} \mathrm{S}$ are extrapolated due to lacking data coverage. Since an extrapolation of local time dependent temperature results is now also performed to include local times that were not sufficiently covered by VIRTIS data (e.g. near the terminators), Fig. 2 slightly differs from Figures 7 and 9 presented by Haus et al. (2014). Variability is zero above $90 \mathrm{~km}$ and below $56 \mathrm{~km}$ as discussed above.

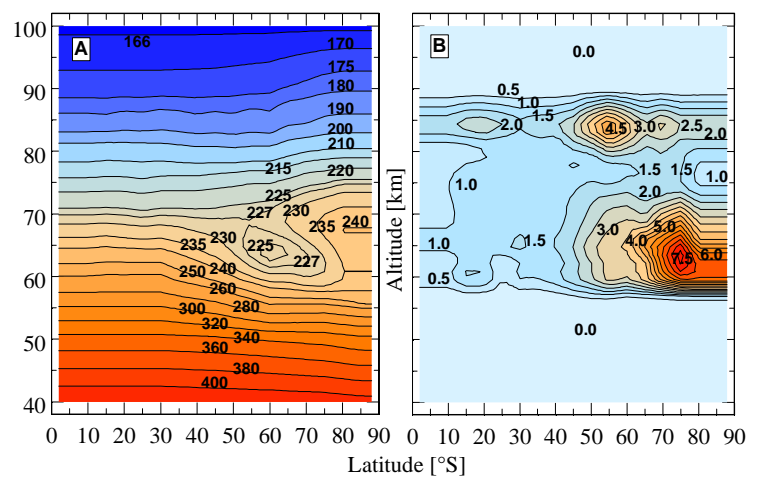

Fig. 2. A: Zonally averaged mean nightside temperature field as function of latitude and altitude based on retrieved values from VIRTIS nightside measurements. B: Corresponding standard deviations. Temperatures and standard deviations are given in $[\mathrm{K}]$.

The main features of the retrieved zonally averaged temperature field correspond to previous results from Pioneer Venus Infrared Radiometer and Venera-15-PMV data (Taylor et al., 1980; Zasova et al., 2006, 2007) and also well agree with analyses of VIRTIS-M-IR data (Grassi et al., 2010) and VeRa data (Tellmann et al., 2009). Observed similarities between northern and southern hemisphere temperature fields (not shown here, but see Haus et al., 2013) indicate global N-S axial symmetry of atmospheric temperature structure. Temperatures equatorward of $30^{\circ} \mathrm{S}$ are nearly constant with latitude at fixed altitudes. They decrease quite continuously poleward of $30^{\circ} \mathrm{S}$ below $58 \mathrm{~km}$. The pole is colder by about $40 \mathrm{~K}$ at $55 \mathrm{~km}$ altitude and colder by $20 \mathrm{~K}$ at $50 \mathrm{~km}$. Recall that retrieved temperature profiles below about $58 \mathrm{~km}$ tend to follow the initial profile (VIRA-N) due to the lack of weighting functions. At latitudes between 55 and $75^{\circ} \mathrm{S}$, there is a strong temperature inversion layer centered between 62 and 67 $\mathrm{km}$ altitude. It is well known as the cold 
collar'. Another striking feature of Venus' temperature field is a warmer region poleward of $70^{\circ} \mathrm{S}$, which is centered at 60-70 $\mathrm{km}$. This phenomenon is called 'hot dipole' due to its double-eyed, highly variable structure over the pole that was observed on both hemispheres (Piccioni et al., 2007b). These two features, mainly the cold collar, divide the atmosphere vertically. Below the collar, the temperature decreases with increasing distance from equator at the same altitude. At altitudes above about $70 \mathrm{~km}$, the temperature increases from the equator to the pole. Polar regions are warmer than equatorial regions by $10-15 \mathrm{~K}$ at altitudes up to about $90 \mathrm{~km}$.

The cold collar region exhibits the strongest temperature variability (display B) with values of $7-8 \mathrm{~K}$ near $62 \mathrm{~km}$ and $75^{\circ} \mathrm{S}$. This may correspond to absolute temperature changes of about $30 \mathrm{~K}\left(\mathrm{~T} \pm 2 \sigma_{\mathrm{T}}\right) \cdot \sigma_{\mathrm{T}}$ values below $57 \mathrm{~km}$ and above $90 \mathrm{~km}$ are very small or even zero. This indicates the altitudes where retrieved temperatures tend to follow the initial ones due to the lack of appropriate weighting functions.

Temperatures retrieved from VIRTIS measurements are often slightly lower than VIRA-N values with maximum deviations of $4 \mathrm{~K}$ near $65 \mathrm{~km}$ and $65^{\circ} \mathrm{S}$. This holds true at all altitudes from low to higher latitudes, while poleward of $75^{\circ} \mathrm{S}$, VIRTIS temperatures are slightly higher compared to VIRA-N between 60 and $70 \mathrm{~km}$ by up to 2.5

$\mathrm{K}$. But the differences between VIRTIS and VIRA-N temperatures are usually not larger than the observed temperature variability of VIRTIS results shown in Fig. 2B. This was a good argument for using VIRA-N profiles in the precursor study (Haus et al., 2015b) on radiative energy balance responses to atmospheric temperature profile changes.

Considering local time (LT) dependent thermal profiles, retrieval results can be sorted into different kinds of twodimensional maps where temperatures are sampled either "vertically" (as functions of latitude and altitude at fixed local times and as functions of local time and altitude at fixed latitudes, respectively) or "horizontally" (as functions of local time and latitude) at fixed altitude levels of the atmosphere.

Two "horizontal" maps are exemplarily shown in Fig. 3 for altitudes of $65 \mathrm{~km}$ (display A) and $80 \mathrm{~km}$ (display B). Displays $\mathrm{C}$ and $\mathrm{D}$ describe corresponding temperature differences from the zonally averaged (ZA) temperature field (Fig. 2A), $\left.\Delta \mathrm{T}(\mathrm{LT}, \varphi)=\mathrm{T}(\mathrm{LT}, \varphi)-\mathrm{T}_{\mathrm{ZA}}(\varphi)\right] . \quad$ Absolute differences between mean local time dependent and mean zonal average nightside temperatures do not exceed $5 \mathrm{~K}$ at fixed latitude and local time. This corresponds well to the findings of Grassi et al. (2010).

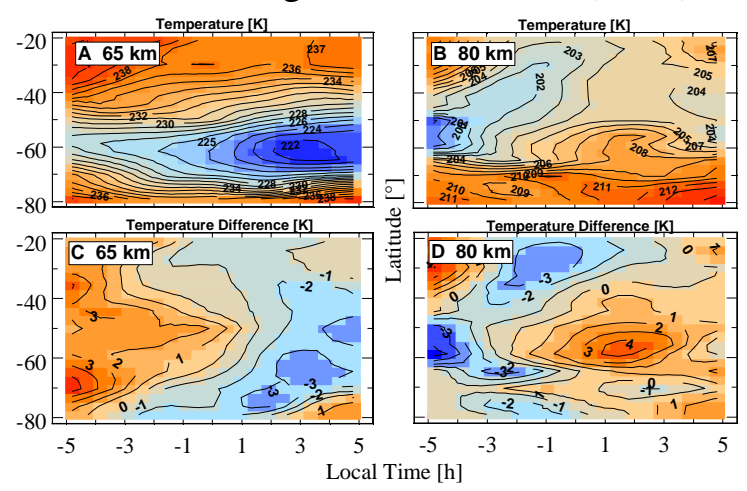

Fig. 3. Mean temperature fields as functions of local time and latitude at altitudes $65 \mathrm{~km}(\mathrm{~A})$ and $80 \mathrm{~km}(\mathrm{~B})$ as retrieved from VIRTIS measurements. Displays (C) and (D) show corresponding differences between local time dependent and local time averaged mean temperatures. Local time $-5 \mathrm{~h}$ corresponds to 19:00 $\mathrm{h}$. From Haus et al. (2014).

Near $65 \mathrm{~km}$ and equatorward of $75^{\circ} \mathrm{S}$, the atmosphere is warmer at early night and colder at late night. Keeping in mind that only mean temperatures are visualized in Fig. 3, the temperature at $65{ }^{\circ} \mathrm{S}$ decreases from $232 \mathrm{~K}$ at 19:00 $\mathrm{h}$ to $222 \mathrm{~K}$ at 03:00 h and remains almost constant during the rest of night. Local time dependent temperature standard deviations $\sigma_{\mathrm{T}}$ (not shown here, but see Figure 15 in Haus et al., 2014) are particularly large at $65 \mathrm{~km}$ at high latitudes $\left(70-80^{\circ} \mathrm{S}\right)$ in the first two thirds of night and reach maximum values of about $9 \mathrm{~K}$ near midnight. Temperature variability is also large in the region of the cold collar, which extends northward to about $55-60^{\circ} \mathrm{S}$. The 0 $\mathrm{K}$ isoline in the temperature difference map (Fig. 3C) fluctuates around midnight 
between 45 and $65^{\circ} \mathrm{S}$, but it is located near 21:00 $\mathrm{h}$ at low and high latitudes. Toward the end of night, polar latitude temperatures tend to increase again.

Near $80 \mathrm{~km}$ and poleward of $45^{\circ} \mathrm{S}$, the atmosphere is colder at early night and warmer at late night, thus showing a reversed trend compared with $65 \mathrm{~km}$. Strongest temperature changes occur between 50 and $60^{\circ} \mathrm{S}$ with local minima and maxima of 198 and $209 \mathrm{~K}$ at 19:00 $\mathrm{h}$ and 02:00 $\mathrm{h}$, respectively. Equatorward of $45^{\circ} \mathrm{S}$, a cell of warmer air (up to $211 \mathrm{~K}$ at $30^{\circ} \mathrm{S}$ ) is observed at early night, which cools down to $202 \mathrm{~K}$ at 23:00 h. As in case of more southern latitudes, temperature then increases toward the end of night. Local time dependent temperature standard deviations $\sigma_{\mathrm{T}}$ at $80 \mathrm{~km}$ (not shown here) are much smaller compared with $65 \mathrm{~km}$ and usually not exceed $2.5 \mathrm{~K}$ at all latitudes.

\subsection{Cloud parameters}

The initial (or standard) model of cloud particle number density distribution functions that is adapted from the precursor work of Haus et al. (2015b) is shown in Fig. 4. Supplemental information is given in Tables 1 and 2 . Note that Table 1 slightly differs from the versions used by Haus et al. (2013, 2014, 2015a) as will be explained below. An advantage of this model consists in the possibility to describe cloud particle distributions of all four modes by simple analytical expressions (see footnote Table 1). The figure also displays the cumulative cloud optical depth (COD) at $1 \mu \mathrm{m}$ that was calculated using $\mathrm{H}_{2} \mathrm{SO}_{4}$ microphysical parameters of the four modes characterized in Section 2. Unity COD is reached at 70.8 $\mathrm{km}$, and the total column optical depth (denoted as cloud opacity in the following) for this standard cloud model is 35.0 at 1 $\mu \mathrm{m}$. The altitude of unity optical depth $(C O D=1.0)$ is usually denoted as "cloud top altitude $\mathrm{z}_{\mathrm{t}}$ '. Since aerosol microphysical parameters are functions of wavelength according to their refractive index specifics, any optical depth and cloud top altitude results can be easily referenced to a selected wavelength (here $1 \mu \mathrm{m}$ ). Table 2 provides corresponding values at other wavelengths. Note that cloud top altitudes longward of about $2 \mu \mathrm{m}$ are considerably lower than at shorter wavelengths and reach about $59 \mathrm{~km}$ in the range of the $15 \mu \mathrm{m} \mathrm{CO} \mathrm{CO}_{2}$ absorption band that dominates thermal cooling of the atmosphere. $\mathrm{z}_{\mathrm{t}}$ further decreases down to 50 $\mathrm{km}$ near $166 \mu \mathrm{m}\left(60 \mathrm{~cm}^{-1}\right)$.

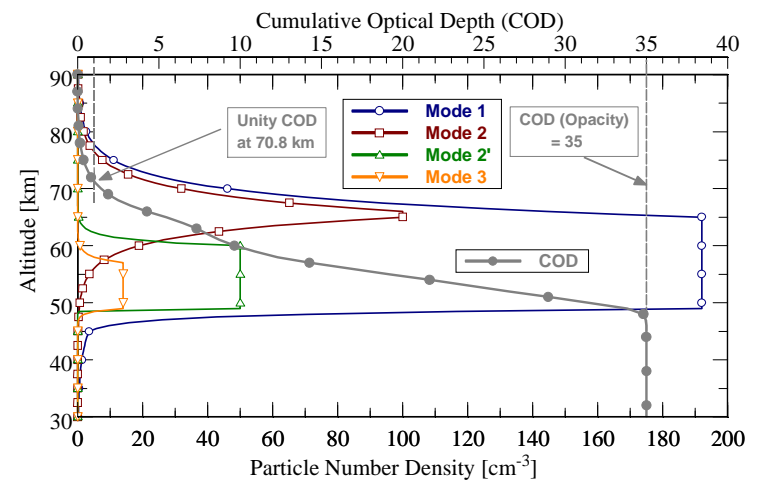

Fig. 4. Standard model of cloud particle distribution with altitude.

The method to retrieve parameters of Venus' clouds was extensively described by Haus et al. $(2013,2014)$. The applied self-consistent temperature profile and cloud parameter multi-window retrieval technique made simultaneous use of information from different atmospheric transparency windows and absorption bands of an individual spectrum. It iteratively optimized the parameters until the simulated radiance spectrum well fitted the measurement for all utilized spectral ranges in the least-squares sense. The determined parameters were interpreted to represent the state of atmosphere that led to the observed spectrum. Dedicated spectral ranges of both the $4.3 \mu \mathrm{m} \mathrm{CO}_{2}$ absorption band and the 2.3 $\mu \mathrm{m}$ transparency window were used to disentangle influences of temperature profile, so-called cloud mode factors $\mathrm{MF}_{1,2}$ for modes 1 and 2, and cloud mode factor $\mathrm{MF}_{3}$ for mode 3. The cloud mode factors $\mathrm{MF}_{\mathrm{i}}$ change the column densities independently for each cloud mode i, but maintain their altitude distribution that is determined by the standard cloud model. Mode 1 aerosols play a minor role at IR wavelengths. They were treated together with mode 2 aerosols in the original retrieval procedures. Mode 2' 
abundance changes could not be retrieved, and $\mathrm{MF}_{2}$, $=1.0$ was always used assuming that possible changes were reflected by mode 3 variations. Moreover, these original Table 1. Parameters of the standard cloud model: Single-mode characteristics. Values in parentheses for mode 1 refer to the version used by Haus et al. (2013, 2014, 2015a).

\begin{tabular}{|c|c|c|c|c|}
\hline Mode & 1 & 2 & $2^{\prime}$ & 3 \\
\hline Lower base of peak altitude $\mathrm{z}_{\mathrm{b}}[\mathrm{km}]$ & 49.0 & $65.0^{\mathrm{a}}$ & 49.0 & 49.0 \\
\hline $\begin{array}{l}\text { Layer thickness of constant peak particle number } \\
z_{c}[\mathrm{~km}]\end{array}$ & 16.0 & 1.0 & 11.0 & 8.0 \\
\hline Upper scale height $\mathrm{H}_{\text {up }}[\mathrm{km}]$ & $\begin{array}{l}3.5^{\mathrm{b}} \\
(5.0)\end{array}$ & $3.5^{\mathrm{a}, \mathrm{b}}$ & 1.0 & 1.0 \\
\hline Lower scale height $\mathrm{H}_{\mathrm{lo}}[\mathrm{km}]$ & $1.0^{\mathrm{c}}$ & 3.0 & 0.1 & 0.5 \\
\hline Particle number density $\mathrm{N}_{0}$ at $\mathrm{z}_{\mathrm{b}}\left[\mathrm{cm}^{-3}\right]^{\mathrm{d}}$ & $\begin{array}{l}193.5^{\mathrm{a}} \\
\left(181.0^{\mathrm{a}}\right)\end{array}$ & $100^{\mathrm{a}}$ & 50 & $14^{\mathrm{a}}$ \\
\hline $\begin{array}{l}\text { Total column particle number density } \\
{\left[10^{5} \mathrm{~cm}^{-2}\right]}\end{array}$ & $\begin{array}{l}3982.04^{\mathrm{a}} \\
\left(3970.75^{\mathrm{a}}\right)\end{array}$ & $748.54^{\mathrm{a}}$ & 613.71 & $133.86^{\mathrm{a}}$ \\
\hline $\begin{array}{l}\text { Total column optical depth (opacity) } \\
\text { at } 1 \mu \mathrm{m} \text {,ff }\end{array}$ & $\begin{array}{c}3.88^{\mathrm{a}} \\
\left(3.87^{\mathrm{a}}\right)\end{array}$ & $7.62^{\mathrm{a}}$ & 9.35 & $14.14^{\mathrm{a}}$ \\
\hline $\begin{array}{l}\text { Altitude of unity optical depth } \mathrm{z}_{\mathrm{t}}[\mathrm{km}] \\
\text { at } 1 \mu \mathrm{m}^{\mathrm{e}, \mathrm{f}}\end{array}$ & $\begin{array}{c}63.19^{\mathrm{a}} \\
\left(64.25^{\mathrm{a}}\right)\end{array}$ & $70.36^{\mathrm{a}}$ & 59.71 & $57.50^{\mathrm{a}}$ \\
\hline
\end{tabular}

${ }^{\mathrm{a}}$ Values may change with latitude.

${ }^{\mathrm{b}}$ An upper scale height of $2 \mathrm{~km}$ is assumed above $80 \mathrm{~km}$.

${ }^{c}$ A lower haze is considered below $45 \mathrm{~km}$ using $\mathrm{H}_{\mathrm{lo}}=5 \mathrm{~km}$.

${ }^{\mathrm{d}}$ The particle number density altitude profile $\mathrm{N}(\mathrm{z})$ is calculated according to

$$
N(z)=\left\{\begin{array}{ll}
N_{0}\left(z_{b}\right) \exp \left[-\left(z-\left(z_{b}+z_{c}\right)\right) / H_{u p}\right], & z>\left(z_{b}+z_{c}\right) \\
N_{0}\left(z_{b}\right), & \left(z_{b}+z_{c}\right) \geq z \geq z_{b} \\
N_{0}\left(z_{b}\right) \exp \left[-\left(z_{b}-z\right) / H_{l o}\right], & z<z_{b}
\end{array}\right\}
$$

${ }^{\mathrm{e}}$ New version mode 1: The total cloud ensemble yields an opacity of 35.0 and $\mathrm{z}_{\mathrm{t}}=70.81 \mathrm{~km}$ (cf. Table 2).

${ }^{\mathrm{f}}$ Old version mode 1: The total cloud ensemble yielded an opacity of 35.0 and $\mathrm{z}_{\mathrm{t}}=71.31 \mathrm{~km}$.

Table 2. Parameters of the (new) standard cloud model: Opacity and top altitude $z_{t}$ at different wavelengths $\lambda$ and wavenumbers $v$, respectively.

\begin{tabular}{lccccccccc}
\hline$\lambda[\mu \mathrm{m}]$ & 15 & 10 & 5 & 2.5 & 1.5 & 1.0 & 0.55 & 0.35 & 0.2 \\
$v\left[\mathrm{~cm}^{-1}\right]$ & 667 & 1000 & 2000 & 4000 & 6667 & 10000 & 18182 & 28570 & 50000 \\
\hline Opacity & 15.29 & 28.34 & 25.59 & 32.09 & 39.95 & 35.00 & 34.72 & 33.17 & 31.84 \\
$\mathrm{z}_{\mathrm{t}}[\mathrm{km}]$ & 59.35 & 66.56 & 66.39 & 68.93 & 71.33 & 70.81 & 70.45 & 70.23 & 70.04 \\
\hline
\end{tabular}

maximum mode 2 particle number density in the standard cloud model resides at 65-66 $\mathrm{km}$ (cf. Fig. 5 and Table 1). Even the assignment of an upper aerosol scale height close to zero in the simulations did not fit the measurements at high latitudes. The parameters $\mathrm{z}_{\mathrm{up}}$ and $\mathrm{MF}_{\mathrm{i}}$ were used to calculate the cumulative optical depth altitude profiles $u(z)$, and thus, the actual cloud top altitude $\mathrm{z}_{\mathrm{t}}$ and the total cloud opacity.

$\underline{\text { Fig. } 5}$ shows retrieved zonal averages and standard deviations $\sigma$ of mean cloud mode factors $\mathrm{MF}_{1,2}$ (display A), cloud mode factor $\mathrm{MF}_{3}$ (display B), resulting cloud opacity at 1 
$\mu \mathrm{m}$ (display C), and cloud top altitude $\mathrm{z}_{\mathrm{t}}$ at 1 $\mu \mathrm{m}$ (display D) as functions of latitude for the southern hemisphere. Since no usable VIRTIS data were available to retrieve parameters equatorward of $10^{\circ} \mathrm{S}$ and poleward of $80^{\circ} \mathrm{S}$, values at $0,5,85$, and $90^{\circ} \mathrm{S}$ were set equal to the corresponding values at 10 and $80^{\circ} \mathrm{S}$, respectively. $\sigma_{\mathrm{MF}}$ values were calculated using all spectra that were processed at a certain latitude and for each local time. The general latitude dependence of these cloud parameters was found to be very similar on both hemispheres (Haus et al., 2014), but the reliability of an average over strongly time-dependent cloud features depends on the number of measurements, which is much larger on the southern hemisphere.

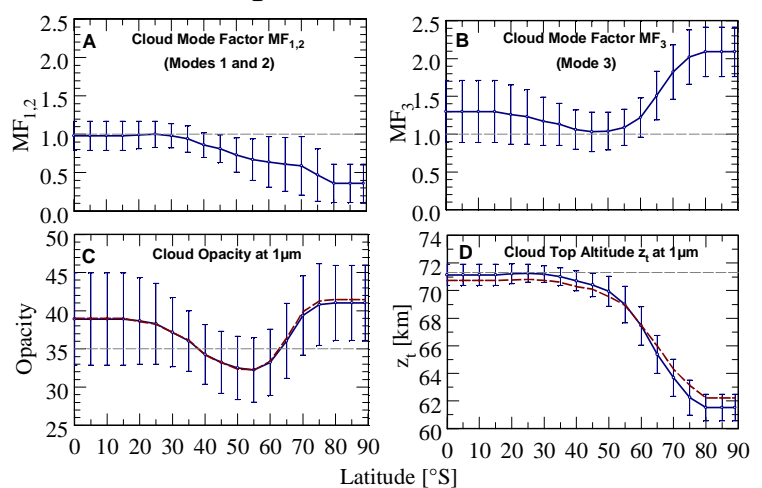

Fig. 5. Zonally averaged mean cloud parameters and their standard deviations as functions of latitude based on retrieved values from VIRTIS nightside measurements. The broken curves in displays $\mathrm{C}$ and $\mathrm{D}$ describe changes due to retrieval scheme modifications.

Mode 1 and 2 factors $\left(\mathrm{MF}_{1,2}\right)$ are fairly constant at equatorial latitudes up to $30^{\circ} \mathrm{S}$ with values close to the standard ones (1.0, indicated by the horizontal broken line). $\mathrm{MF}_{1,2}$ gradually decrease poleward of $30^{\circ} \mathrm{S}$. They reach minimum values of about 0.35 near the pole. $\mathrm{MF}_{1,2}$ standard deviations range between 0.15 and 0.35 . Factor $\mathrm{MF}_{3}$ slowly decreases from the equator up to $45^{\circ} \mathrm{S}$ where it exhibits a minimum value close to the standard value (1.0, indicated by the horizontal broken line). $\mathrm{MF}_{3}$ strongly increases poleward of $55^{\circ} \mathrm{S} . \mathrm{MF}_{3}$ standard deviations range between 0.25 and 0.40 . The combined influence of $\mathrm{MF}_{1,2}$ and $\mathrm{MF}_{3}$ is reflected in the latitudinal behavior of opacity with larger values compared with the standard one (horizontal broken line at 35.0) equatorward of $35-40^{\circ} \mathrm{S}$ and poleward of $60-$ $65^{\circ} \mathrm{S}$, and lower values at intermediate latitudes. Opacity is minimal at $55^{\circ} \mathrm{S}$ where the standard deviation has also a minimum (about 4). Standard deviations increase up to 5 and 6 close to the pole and the equator, respectively.

The horizontal broken line in display D corresponds to the cloud top altitude $\mathrm{z}_{\mathrm{t}}=71.3$ $\mathrm{km}$ resulting from the cloud standard model in the original retrieval procedure. Note that this value is slightly higher than the one given in Fig. $4(70.8 \mathrm{~km})$. The reason will be discussed below where the meaning of the broken curves in displays $\mathrm{C}$ and $\mathrm{D}$ is also explained. There is a slow decrease of cloud top altitude $(1 \mu \mathrm{m})$ from about $71 \mathrm{~km}$ at the equator to about $70 \mathrm{~km}$ at $50^{\circ} \mathrm{S} . \mathrm{z}_{\mathrm{t}}$ quickly drops poleward of $50^{\circ} \mathrm{S}$ and reaches about $61.5 \mathrm{~km}$ over the poles. Standard deviations extend between 0.6 and $1.3 \mathrm{~km}$ with maximum values near $60^{\circ} \mathrm{S}$. These findings are in good qualitative correspondence with earlier results (Zasova et al., 2006; Ignatiev et al., 2009; Lee et al., 2012) including observed scatter. This was discussed in more detail by Haus et al. (2013).

These results revealed that the average particle size in the vertical cloud column increases from mid latitudes toward the poles. This corresponds to the findings by Wilson et al. (2008) and Lee et al. (2012) who identified larger particles in the south polar atmosphere of Venus. Analyzing Galileo NIMS data, Grinspoon et al. (1993) concluded that mode 3 particle abundance variations represent the dominant source of observed opacity variations in the lower and middle clouds, and that the total cloud optical depth varies between 25 and 40 . VIRTIS observations yield a zonal average opacity range between 32 and 41 with a range extension to about 28 and 46 according to the depicted standard deviations. Note that much smaller or larger individual opacities were observed in an interval of $\pm 2 \sigma$ that then includes $95 \%$ of possible values assuming a normal distribution. This is plausible due to the high 
temporal variability of cloud features. Since the concentration of larger particles also increases from mid latitudes toward equatorial latitudes, it was concluded by Haus et al. (2014) that equatorial and polar latitudes are covered by thicker clouds than mid latitudes between 30 and $60^{\circ} \mathrm{S}$. It should be mentioned here that the retrieval errors described by Haus et al. (2014) did refer to the errors that were determined from synthetic spectra retrievals. Present error bars correspond to real variations calculated from the full processed VIRTIS data sets.

Cloud opacity is the most vigorously varying state parameter of Venus' atmosphere. Not only with respect to latitude but also regarding local time, the cloud formation patterns are very complex. Partly adverse features are observed at NIR wavelengths as detailed maps of opacity as functions of local time and latitude for different solar days have shown (Haus et al., 2014). This is mainly due to the well-known superrotation of the cloud cover, which encircles the planet in about four Earth days. The overall variability of cloud mode factors $\mathrm{MF}_{\mathrm{i}}$ and cloud top altitude $\mathrm{Z}_{\mathrm{t}}$ (parameters that determine cloud opacity) with latitude and local time is also very complex. In most cases, variations with local time (found from mean VIRTIS spectra processing) are below the standard deviations depicted in Fig. 5. Thus, the specification of certain cloud parameter trends with local time from VIRTIS nightside measurements was not possible. Note that local time variations of $z_{t}$ on the dayside were reported to stay below $\pm 1.0 \mathrm{~km}$ (Ignatiev et al., 2009; Cottini et al., 2012). Consequently, retrieved zonal averages of cloud parameters will be always used when local time dependent features of temperature change rates are investigated below.

Fig. 6 (display A) illustrates the influence of the retrieved parameter $\mathrm{z}_{\mathrm{up}}$ (cloud upper altitude boundary) on mode 2 particle abundance distribution with altitude ('retrieval scheme 1'). The sharp cut of the upper part of the standard distribution at higher latitudes was required to fit observed brightness spectra as already described above. The curves merge below the respective cut altitude. Detailed studies on the influence of particle distribution on simulated spectra in comparison with measured VIRTIS and Venera-15 Fourier spectrometer (PMV) data (Figure 26 shown by Haus et al., 2013) revealed that the measurements in both the $4.3 \mu \mathrm{m}$ and $15 \mu \mathrm{m}$ band regions could be nearly equally well fitted by different mode 2 altitude distributions, since occurring differences in observed brightness temperatures were always compensated by simultaneous changes in retrieved temperature profiles and cloud parameters. Since there is no 'absolute truth' information available, it was not possible to specify a 'best choice' initial model. The somewhat synthetic 'cut approach' that was applied to both mode 1 and 2 particles did work very well, but from the physical point of view it seems to be more realistic to search for an alternative method that can avoid the profile cut, and thus, the extreme sharp upper cloud margin, which leads to a complete cloud-free polar atmosphere at altitudes above $65 \mathrm{~km}$ in the simulations.

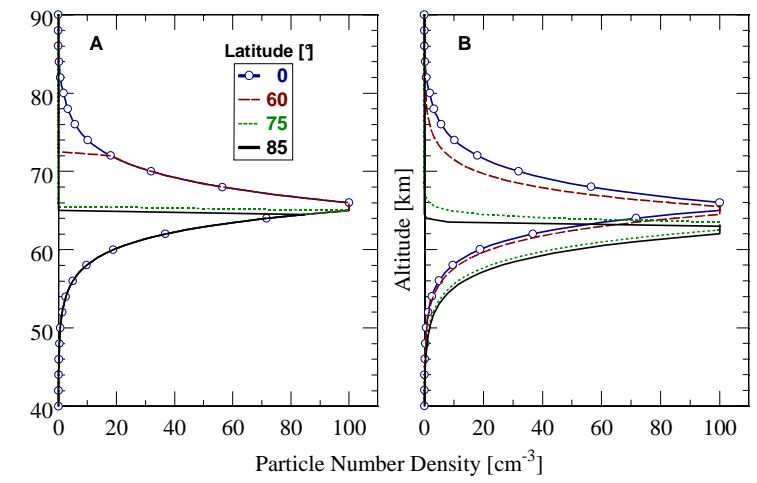

Fig. 6. Influence of different retrieval schemes on cloud mode 2 particle abundance distribution with altitude. A: use of upper altitude boundary parameter $\left(\mathrm{z}_{\mathrm{up}}\right)$, B: use of parameters scale height $\left(\mathrm{H}_{\mathrm{up}}\right)$ and lower base of peak altitude $\left(\mathrm{z}_{\mathrm{b}}\right)$.

Based on these arguments, a modification of the self-consistent temperature profile and cloud parameter multi-window retrieval technique is now applied ('retrieval scheme 2 '). Instead of cutting the mode abundance profiles according to the retrieved $\mathrm{z}_{\mathrm{up}}$ values, the upper scale height of mode $2, \mathrm{H}_{\text {up }}(2)$, is reduced in dependence on latitude to fit all 
measurements equatorward of $60^{\circ} \mathrm{S}$. The mode 1 standard distribution is always left unchanged (allowing the simulated upper haze to exist at all latitudes), but the upper scale height $\mathrm{H}_{\text {up }}(1)$ is now set to $3.5 \mathrm{~km}$ instead of $5.0 \mathrm{~km}$ in the original model (cf. Table 1). A second small change is applied to the former standard cloud model with respect to modes 1 and 2. At altitudes above $80 \mathrm{~km}$, the upper scale heights for both modes are reduced from 3.5 to $2.0 \mathrm{~km}$. This ensures a faster decrease of cloud particle abundances at these altitudes in accordance with Crisp (1986). Omission of the profile cut for modes 2' and 3 does not change the retrieval results, since both modes are located at lower altitudes where the formerly applied cut technique was not effective in any case.

These changes in the retrieval procedures provide again very good fits of measured brightness temperature spectra at all latitudes from the equator poleward up to about $60^{\circ} \mathrm{S}$, but at higher latitudes, the mode 2 scale height decrease alone does no longer produce satisfactory fits. Thus, the lower base of mode 2 peak altitude $\mathrm{z}_{\mathrm{b}}(2)$ (cf. Table 1) is additionally shifted from $65 \mathrm{~km}$ downward step by step with increasing (absolute) latitude, and yet reducing its scale height further on. This effect is illustrated in Fig. 6 (display B). The corresponding latitude-dependent parameters $\mathrm{z}_{\mathrm{b}}(2)$ and $\mathrm{H}_{\text {up }}(2)$ are summarized in Table 3 . They are the results of numerous trial and error tests that were aimed at reproducing the originally retrieved temperature and cloud parameter fields with respect to altitude and latitude as close as possible, while a good agreement of measured and simulated radiance spectra was the most important concern.

Maximum temperature changes due to the two different retrieval schemes do not exceed $0.3 \mathrm{~K}$ at any altitude and latitude, and corresponding plots are omitted here, therefore. The maximum temperature difference of hemispheric average profiles for the two schemes is below $0.1 \mathrm{~K}$ at each altitude. The retrieved cloud mode factors are also quite insensitive against the applied model modifications, and the mode factors and their standard deviations shown in Fig. 5 remain almost unaffected. Maximum factor changes are in the order of 0.03 . The retrieved zonally averaged mean parameters $\mathrm{MF}_{1,2}$ and $\mathrm{MF}_{3}$ are given in Table 4.

Table 3. Latitude dependence of mode 2 cloud parameters. $\varphi$ : Latitude [ $\left.{ }^{\circ} \mathrm{S}\right], \mathrm{z}_{\mathrm{b}}$ : Lower base of peak altitude [km], $\mathrm{H}_{\mathrm{up}}$ : Upper scale height $[\mathrm{km}]$.

\begin{tabular}{lcccccccc}
\hline$\varphi$ & $0-45$ & 50 & 55 & 60 & 65 & 70 & 75 & $80-90$ \\
\hline $\mathrm{z}_{\mathrm{b}}$ & 65.0 & 65.0 & 65.0 & 64.5 & 63.8 & 63.1 & 62.5 & 62.0 \\
$\mathrm{H}_{\text {up }}$ & 3.5 & 3.4 & 3.2 & 2.6 & 2.0 & 1.0 & 0.6 & 0.5 \\
\hline
\end{tabular}

Table 4. Latitude dependence of retrieved cloud mode abundance factors. $\varphi$ : Latitude [ ${ }^{\circ}$ S], $\mathrm{MF}_{1,2}: \mathrm{Mode}_{1}$ and 2 factors, $\mathrm{MF}_{3}$ : Mode 3 factor.

\begin{tabular}{lcccccccccccccc}
\hline$\varphi$ & $0-15$ & 20 & 25 & 30 & 35 & 40 & 45 & 50 & 55 & 60 & 65 & 70 & 75 & $80-90$ \\
\hline $\mathrm{MF}_{1,2}$ & 0.98 & 0.99 & 1.00 & 0.98 & 0.94 & 0.86 & 0.81 & 0.73 & 0.67 & 0.64 & 0.61 & 0.59 & 0.47 & 0.36 \\
$\mathrm{MF}_{3}$ & 1.30 & 1.26 & 1.23 & 1.17 & 1.13 & 1.06 & 1.03 & 1.04 & 1.09 & 1.22 & 1.51 & 1.82 & 2.02 & 2.09 \\
\hline
\end{tabular}

Comparing cloud opacities and top altitudes obtained from the two retrieval schemes, opacities at high latitudes are identified to be slightly higher for the new retrieval scheme 2 , since both the mode factors $\mathrm{MF}_{1,2}$ and $\mathrm{MF}_{3}$ are now slightly higher here, while they mostly compensate (slightly lower $\mathrm{MF}_{1,2}$ and higher $\mathrm{MF}_{3}$ or vice versa) at low and mid latitudes. The scheme 2 results are described by the broken line in Fig. 5C. Cloud top altitudes equatorward of $55^{\circ} \mathrm{S}$ are somewhat smaller according to the new retrieval scheme (up to $0.5 \mathrm{~km}$ ), while they become slightly higher (again up to $0.5 \mathrm{~km}$ ) at high latitudes (see broken line in Fig. 5D). This behavior is mainly due to the different mode 1 parameter $H_{\text {up }}(1)$ (cf. Table 1). The new upper scale height $3.5 \mathrm{~km}$ instead of $5.0 \mathrm{~km}$ results in smaller mode 1 cloud abundance above $65 \mathrm{~km}$ at low latitudes, and optical 
depths of 1.0 are reached only deeper in the atmosphere (now $70.8 \mathrm{~km}$ instead of $71.3 \mathrm{~km}$ for $\mathrm{MF}_{1,2}=1.0$ ). The same mechanism works of course at high latitudes, but former calculations have used the upper profile cut even for mode 1 particles (that was only effective at higher latitudes). Since this step is now omitted in the new retrieval scheme, there are more particles in the vertical column at high latitudes than before, and unity optical depth is reached at somewhat higher altitudes.

This detailed analysis of cloud parameter results based on two different retrieval schemes illustrates an important fact. The definition of parameters like the cloud top altitude always requires a careful description of the exact implementation of the forward model used during the retrieval of these quantities. Different models may produce different numerical results even though these results may be physically equivalent.

The hemispheric (unweighted with latitude) average of cloud opacity derived from VIRTIS data in the southern hemisphere is $37.5 \pm 5.0$ at $1 \mu \mathrm{m}$. The corresponding cloud mode factors are $\mathrm{MF}_{1,2}=0.75 \pm 0.23$ and $\mathrm{MF}_{3}=1.42 \pm 0.33$. These numbers slightly differ from those reported by Haus et al. (2014), since latitude averaging is now performed between 0 and $90^{\circ} \mathrm{S}$. When a weighting of latitude $\varphi$ dependent cloud parameters is used where the weights correspond to $\cos (\varphi)$, the southern hemispheric averages are 37.0 \pm 5.1 , $0.87 \pm 0.21$, and $1.27 \pm 0.34$, respectively. The changes in the three parameters compared with unweighted averages reflect the lower weight of high latitudes.

Fig. 7 displays altitude profiles of retrieved zonally averaged cumulative cloud optical depths $\mathrm{u}(\mathrm{z})$ (COD) at four different wavelengths and five latitudes in each case. Profiles for the new standard model ('S') and locations of corresponding cloud top altitudes are also shown. Single atmospheric layer values of optical depth are important input quantities for DISORT that is currently used for radiative transfer simulations.
Above about $53 \mathrm{~km}$ and apart from the equator, $\mathrm{u}^{1 \mu \mathrm{m}}(\mathrm{z})$ is usually smaller compared with the standard model. Below that altitude, $\mathrm{u}^{1 \mu \mathrm{m}}(\mathrm{z})$ is larger at equatorial and polar latitudes but smaller at mid latitudes (in accordance with Fig. 5C). At altitudes below $45 \mathrm{~km}, \mathrm{u}^{1 \mu \mathrm{m}}(\mathrm{z})$ remains nearly constant down to the surface. Increments due to contributions from the lower haze do no exceed $0.1 \%$ of $45 \mathrm{~km}$ values. Absolute $\mathrm{u}(\mathrm{z})$ values as well as their altitude-dependent change with latitude look different at other wavelengths due to the strong wavelength dependence of aerosol microphysical parameters. Below about $57 \mathrm{~km}$, optical depths at all latitudes and at depicted wavelengths $(5,12,20 \mu \mathrm{m})$ are larger than the standard model values (cf. Table 2), but mid latitude results are still smaller than those at low and high latitudes. The inset in Fig. 7C that is a zoom of the main figure reveals that CODs at altitudes above $57 \mathrm{~km}$ are always smaller than standard model CODs except for the equator. This is a consequence of retrieved $\mathrm{MF}_{1,2}$ values that are significantly smaller than 1.0 at latitudes poleward of $35^{\circ} \mathrm{S}$ (cf. Fig. 5A). Zooms of the other figures look similar. Reduced cumulative cloud optical depths at altitudes above $57 \mathrm{~km}$ and the latitude-specific behavior of single layer depths due to varying cloud mode factors have a huge influence on resulting temperature change rates as will be shown below.

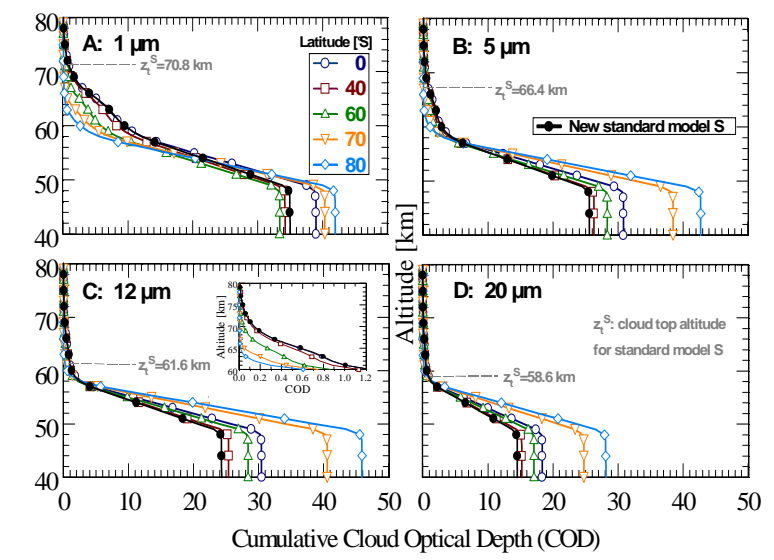

Fig. 7. Altitude profiles of retrieved zonally averaged cumulative cloud optical depths at four wavelengths and five latitudes. New standard model results are additionally given. The inset in display $\mathrm{C}$ is a zoom into the lefthand part of $12 \mu \mathrm{m}$ results. 


\subsection{Trace gas abundances}

Water vapor $\left(\mathrm{H}_{2} \mathrm{O}\right)$, carbon monoxide $(\mathrm{CO})$, sulfur dioxide $\left(\mathrm{SO}_{2}\right)$, and carbonyl sulfide (OCS) are the most important radiatively active trace gases (also denoted as minor constituents) in the atmosphere of Venus. Hydrogen halides $(\mathrm{HCl}, \mathrm{HF})$ play a minor role. Fig. 8 shows the used standard model of trace gas abundance altitude distributions that essentially correspond to that of Tsang et al. (2008). The main gaseous constituent $\mathrm{CO}_{2}$ has a vertically uniform volume mixing ratio of $9.65 \cdot 10^{5}$ ppmv. $\mathrm{H}_{2} \mathrm{O}$ and $\mathrm{SO}_{2}$ are assumed to be uniformly mixed in the lower atmosphere below $50 \mathrm{~km}$ with volume mixing ratios of 32.5 and 150 ppmv, respectively. $\mathrm{CO}$ and OCS are modeled to have a constant mixing ratio of 20 and 15 ppmv below about $30 \mathrm{~km}$. While CO abundance increases to about $50 \mathrm{ppmv}$ at 60 $\mathrm{km}$, OCS abundance quickly drops down to 0.05 ppmv at this altitude. $\mathrm{CO}$ enhancement at altitudes above $70 \mathrm{~km}$ is due to the photolysis of $\mathrm{CO}_{2}$ by UV radiation above the cloud tops. $\mathrm{HCl}$ and $\mathrm{HF}$ are assumed to be uniformly mixed with mixing ratios of 500 and 5 ppbv, respectively. The $\mathrm{D} / \mathrm{H}$ ratio is considered as 150 times the telluric one (de Bergh et al., 1991).

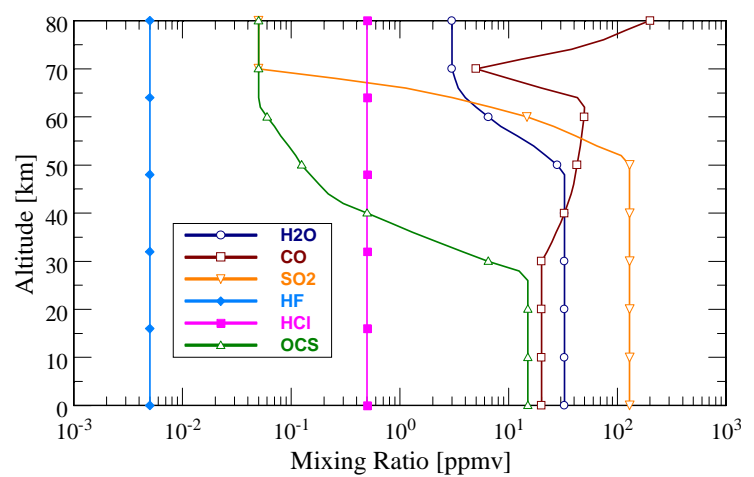

Fig. 8. Standard model of volume mixing ratios of trace gases.

It was concluded in the precursor study (Haus et al., 2015b) that the overall response of the radiative energy balance to trace gas variations is rather small in the mesosphere (except for observed episodic strong $\mathrm{SO}_{2}$ abundance boosts), but trace gas variations (especially $\mathrm{H}_{2} \mathrm{O}$ and $\mathrm{SO}_{2}$ ) near the cloud base may become more important. Hence, available data on latitudinal variability of trace gas abundances are included in the present study.

Atmospheric minor constituent abundances for $\mathrm{CO}$, OCS, and $\mathrm{H}_{2} \mathrm{O}$ have recently been retrieved from measured VIRTIS-M-IR spectra in the $2.3 \mu \mathrm{m}$ transparency window in the southern hemisphere of Venus (Haus et al., 2015a). A so-called gas factor ' $\mathrm{GF}_{\mathrm{i}}$ ' was specified that modifies the initial (standard) gas i mixing ratio profile at all atmospheric levels, that is, it changes the total atmospheric column density of that gas. Unfortunately, the $2.3 \mu \mathrm{m}$ window is only sensitive to the altitude range of about 30-40 $\mathrm{km}$, and retrieval results mostly reflect abundance changes at altitudes between 35 and $37 \mathrm{~km}$. If, for example, a carbon monoxide factor of 1.1 has been retrieved, this means that the $\mathrm{CO}$ mixing ratio at $35 \mathrm{~km}$ is 28.9 instead of 26.3 ppmv as given by the standard model shown in Fig. 8. This does not necessarily mean, however, that the near surface mixing ratio is 22 instead of 20 ppmv. Nevertheless, the retrieved gas factors are used over the entire altitude range as outlined above.

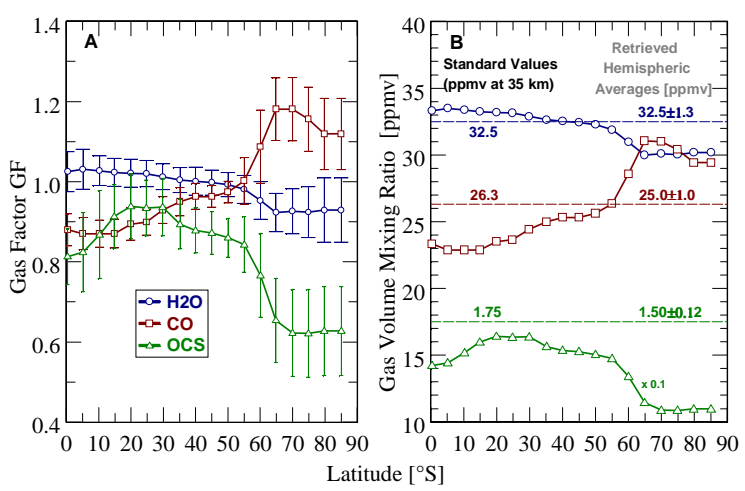

Fig. 9. Zonally averaged mean gas factors and their standard deviations (A) and corresponding trace gas volume mixing ratios at $35 \mathrm{~km}$ (B) as functions of latitude based on retrieved values from VIRTIS nightside measurements. OCS mixing ratios are multiplied by a factor of 10 to fit into plot B.

Fig. 9 displays zonally averaged mean gas factors and their standard deviations (display A) and corresponding volume mixing ratios (display B) as functions of latitude that are based on retrieved values from VIRTIS nightside measurements. Recall that exclusively M-IR data were used for all atmospheric parameter retrievals. As in case 
of temperature profile and cloud parameter retrievals, standard deviations of retrieved parameters are a measure of the statistical bandwidth with respect to selected spectra sub-populations at each grid point in the local time and latitude space and not the standard deviation resulting from the entire measurement ensemble. These standard deviations do not include possible errors caused by the retrieval procedures themselves. As mentioned above, the mixing ratios are primarily valid at altitudes around $35 \mathrm{~km} . \mathrm{SO}_{2}$ mixing ratios cannot be reliably retrieved from VIRTIS-M-IR spectra. A constant value of $(130 \pm 50)$ ppmv was suggested for modeling purposes. Standard volume mixing ratios in Fig. 9B are indicated by broken lines with the values typed on the left side near these lines (cf. Fig. 8). The curves in display B are obtained by multiplying the initial mixing ratios at the reference altitude by the retrieved gas factors from display A. Note that the OCS mixing ratio curve is multiplied by a factor of 10 . The corresponding values for the hemispheric averages of retrieved mixing ratios and mixing ratio standard deviations are also given on the right side in display B. Hemispheric averages are calculated here by weighting the latitude-dependent values with the cosine of latitude.

Zonal averages of $\mathrm{CO}$ abundances at $35 \mathrm{~km}$ increase by about $35 \%$ from $(22.9 \pm 0.8)$ ppmv at equatorial latitudes to $(31.0 \pm 2.1)$ ppmv at $65^{\circ} \mathrm{S}$ and then decrease to $(29.4 \pm$ 2.4) $\mathrm{ppmv}$ at $80^{\circ} \mathrm{S}$. The observed latitudinal variation of tropospheric $\mathrm{CO}$ was interpreted by Haus et al. (2015a) in agreement with Tsang et al. (2008) to be consistent with a Hadley cell-like circulation on Venus where the downwelling branch at high latitudes transports CO rich air from cloud top altitudes down to the troposphere. Dawn side $\mathrm{CO}$ abundances at high latitudes are slightly smaller than dusk side values by about $7 \%$. The latitudinal distribution of OCS at $35 \mathrm{~km}$ is anticorrelated with that of $\mathrm{CO}$, ranging from about $(1.15 \pm 0.2) \mathrm{ppmv}$ at $65^{\circ} \mathrm{S}$ to $(1.60 \pm 0.2) \mathrm{ppmv}$ at low latitudes (poleward decrease of $28 \%$ ). Zonal averages of $\mathrm{H}_{2} \mathrm{O}$ abundances near $35 \mathrm{~km}$ slightly decrease toward the South Pole by about $10 \%$, and the hemispheric average is $(32.0 \pm 1.3)$ ppmv. A significant local time dependence of OCS and $\mathrm{H}_{2} \mathrm{O}$ was not observed. Detailed analyses of individual spectrum retrieval errors for different atmospheric models have revealed that $\mathrm{CO}$ abundance results are reliable (error 4-7\%), while $\mathrm{H}_{2} \mathrm{O}$ and OCS results have lower confidence (errors 30$47 \%$ and $41-86 \%$, respectively).

These retrieval results from Venus Express data are fairly well aligned with groundbased observations recently reported by Arney et al. (2014) who have used high spectral resolution data recorded by the Apache Point Observatory Triple Spec instrument to determine $\mathrm{H}_{2} \mathrm{O}, \mathrm{CO}$, OCS, $\mathrm{SO}_{2}$, and $\mathrm{HCl}$ abundances in Venus' lower atmosphere from 1.18, 1.74, and $2.3 \mu \mathrm{m}$ transparency window spectral signatures. Latitudinal averages between -55 and $+55^{\circ}$ around $35 \mathrm{~km}$ (determined from $2.3 \mu \mathrm{m}$ signatures) and from campaigns performed in 2009 and 2010 are $(33.5 \pm 2)$ ppmv for $\mathrm{H}_{2} \mathrm{O},(23.5 \pm 3)$ ppmv for $\mathrm{CO},(0.50 \pm 0.11)$ ppmv for OCS, and $(133 \pm 35)$ ppmv for $\mathrm{SO}_{2}$. Latitudinal trends of $\mathrm{H}_{2} \mathrm{O}, \mathrm{CO}$, and OCS in the southern hemispheric are very similar to those shown in Fig. 9.

\section{Unknown UV absorber model}

There is a broad depression in the observed spectral Bond albedo of Venus at wavelengths between 0.32 and about $0.8 \mu \mathrm{m}$ that cannot be explained by known absorption features of gases or clouds. Shortward of $0.32 \mu \mathrm{m}, \mathrm{SO}_{2} \mathrm{UV}$ absorption provides sufficient opacity to match the observed albedo features. A new model for this additional opacity source, which may be either composed of aerosol particles or of gaseous molecules or solid atom conglomerates or even mixtures of all these agents, was recently proposed by Haus et al. (2015b). Two different synthetic altitude profiles of unknown UV absorber number densities were assumed that peak at a constant value of either $10 \mathrm{~cm}^{-3}$ between 58 and $70 \mathrm{~km}$ (case 1, high altitude (nominal) 
model) or $20 \mathrm{~cm}^{-3}$ between 58 and $64 \mathrm{~km}$ (case 2, low altitude model). The use of a 'high and low UV absorber case' was originally proposed by Crisp (1986). Both profiles decrease with a scale height of $1 \mathrm{~km}$ above and below the above defined bounds of constant particle number density. The particle number density altitude profiles $\mathrm{N}(\mathrm{z})$ are calculated according to Eq. (T1) given in the footnote of Table 1 . This equation can be also applied for molecular agents replacing the notation 'particle' by 'molecule' wherever required. Using these profiles, altitude-independent absorption cross-section spectra were calculated ('retrieved') that yield good fits of the Bond albedo spectrum presented by Moroz (1981). This way, the unknown absorber is not directly linked to cloud particle modes 1 or 2 (contrary to assumptions in previous studies, e.g. Crisp, 1986; Pollack et al., 1980). This approach that is based on a suitable parameterization of optical properties permits an investigation of the absorbers' radiative effects regardless of its chemical composition and independently of the used cloud model.

Fig. 10 illustrates altitude profiles and spectral features of the UV absorber (UVA). Display A shows altitude profiles of $1 \mathrm{~km}$ layer optical depths as well as cumulative optical depths at $0.35 \mu \mathrm{m}$ (the wavelength of maximum UV absorption) for the assumed high and low altitude distribution cases described above. Maximum layer optical depths at around $62 \mathrm{~km}$ are in the order of 0.015 and 0.05 , while total cumulative depths (opacities) reach 0.2 and 0.4 , respectively. Display $B$ describes the variation of UV absorber opacities with wavelength. A change of UVA opacity in one of these altitude distribution models (that is, a change of UVA column abundance)
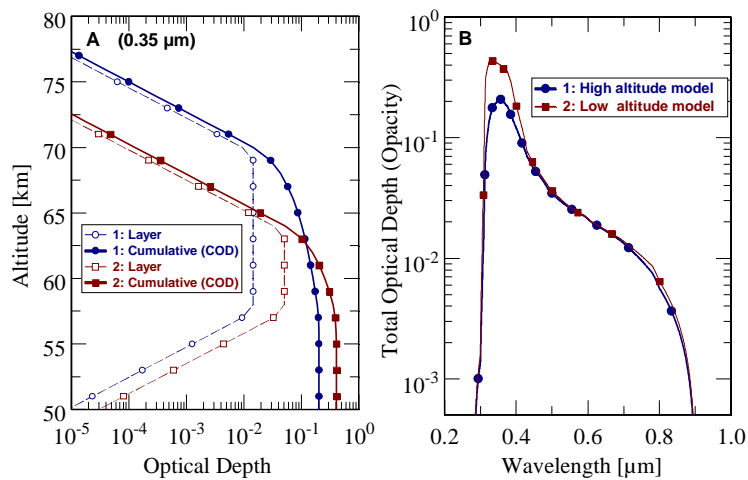

Fig. 10. Parameters of the unknown UV absorber model assuming two different altitude profiles of absorber number densities (Case 1: High altitude (nominal) model), Case 2: Low altitude model). A: Altitude profiles of single (1 km thick) layer and cumulative optical depths at $0.35 \mu \mathrm{m}$. B: Variation of UV absorber opacities with wavelength.

may well reproduce observed bright and dark UV regions on the planet. Modeling of UV brightness variations can be easily achieved without costly on-line recalculations of cloud microphysical parameters by simple multiplication of the UVA number density profile (or layer optical depths) by a suitable factor. This is further discussed below in Sections 5.2 and 6.1.

\section{Results}

\subsection{Radiative cooling}

Radiative temperature change rates are calculated according to Haus et al. (2015b),

$\mathrm{Q}_{\Delta \lambda}(\mathrm{z}, \varphi)=\frac{\mathrm{dT}_{\Delta \lambda}(\mathrm{z}, \varphi)}{\mathrm{dt}^{*}}=\frac{1}{\rho(\mathrm{z}) \mathrm{c}_{\mathrm{p}}(\mathrm{z})} \frac{\mathrm{dF}_{\Delta \lambda}^{\mathrm{n}}(\mathrm{z}, \varphi)}{\mathrm{dz}}$. (1) $\mathrm{Q}_{\Delta \lambda}(\mathrm{z}, \varphi)$ is the atmospheric temperature change rate with time $\left(\mathrm{t}^{*}\right)$ at level $\mathrm{z}$ and latitude $\varphi$ considering integrated contributions from a defined spectral interval $\Delta \lambda$ per time unit [1s]. $\mathrm{F}_{\Delta \lambda}^{\mathrm{n}}=\mathrm{F}_{\Delta \lambda}^{-}-\mathrm{F}_{\Delta \lambda}^{+}$is the atmospheric net flux of radiative energy where $\mathrm{F}_{\Delta \lambda}^{-}$and $\mathrm{F}^{+}{ }_{\Delta \lambda}$ refer to the downward and upward directed flux components of either solar (sol) or thermal (the) radiation. Subscript $\Delta \lambda$ is omitted in the following. $\rho$ is the air (atmospheric mass) density, $\mathrm{c}_{\mathrm{p}}$ is the specific heat capacity. Upward directed thermal radiation fluxes $\mathrm{F}^{+}$the are mostly larger than downward fluxes $\mathrm{F}_{\text {the. }}^{-}$According to the net flux definition, $F_{\text {the }}^{\mathrm{n}}$ then has a negative sign. Since absolute values of $\mathrm{F}^{\mathrm{n}}$ the 
mostly decrease with decreasing altitude, $\mathrm{Q}_{\text {the }}$ is usually also negative and radiative cooling' prevails in this case. The subscript 'the' that denotes thermal radiation is therefore replaced by superscript ' $C$ ' in the following. Real world thermal fluxes are always positive of course. Therefore, it is important to note from the very beginning that the convention of negatively marked thermal quantities is consequently used throughout this paper, leading to the required interpretation that for example $Q^{C}=-2 \mathrm{~K} / \mathrm{s}$ characterizes stronger cooling than $Q^{C}=-1$ $\mathrm{K} / \mathrm{s}$. This conforms to the usually applied convention and simplifies illustration of thermal and solar quantities in one plot wherever performed. Downward directed solar radiation fluxes $\mathrm{F}_{\text {sol }}^{-}$are generally larger than corresponding upward fluxes, the net flux $\mathrm{F}_{\text {sol }}^{\mathrm{n}}$ monotonically decreases with decreasing altitude, and 'radiative heating $\left(\mathrm{Q}^{\mathrm{H}}\right)^{\prime}$ takes place. Total atmospheric cooling and heating rates are determined separately, extending the flux calculations over the entire required spectral range, that is, 1.67$1000 \mu \mathrm{m}\left(10-6000 \mathrm{~cm}^{-1}\right)$ in case of cooling and $0.125-1000 \mu \mathrm{m}\left(10-80000 \mathrm{~cm}^{-1}\right)$ in case of heating (Haus et al. 2015b).

Diurnal averages are calculated according to

$$
\mathrm{Y}(\mathrm{z}, \varphi)=\frac{1}{\mathrm{~T}_{\mathrm{R}}} \int_{0}^{\mathrm{T}_{\mathrm{R}}} \mathrm{Y}_{\mathrm{t}}(\mathrm{z}, \varphi, \theta(\mathrm{t})) \mathrm{dt} .
$$

$\mathrm{Y}$ and $\mathrm{Y}_{\mathrm{t}}$ are used as synonyms for timeaveraged and local time ( $\mathrm{t}$ ) dependent fluxes, flux divergences, and temperature change rates, respectively. $T_{R}$ is the rotational period of the planet (the course of a full planetary day), and $\theta$ is the solar zenith angle (zero at zenith), which depends on local time. A full day in Eq. (2) encompasses all day and night hours, that is, for instance 24 hours on Earth. Although a full day on Venus is much longer than on Earth, time averaged quantities remain the same when referring to an Earth or Venus day. The basic unit of temperature change rates that results from Eq. (1) and consequently also from Eq. (2) is [K/s]. Q is finally usually given in [K/day] where day then refers to one Earth day. Thermal emissions take place at day and night hours, and the corresponding quantities do not depend on $t$ as long as atmospheric parameters remain unchanged with local time. The calculation of solar quantities requires consideration of insolation changes. Due to the small axis tilt of Venus $\left(\delta=2.64^{\circ}\right.$ according to the IAU standard based on the retrograde rotation definition), seasonal changes of solar quantities can be neglected. It was shown by Haus et al. (2015b) that the maximum deviation of heating rates does not exceed $0.05 \mathrm{~K} /$ day $(\sim 0.06 \%)$ at altitudes below $100 \mathrm{~km}$ when constant $\delta$ values of either $2.64^{\circ}$ or $0.0^{\circ}$ are considered. An approximate and constant solar declination $\delta=0^{\circ}$ is used hereafter. Hence, when calculating diurnal averages, the solar day integration on Venus extends independently of latitude over 12 hours local time (de facto 6 hours and multiplication by 2 , since the heliac arc is symmetric).

Eq. (2) can also be applied to determine averaged solar quantities at any insolation condition (e.g. at the subsolar point) where $\theta$ is artificially fixed to that condition resulting in a time-independent quantity $Y_{t}$ in the integrand. Diurnal averaging of solar quantities is performed using steps of either 0.5 or $1.0 \mathrm{~h}$ in Eq. (2). A coarser step significantly accelerates the calculations. It was verified that heating rate differences resulting from use of these two grids are negligible below $80 \mathrm{~km}$ and do not exceed $0.3 \mathrm{~K} /$ day at $100 \mathrm{~km}$. For more details with respect to the calculation of solar fluxes and heating rates, the reader is referred to the paper by Haus et al. (2015b).

Many figures that are shown in the following illustrate temperature change rate differences

$$
\Delta \mathrm{Q}(\mathrm{A}, \mathrm{B})=\mathrm{Q}(\mathrm{A})-\mathrm{Q}(\mathrm{B})
$$

that result from use of different sets $(\mathrm{A}, \mathrm{B})$ of atmospheric parameters. This definition is now applied for both cooling and heating rate differences $\left(\Delta \mathrm{Q}^{\mathrm{C}}, \Delta \mathrm{Q}^{\mathrm{H}}\right)$. Haus et al. (2015b) have utilized a different definition in case of cooling, $\Delta \mathrm{Q}^{\mathrm{C}}(\mathrm{A}, \mathrm{B})=-\left[\mathrm{Q}^{\mathrm{C}}(\mathrm{A})-\mathrm{Q}^{\mathrm{C}}(\mathrm{B})\right]$, but Eq. (3) in case of heating. This ensured that both increased set A cooling and set A heating could be described by positive values. Some figures in the present paper also display differences of net heating 
$\left(\mathrm{Q}^{\mathrm{N}}=\mathrm{Q}^{\mathrm{H}}+\mathrm{Q}^{\mathrm{C}}\right)$ that may become positive or negative. Thus, it would be somewhat puzzling to give a correct interpretation of results using the previously applied different difference definitions. Now, larger heating and net heating for case A will be characterized by enlarged positive values and positive differences (as before), but larger cooling and stronger negative net heating (net cooling) by enlarged negative values and negative differences.

\section{Temperature effects}

Fig. 11 shows zonally averaged mean thermal net flux divergence $\mathrm{dF}^{\mathrm{nC}} / \mathrm{dz}$ and cooling rate $\mathrm{Q}^{\mathrm{C}}$ altitude profiles at low $\left(20^{\circ} \mathrm{S}\right)$, mid $\left(45^{\circ} \mathrm{S}\right)$, high $\left(65^{\circ} \mathrm{S}\right)$, and polar $\left(80^{\circ} \mathrm{S}\right)$ latitudes based on mean temperature fields that were retrieved from VIRTIS-MIR measurements. Cooling rates are referred to one Earth day $(24 \mathrm{~h})$. Standard cloud parameter and trace gas distribution models are utilized here, that is, latitudinal variations of cloud parameters and trace gas abundances are not yet considered at this point. Net flux divergences and cooling rates strongly depend on thermal structure, and thus, on latitude over the entire range of the mesosphere (60-100 km) and upper troposphere $(50-60 \mathrm{~km})$. They vary only weakly in the region of the cloud bottom (48 $\mathrm{km}$ ). Cooling rates become very small below that level. This is mainly due to the strongly increasing air density and specific heat capacity with decreasing altitude. Net flux divergences above $80 \mathrm{~km}$ are very small (about $0.02 \mathrm{~W} /\left(\mathrm{m}^{2} \mathrm{~km}\right.$ ) at $\left.100 \mathrm{~km}\right)$. But since the product $\rho c_{p}$ (cf. Eq. (1)) faster decreases with increasing altitude than $\mathrm{dF}^{\mathrm{nC}} / \mathrm{dz}$ does, cooling rates quickly increase with altitude. Recall that both $\mathrm{dF}^{\mathrm{nC}} / \mathrm{dz}$ and $\mathrm{Q}^{\mathrm{C}}$ are mostly positive in reality and gain negative signs only by convention. $\mathrm{Q}^{\mathrm{C}}$ profiles at high altitudes are thus strongly determined by temperature and pressure induced changes of the quantity $\rho c_{p}$. Due to a peculiarity in the net flux altitude profiles that have distinct (absolute) local minima between 45 and 55 km (see Fig. 12 below), net flux divergences change their sign in this altitude domain leading to a small thermal heating of the atmosphere. Fig. 11 in comparison with Fig.
1 reveals that atmospheric cooling at altitudes between 55 and $95 \mathrm{~km}$ increases with increasing temperature, but see the discussion below with respect to Fig. 12 .

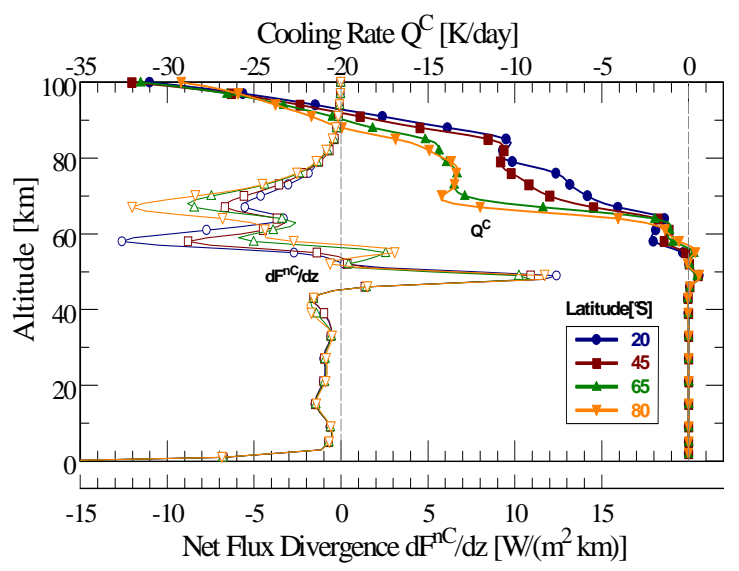

Fig. 11. Zonally averaged mean thermal net flux divergence $\mathrm{dF}^{\mathrm{nC}} / \mathrm{dz}$ and cooling rate $\mathrm{Q}^{\mathrm{C}}$ altitude profiles at four latitudes based on retrieved mean VIRTIS temperature fields but standard cloud parameter and trace gas distribution models.

Local cooling minima and maxima may occur at about $82 \mathrm{~km}$ and $80 \mathrm{~km}$, respectively. These effects that depend on the actual temperature conditions at those altitudes are due to very different contributions of distinct spectral ranges longward of $10 \mu \mathrm{m}$ (wavenumber $v<1000$ $\mathrm{cm}^{-1}$ ). The center range of the $15 \mu \mathrm{m} \mathrm{CO}_{2}$ absorption band (650-700 $\left.\mathrm{cm}^{-1}\right)$ clearly dominates radiative cooling at altitudes above $85 \mathrm{~km}$ and yields ever increasing cooling rates above $70 \mathrm{~km}$ up to more than $10^{4} \mathrm{~K} /$ day at the assumed top of atmosphere (TOA, $140 \mathrm{~km}$ ). Band wing contributions are comparatively small here but dominate cooling at lower altitudes (see Figure 27A in Haus et al, 2015b). Especially the 600-650 $\mathrm{cm}^{-1}$ range shows a stronger response to temperature changes than the center range does. It is mainly responsible for the observed total cooling rate local maxima/minima between 78 and $84 \mathrm{~km}$ that appear in form of an 'inverse $S$ ' shape in Fig. 11 . Note that these profile peculiarities may change locations and strengths. They may shift with altitude or even disappear when other temperature profiles are used (e.g. T(z, $80^{\circ} \mathrm{S}$ ) in this plot). 
Fig. 12 compares different parameters (thermal downward flux $\mathrm{F}^{-\mathrm{C}}$, upward flux $\mathrm{F}^{+\mathrm{C}}$, net flux $\mathrm{F}^{\mathrm{nC}}$, and cooling rate $\mathrm{Q}^{\mathrm{C}}$ ) at $80^{\circ} \mathrm{S}$ obtained from the two VIRTIS temperature profiles $\mathrm{T}^{\text {mean }}$ (profile 1) and $\mathrm{T}^{\text {mean }}+\mathrm{T}^{\text {std }}$ (profile 2) where std denotes the standard deviation $\sigma_{\mathrm{T}}$. The standard cloud and trace gas distribution models are still used here. Temperature profiles 1 and 2 are illustrated in display A. They do not strongly differ at altitudes above $70-72 \mathrm{~km}$ and below $57 \mathrm{~km}$ (cf. Fig. 2B, which provides a much better resolution of temperature differences). Consequently, the downward fluxes differ just within the altitude range $57-70 \mathrm{~km}$ (called 'cell' in the following). Upward fluxes start to diverge at $57 \mathrm{~km}$, but $\mathrm{F}^{+\mathrm{C}(2)}$ carries the information on changed temperature conditions in the cell up to the top of atmosphere. Thus, net fluxes do not only change in the cell but also at higher altitudes. In so doing, $\mathrm{F}^{\mathrm{nC}(2)}$ may intersect the $\mathrm{F}^{\mathrm{nC}(1)}$ curve as it is observed at $60 \mathrm{~km}$. Moreover, net flux divergences $\mathrm{dF}^{\mathrm{nC}} / \mathrm{dz}$ (display B) may change their specific profile features in a way that cannot be foreseen from temperature profile and flux comparisons alone. Compared with $\mathrm{dF}^{\mathrm{nC}(1)} / \mathrm{dz}, \quad \mathrm{dF}^{\mathrm{nC}(2)} / \mathrm{dz}$ becomes generally larger (in absolute values) within the cell in this example. This leads to a stronger cooling here, although the difference between cooling results is very small. At first sight, net flux divergences for profiles 1 and 2 at altitudes above $70 \mathrm{~km}$ seem to be identical, but the inset in display $B$ reveals that there are several small but important changes. Absolute values of $\mathrm{dF}^{\mathrm{nC}(2)} / \mathrm{dz}$ are smaller between 70 and $80 \mathrm{~km}$ compared with $\mathrm{dF}^{\mathrm{nC}(1)} / \mathrm{dz}$. This results in less cooling. Although net flux divergence differences are so small, the cooling difference around 75 $\mathrm{km}$ is larger than at $60 \mathrm{~km}$ due to decreasing $\rho c_{p}$ values (cf. Eq. (1)). Absolute values of $\mathrm{dF}^{\mathrm{nC}(2)} / \mathrm{dz}$ marginally but generally exceed those of $\mathrm{dF}^{\mathrm{nC}(1)} / \mathrm{dz}$ above $80 \mathrm{~km}$. Nevertheless, $\mathrm{Q}^{\mathrm{C}(2)}$ around $84 \mathrm{~km}$ becomes stronger, but abruptly decreases above $87 \mathrm{~km}$ compared with $\mathrm{Q}^{\mathrm{C}(1)}$. This can be understood by detailed numerical analyses of net flux divergence differences at adjacent altitude levels and corresponding differences in the $\rho c_{p}$ values. As already mentioned above, $Q^{C}$ profiles at high altitudes are mainly determined by temperature and pressure induced changes of the quantity $\rho c_{p}$.

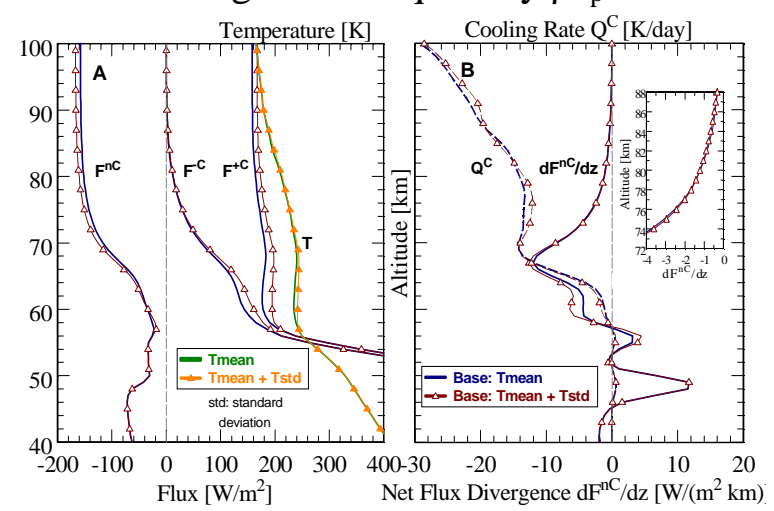

Fig. 12. Comparison of temperatures (A), thermal fluxes (A), thermal net flux divergences (B), and cooling rates (B) for two similar temperature profiles at $80^{\circ} \mathrm{S}$. Standard cloud and trace gas distribution models are used here. The inset in display B is a zoom into the upper part of net flux divergences.

This somewhat lengthy discussion is very important to understand the possible responses of cooling rates to temperature profile changes especially at altitudes above $70 \mathrm{~km}$. At other latitudes, many other (and often unexpected) responses are additionally observed. This behavior is due to the complex character of radiative transfer through different atmospheric layers. A certain atmospheric layer and its radiative properties cannot be investigated on its own. It is always coupled with adjacent layers where temperature and pressure variations and resulting changes of gaseous and particulate absorber properties may seriously influence the layer features and their interaction. This may possibly hamper the search for parameterization rules for atmospheric cooling and heating rates as it is planned for future work.

Apart from comparatively small temperature profile changes and resulting cooling rate changes as discussed with respect to Fig. 12, large temperature differences as associated with the latitudinal variability of the temperature field cause a more pronounced and more directed response of cooling rates where cooling at altitudes between 55 and 95 $\mathrm{km}$ mostly increases with increasing temperature as shown in Fig. 11. 


\section{Cloud effects}

Consideration of latitude dependent cloud parameters does seriously change both net flux divergences and cooling rates especially at mid and high latitudes. This is illustrated in Fig. 13 where each display (latitudes $20^{\circ} \mathrm{S}, 45^{\circ} \mathrm{S}, 65^{\circ} \mathrm{S}$, and $80^{\circ} \mathrm{S}$ ) provides a comparison of cooling rate $\mathrm{Q}^{\mathrm{C}}$ results obtained for standard and retrieved mean cloud parameters as well as for retrieved cloud parameter standard deviations shown in Fig. 5. Retrieved temperature and trace gas abundance profiles are considered here. Retrieved cloud parameters encompass cloud mode factors $\mathrm{MF}_{1,2}, \mathrm{MF}_{3}$, cloud top altitudes $\mathrm{Z}_{\mathrm{t}}$, and cloud optical depth profiles $\mathrm{u}(\mathrm{z})$ (cf. Figs. 5 and 7). As it was shown by Haus et al. (2015b) (Figure 33 in that paper), there is little response of both cooling and heating rates to abundance changes of mode 1 particles. The responses to changes of mode 2 and mode 3 parameters were identified to be much stronger. Mode 2' abundance changes could not be retrieved from VIRTIS data, and $\mathrm{MF}_{2},=1.0$ was always used assuming that possible changes were reflected by mode 3 variations.

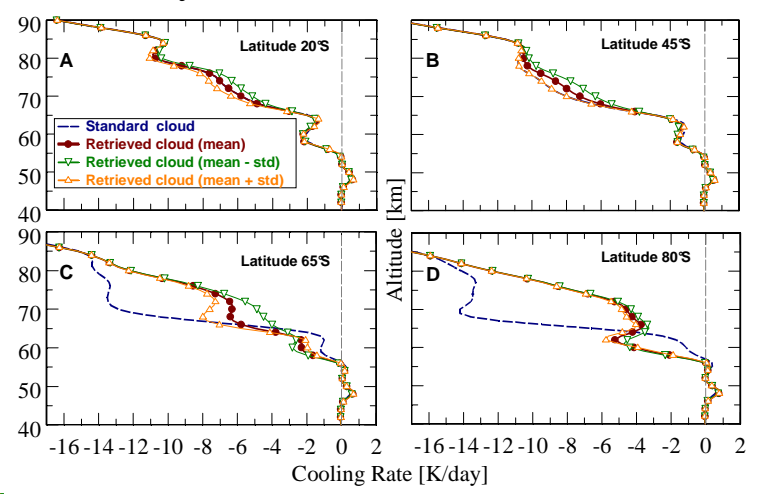

Fig. 13. Cooling rate altitude profiles at four latitudes based on VIRTIS (mean and added/subtracted standard deviations std) and standard model cloud parameters. VIRTIS temperature and trace gas abundance profiles are used.

The two curves for standard and retrieved mean cloud parameters in Fig. 13 coincide at equatorial and low latitudes (display $\mathrm{A}$ ) where the mode factor $\mathrm{MF}_{1,2}$ is close to unity (corresponding to the standard model, cf. Fig. 5). Considering the retrieved $\mathrm{MF}_{1,2}$ standard deviations, smaller mode 2 particle abundances result in smaller (absolute) $\mathrm{Q}^{\mathrm{C}}$ values between 65 and $80 \mathrm{~km}$, while slightly stronger cooling occurs around $60 \mathrm{~km}$ due to specific thermal net flux divergence changes. Increasing abundances produce an opposite cooling effect. Since cloud top altitudes at thermal wavelengths $(5-50 \mu \mathrm{m})$ vary between 57 and $68 \mathrm{~km}$ (cf. Fig. 7), it is very noticeable that small amounts of mode 2 particles (optical depths smaller than 1.0) and occurring changes at altitudes between 65 and $75 \mathrm{~km}$ may influence the cooling rates quite strongly.

Moving to mid latitudes (display B), stronger $\mathrm{Q}^{\mathrm{C}}$ changes take place comparing standard and retrieved mean cloud parameters due to decreasing $\mathrm{MF}_{2}$ factors $\left(\mathrm{MF}_{1,2}=0.8\right.$ at $45^{\circ} \mathrm{S}$, cf. Fig. $5 \mathrm{~A}$ ). $\mathrm{MF}_{3}$ at $45^{\circ} \mathrm{S}$ is close to unity. Largest cooling rate changes are observed at high and polar latitudes (displays $\mathrm{C}$ and $\mathrm{D}$ in Fig. 13) where both $\mathrm{MF}_{1,2}$ and $\mathrm{MF}_{3}$ deviations from standard conditions $\left(\mathrm{MF}_{\mathrm{i}}=1.0\right)$ are also largest. These latitudes are additionally characterized by decreasing upper scale height and decreasing distribution downshift of mode 2 particles (cf. Fig. 6B). The latter two parameters cause the drop of altitude where $\mathrm{MF}_{2}$ standard deviations start to significantly affect the cooling rates $\left(76 \mathrm{~km}\right.$ at $65^{\circ} \mathrm{S}, 72 \mathrm{~km}$ at $\left.80^{\circ} \mathrm{S}\right)$. They also reduce the 'response switch altitude' where cooling rate responses to mode 2 parameter variations change their sign. It is $65 \mathrm{~km}$ at equatorial and mid latitudes, about $63 \mathrm{~km}$ at $65^{\circ} \mathrm{S}$ and $60 \mathrm{~km}$ at the pole, respectively. $\mathrm{MF}_{3}$ at $80^{\circ} \mathrm{S}$ attains 2.1 (cf. Fig. 5B). This is large enough to produce a strong cooling excess over standard conditions around $60 \mathrm{~km}$ compared with other latitudes where $\mathrm{MF}_{3}$ does not exceed 1.5. Increasing $\mathrm{MF}_{3}$ according to the considered standard deviations now even shrouds the above mentioned thermal net flux divergence peculiarity around $60 \mathrm{~km}$ and also intensifies cooling at these altitudes.

Summarizing this discussion, it can be stated once more that the clouds of Venus strongly influence radiative cooling of the atmosphere. Cooling at altitudes between 65 and $80 \mathrm{~km}$ mostly increases with increasing cloud mode 2 abundances but decreases at lower altitudes. Increasing mode 3 
abundances enforce cooling at altitudes between 55 and $65 \mathrm{~km}$.

The precursor study (Haus et al., 2015b) has already pointed out that trace gas variations have a very small influence on mesospheric temperature change rates. When doubling $\mathrm{H}_{2} \mathrm{O}$ and $\mathrm{SO}_{2}$ column abundances, the resulting cooling rate variations did not exceed $0.2 \mathrm{~K} /$ day at altitudes between 45 and $80 \mathrm{~km}$. Sensitivity to OCS and CO changes is extremely small. Fig. 9 shows that $\mathrm{H}_{2} \mathrm{O}$ abundance variation with latitude does not exceed $10 \%$. Maximum standard deviations of retrieved $\mathrm{H}_{2} \mathrm{O}$ abundances are in the same order of magnitude. Taking into account the variability of all trace gases, resulting cooling rate changes that occur at the assumed cloud bottom $(48 \mathrm{~km})$ do not exceed $0.03 \mathrm{~K} /$ day at 65 and $80^{\circ} \mathrm{S}$. Note that slight radiative heating takes place in this altitude domain. Equatorial and mid latitude cooling rate changes at $48 \mathrm{~km}$ as well as changes at other altitudes for all latitudes are less than $0.001 \mathrm{~K} /$ day. Although trace gas variations are always included in the energy balance calculations, their influence is marginal and could also be neglected. It was shown by Haus et al. (2015b) that episodic $\mathrm{SO}_{2}$ abundance boosts by a factor of 10 may produce cooling rate changes of $0.8 \mathrm{~K} /$ day at $65 \mathrm{~km}$. This case is not further investigated, however.

Fig. 14 (display A) shows the 2D field of zonally averaged mean radiative cooling rates in the mesosphere and upper troposphere of Venus, that is, cooling rates $\mathrm{Q}^{\mathrm{C}}$ as functions of latitude and altitude. Note that the step between isolines varies to ensure optimum graphical representation. The results are based on atmospheric parameters that were retrieved from VIRTISM-IR measurements (thermal profiles, cloud abundances and cloud top altitudes, trace gas abundances). Cooling mostly increases with increasing altitude except for 58-62 km (low, mid, cold collar latitudes), $80-83 \mathrm{~km}$ at low latitudes, and $60-65 \mathrm{~km}$ at polar latitudes. At each altitude, there are almost no latitudinal changes at low latitudes, while cooling increases between 57 and $95 \mathrm{~km}$ with latitude poleward of $35^{\circ} \mathrm{S}$ excluding the altitude range $60-65 \mathrm{~km}$ at the pole. Cooling below $55 \mathrm{~km}$ becomes very small, but a slight negative cooling (heating) is observed at altitudes around the cloud bottom range $(43-52 \mathrm{~km})$ and even up to $54 \mathrm{~km}$ at the pole. Above $95 \mathrm{~km}$, cooling remains almost constant with latitude and reaches about -30 $\mathrm{K}$ at $100 \mathrm{~km}$.

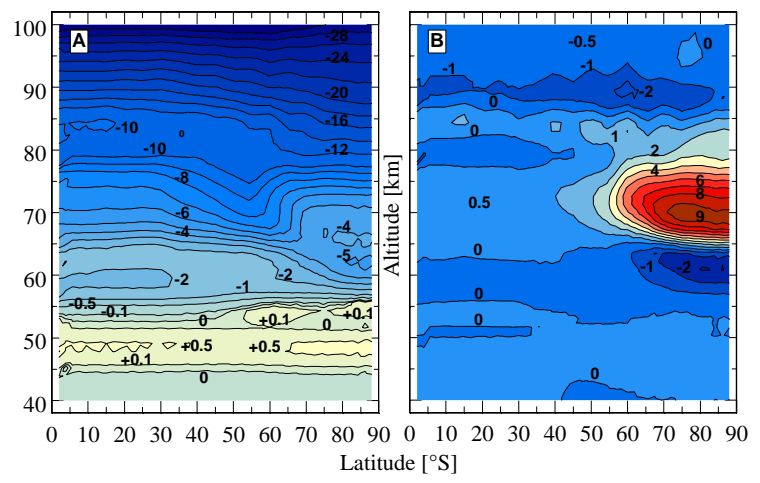

Fig. 14. A: Zonally averaged mean radiative cooling rates as functions of latitude and altitude based on atmospheric parameters retrieved from VIRTIS measurements. B: Corresponding differences $\Delta Q^{C}$ (VIRTIS, VIRA-N). Positive $\Delta \mathrm{Q}^{\mathrm{C}}$ values indicate less cooling in case of VIRTIS. VIRA-N results neglect the change of cloud parameters and trace gas abundances with latitude. Cooling rates and differences are given in [K/day].

Display B in Fig. 14 illustrates zonally averaged cooling rate differences between VIRTIS and VIRA-N results. $\Delta \mathrm{Q}^{\mathrm{C}}$ (VIRTIS, VIRA-N) is defined according to Eq. (3). VIRA-N results neglect the change of cloud parameters (and trace gas abundances) with latitude. Positive $\Delta Q^{C}$ values indicate less cooling in case of VIRTIS data, negative values characterize more cooling. It is a very important result of present investigations that radiative cooling of the atmosphere between 63 and $85 \mathrm{~km}$ is weaker than predicted in the precursor study (Haus et al., 2015b) where cloud parameter changes were neglected (cf. Fig. 13). This holds especially true poleward of about $55^{\circ} \mathrm{S}$ and altitudes between 65 and $80 \mathrm{~km}$ where up to $9 \mathrm{~K} /$ day reduced cooling is identified.

Fig. 15 shows maps of mean cooling rates as functions of local time (LT) and latitude $(\varphi)$ for altitudes of $65 \mathrm{~km}$ (display A) and $80 \mathrm{~km}$ (display B). Results are always referred to a full Earth day. Displays C and D describe 
corresponding cooling rate differences $\Delta Q^{C}$ (LT, ZA) from the zonally averaged (ZA) cooling rate field (Fig. 14A) according to Eq. (3). The results are based on atmospheric parameters that were retrieved from VIRTISM-IR measurements. Note that zonally averaged cloud parameters are used due to the lack of reliable local time dependent values (see Section 3.2). Small abundance variations of trace gases with local time can be safely neglected.

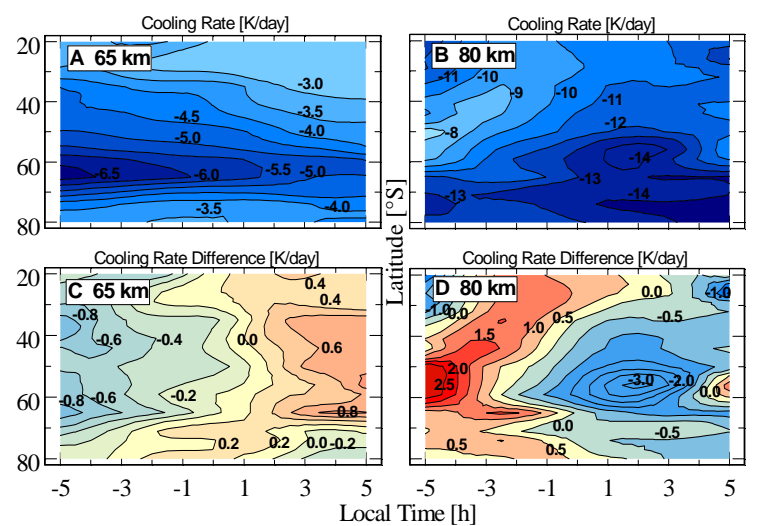

Fig. 15. Mean radiative cooling rates as functions of local time (LT) and latitude at $65 \mathrm{~km}$ (A) and $80 \mathrm{~km}$ (B) based on atmospheric parameters retrieved from VIRTIS measurements. C, D: Cooling rate differences $\Delta Q^{C}$ (LT, ZA) from the zonally averaged (ZA) cooling rate field. Positive $\Delta \mathrm{Q}^{\mathrm{C}}$ values indicate less cooling in case of local time dependent quantities. Local time $-5 \mathrm{~h}$ corresponds to 19:00 $\mathrm{h}$.

Fig. 15 is formatted to be well comparable with Fig. 3 where the retrieved temperature fields and corresponding differences are plotted. Near $65 \mathrm{~km}$, the development of the cold collar over the course of night is clearly discernible even in terms of cooling rates. Due to higher temperatures at early night and lower temperatures at late night equatorward of $75^{\circ} \mathrm{S}$, cooling rates decrease with local time. This effect is well pronounced near $65^{\circ} \mathrm{S}$ (cold collar) where the cooling rate decrease amounts to about $1.7 \mathrm{~K} /$ day (from $6.7 \mathrm{~K} /$ day at $19: 00 \mathrm{~h}$ to $5.0 \mathrm{~K} /$ day at 05:00 h). The zonally averaged value between 50 and $60^{\circ} \mathrm{S}$ at $65 \mathrm{~km}$ is about $5.8 \mathrm{~K} /$ day. The overall response of cooling rates to temperature variations with local time at 65 $\mathrm{km}$ altitude can be rated to be rather small, however. This is verified by Fig. 12B where the cooling rate response to added temperature standard deviations at $80^{\circ} \mathrm{S}$ is shown. Standard deviations at $65 \mathrm{~km}$ between 65 and $80^{\circ} \mathrm{S}$ are in the order of 5-8 K (cf. Fig. 2B). This corresponds to observed maximum temperature changes with local time (cf. Fig. 3C). These temperature differences do not seriously change the cooling rates, however.

Compared with $65 \mathrm{~km}$, the atmosphere near $80 \mathrm{~km}$ and poleward of $45^{\circ} \mathrm{S}$ is colder at early night and warmer at late night. As a consequence, cooling rates increase with local time. Strongest temperature changes occur between 50 and $60^{\circ} \mathrm{S}(\sim 10 \mathrm{~K})$ leading to local cooling rate minima and maxima of $8 \mathrm{~K} /$ day and $14 \mathrm{~K} /$ day at 19:00 $\mathrm{h}$ and 02:00 $\mathrm{h}$, respectively. The zonally averaged value between 50 and $60^{\circ} \mathrm{S}$ at $80 \mathrm{~km}$ is about 11 $\mathrm{K} /$ day. Thus, observed cooling rate changes with local time near $80 \mathrm{~km}$ are stronger by a factor of 3.5 compared with $65 \mathrm{~km}$.

The different patterns of altitude, latitude, and local time dependent mesospheric temperature structure may be forced by thermal tides, which are generated by absorption of solar radiation on Venus' dayside mainly in the upper clouds. Their presence was recognized in Pioneer-Venus Infrared Radiometer (PV-OIR) (Schofield and Taylor, 1983) and Venera-15 Fourier spectrometer (FS or also called PMV) (Zasova et al., 2006, 2007) data in the northern hemisphere in terms of different components (diurnal or wavenumber-1, semi-diurnal or wavenumber-2, and even larger wavenumbers). Temperature field retrievals by the present authors were only performed using VIRTIS-M-IR nightside measurements (see Section 3.1). Thus, information on dayside variations from this data source is not available, and it is difficult to attribute observed patterns of temperature variability with local time to the presence of distinct components of thermal tides when half of a full day is absent in the data. Fig. 3 in Section 3.1 indicates that variability with local time (or solar longitude) both at 65 and $80 \mathrm{~km}$ is mainly characterized by a diurnal (wavenumber-1) component with maximum amplitude of about 5-6 K and varying phase. Exceptions are observed at $65 \mathrm{~km} / 80^{\circ} \mathrm{S}$ and $80 \mathrm{~km} / 40$ and $70^{\circ} \mathrm{S}$ where the variability 
resembles more a semi-diurnal wave. Comparison of these thermal tide results with literature results considering the works of Zasova et al. (2006, 2007), Grassi et al. (2010), and Tellmann et al. (2009) were performed by Haus et al. (2014). The latter authors concluded that the agreement between different data sources and resulting interpretations is not very good at present.

\subsection{Radiative heating}

By analogy with Fig. 11, Fig. 16 shows zonally averaged mean solar net flux divergence $\mathrm{dF}^{\mathrm{nH}} / \mathrm{dz}$ and heating rate $\mathrm{Q}^{\mathrm{H}}$ altitude profiles at low $\left(20^{\circ} \mathrm{S}\right)$, mid $\left(45^{\circ} \mathrm{S}\right)$, high $\left(65^{\circ} \mathrm{S}\right)$, and polar $\left(80^{\circ} \mathrm{S}\right)$ latitudes based on mean temperature fields that were retrieved from VIRTIS-M-IR measurements. Heating rates are referred to one Earth day. Latitudinal variations of cloud and trace gas parameters are not considered here. The calculation of heating rates is always based on the assumption that local time averaged (latitude-dependent) temperature profiles on the night and day side of Venus are identical up to $95 \mathrm{~km}$ altitude (cf. Section 3.1). Latitude independent nightside and dayside profiles above $95 \mathrm{~km}$ are averaged for both cooling and heating rate calculations. Heating rates are shown in form of diurnally averaged values (thick solid lines in Fig. 16, all lines in the following figures). The broken lines in Fig. 16 illustrate the change of heating at $20^{\circ} \mathrm{S}$ in the course of a day, that is, in dependence on local time. The thick broken line describes heating at noon $\left(\theta_{\text {Sun }}=20^{\circ}\right)$, the six thin broken lines define the heating rates in steps of $\mathrm{N}$ hours away from noon ( $\mathrm{N}$ from 1 to 6 ). The broken curve in the left upper corner is thus valid for heating shortly before sunset (and shortly after sunrise, $\theta_{\text {Sun }}=89^{\circ}$ ). Heating at $69 \mathrm{~km}$ is less than $0.1 \mathrm{~K} /$ day in the latter case but increases up to $14.3 \mathrm{~K} /$ day at noon.

Heating rates strongly depend on latitude. But this is mainly due to the fact that solar insolation decreases with increasing distance from equator resulting in much smaller heating rates at high latitudes. Solar net fluxes and heating rates $\mathrm{Q}^{\mathrm{H}}$ at a given latitude very weakly respond to atmospheric temperature changes as it is shown in the inset of Fig. 16 for $\mathrm{Q}^{\mathrm{H}}$ at low and polar latitudes. The two groups of curves compare $\mathrm{Q}^{\mathrm{H}}$ results obtained from VIRTIS and standard model (VIRA-N) temperature profiles. Results for VIRTIS temperature standard deviations shown in Fig. 2B are also illustrated. Due to the weak overall response of heating rates to temperature profile changes, it is not critical to neglect local time dependence of temperature profiles at fixed latitudes and altitudes. This information is currently not available as pointed out at the end of Section 5.1.

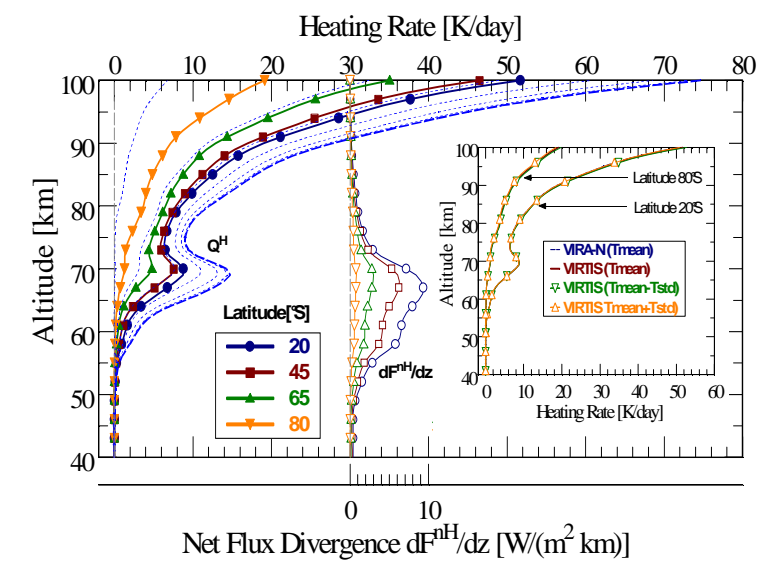

Fig. 16. Zonally averaged mean solar net flux divergence $\mathrm{dF}^{\mathrm{nH}} / \mathrm{dz}$ and heating rate $\mathrm{Q}^{\mathrm{H}}$ altitude profiles at four latitudes based on retrieved mean VIRTIS temperature fields but standard cloud parameter and trace gas distribution models. Solid lines with symbols: diurnal averages, broken lines: local time dependence at $20^{\circ} \mathrm{S}$ in steps of $1 \mathrm{~h}$, thick broken line: heating at noon. Inset: Heating rates at 20 and $80^{\circ} \mathrm{S}$ based on VIRTIS (mean and added/subtracted standard deviations std) and VIRA$\mathrm{N}$ temperature profiles, respectively. Standard cloud and trace gas distribution models are used.

As in case of radiative cooling (Fig. 13), consideration of latitude-dependent cloud parameters significantly changes heating rate profiles especially poleward of $40^{\circ} \mathrm{S}$. This is illustrated in Fig. 17 where each display (latitudes $20^{\circ} \mathrm{S}, 45^{\circ} \mathrm{S}, 65^{\circ} \mathrm{S}$, and $80^{\circ} \mathrm{S}$ ) shows a comparison of heating rate $\mathrm{Q}^{\mathrm{H}}$ results obtained for standard and cloud parameters as well as for retrieved cloud parameter standard deviations depicted in Fig. 5. Note the different abscissa scales in the displays. 


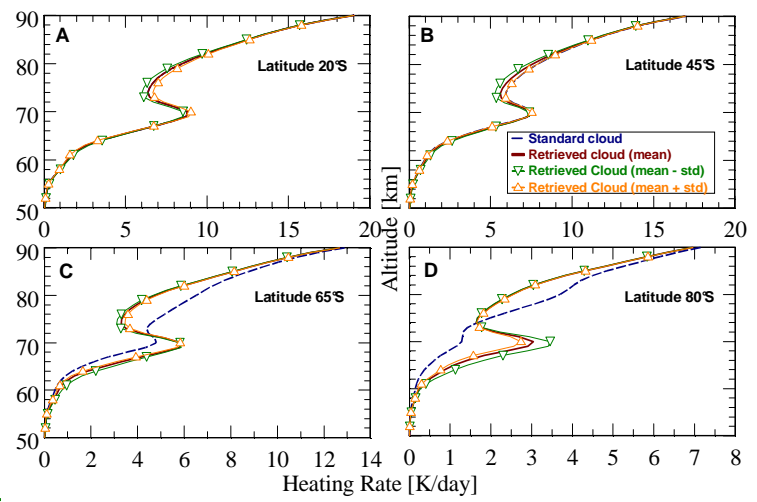

Fig. 17. Heating rate altitude profiles at four latitudes based on retrieved VIRTIS (mean and added/subtracted standard deviations std) and standard model cloud parameters. VIRTIS temperature and trace gas abundance profiles are used.

The retrieved mode factors $\mathrm{MF}_{12}$ at equatorial and low latitudes (display A) correspond to the standard model value $(\sim 1.0)$, and the two curves for standard and retrieved mean cloud parameters coincide therefore. Considering the retrieved $\mathrm{MF}_{12}$ standard deviations, decreasing mode 2 particle abundances result in slightly smaller $\mathrm{Q}^{\mathrm{H}}$ values mainly between 70 and $80 \mathrm{~km}$. Increasing abundances produce an opposite heating effect. This behavior is similar to the observed responses of cooling rates to cloud mode 2 abundance changes, although the differences are smaller compared with cooling differences. This means that heating rates are less sensitive to cloud parameter changes than cooling rates are. This was already concluded by Haus et al. (2015b). Higher cloud abundances produce larger temperature change rates (both cooling and heating) above the 'response switch altitude', which is located between 60 and $65 \mathrm{~km}$ in case of cooling and between 68 and $73 \mathrm{~km}$ in case of heating. Below these altitudes, more clouds lead to slightly smaller temperature change rates. In contrast with cooling where the 'response switch altitude' moves downward at high latitudes $(60-63 \mathrm{~km})$, it shifts slightly upward at polar latitudes in case of heating $(70-73 \mathrm{~km})$. Largest heating rate changes are observed at high and polar latitudes (displays $\mathrm{C}$ and $\mathrm{D}$ ) where both $\mathrm{MF}_{1,2}$ and $\mathrm{MF}_{3}$ deviations from standard conditions $\left(\mathrm{MF}_{\mathrm{i}}=1.0\right.$, broken line $)$ are also largest. These latitudes are additionally characterized by decreasing upper scale height and decreasing distribution downshift of mode 2 particles. The latter two parameters cause the drop of altitude where $\mathrm{MF}_{2}$ standard deviations start to affect the heating rates $\left(78 \mathrm{~km}\right.$ at $65^{\circ} \mathrm{S}, 72 \mathrm{~km}$ at $\left.80^{\circ} \mathrm{S}\right)$. It is interesting to observe that the heating maximum located at $70 \mathrm{~km}$ is strongest modified by reduced cloud mode 2 amounts at polar latitudes even though absolute heating is small there.

In summary, it can be stated that the clouds of Venus significantly influence radiative heating of the atmosphere, although heating responses to cloud parameter changes are smaller compared with cooling responses. Heating at altitudes between 70 and $80 \mathrm{~km}$ usually increases with increasing cloud abundances but decreases at altitudes below about $70 \mathrm{~km}$ (almost exclusively due to mode 2 particle influence). A doubling of mode 3 abundances (not yet discussed above) also slightly intensifies heating near $55 \mathrm{~km}$ by about $0.2 \mathrm{~K} /$ day.

By analogy with Fig. 14, Fig. 18 (display A) shows the 2D field of zonally and diurnally averaged mean radiative heating rates in the mesosphere and upper troposphere of Venus, that is, heating rates $\mathrm{Q}^{\mathrm{H}}$ as functions of latitude and altitude. Heating usually increases with increasing altitude. Local minima, however, occur around $74 \mathrm{~km}$. Local maxima around $70 \mathrm{~km}$ are due to the influence of the unknown UV absorber (cf. Fig. 19 below). Heating decreases from the equator toward the South Pole. Heating below $55 \mathrm{~km}$ is very small.

Display B in Fig. 18 illustrates heating rate differences between VIRTIS and VIRA-N results. VIRA-N results neglect the change of cloud parameters (and trace gas abundances) with latitude. $\Delta \mathrm{Q}^{\mathrm{H}}$ (VIRTIS, VIRA-N) is calculated according to Eq. (3). Thus, positive $\Delta \mathrm{Q}^{\mathrm{H}}$ values indicate more heating in case of VIRTIS data. Differences are generally smaller than cooling rate differences (cf. Fig. 14B). Largest absolute deviations are observed poleward of $55^{\circ} \mathrm{S}$ at altitudes between 65 and $85 \mathrm{~km}$ (larger 
VIRTIS heating in the lower and smaller heating in the upper altitude domain), but they do seldom exceed $1.5 \mathrm{~K} /$ day.

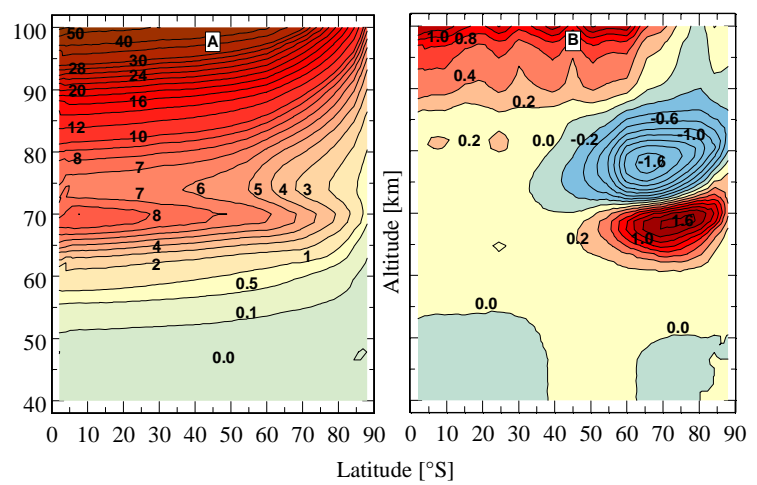

Fig. 18. A: Zonally and diurnally averaged mean radiative heating rates as functions of latitude and altitude based on atmospheric parameters retrieved from VIRTIS measurements. B: Corresponding differences $\Delta \mathrm{Q}^{\mathrm{H}}$ (VIRTIS, VIRA-N). Positive $\Delta \mathrm{Q}^{\mathrm{H}}$ values indicate more heating in case of VIRTIS. VIRA-N results neglect the change of cloud parameters and trace gas abundances with latitude. Heating rates and differences are given in [K/day].

Fig. 19 illustrates the influence of different models of the unknown UV absorber (UVA) on the calculated heating rates at latitudes of $20^{\circ} \mathrm{S}, 45^{\circ} \mathrm{S}, 65^{\circ} \mathrm{S}$, and $80^{\circ} \mathrm{S}$. The UVA based on the nominal high altitude model 1 (cf. Fig. 10) generally increases heating at altitudes $55-75 \mathrm{~km}$, while the low altitude model 2 UVA produces stronger heating between 55 and $70 \mathrm{~km}$. At around $70 \mathrm{~km}$ and $20^{\circ} \mathrm{S}$, the nominal model provides about 4.5 $\mathrm{K} /$ day more heating than it would result from an exclusion of this opacity source (broken line) and thus, a doubling of solar heating rate. The relative UVA influence at $70 \mathrm{~km}$ increases with latitude (factors of 2.1, 2.6 and 3.6 at 45,65 and $80^{\circ} \mathrm{S}$, respectively). Changing the UVA-model 1 abundance by a constant factor of two (without adjusting the albedo curve) yields the heating profile described by the solid line with empty rectangles. Model 2 was constructed to provide the same spectral albedo curve as model 1 (cf. Section 4). Its maximum influence on the heating rates occurs at 64 $\mathrm{km}$ at each latitude, and due to higher peak abundance concentration, model 2 causes a stronger heating below this level compared with model 1 .

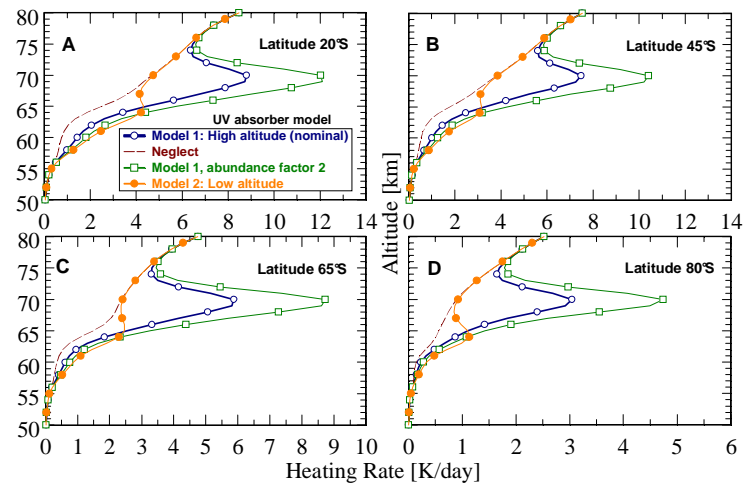

Fig. 19. Influence of different UV absorber models on mesospheric heating rates at four latitudes.

The great advantage of the present UVA model is that it simulates the unknown absorber as an agent that is independent of cloud microphysical parameters. This way, modeling of UV brightness variations that were observed by the $\mathrm{VMC}$ instrument on VEX (e.g. Titov et al., 2008b) can be achieved by simple multiplication of the UVA number density or optical depth profile (cf. Fig. 10A) by a suitable factor, thereby modifying the spectral albedo curve. Recall that spectral albedos resulting from different absorber distributions but from the same UVA absorption cross-section spectrum are not the same, since interferences with other atmospheric constituents shortward of about $800 \mathrm{~nm}$ (mainly clouds and $\mathrm{SO}_{2}$ ) cause different vertical flux profiles.

\subsection{Net radiative heating}

Radiative heating and radiative cooling together determine the net radiative heating (radiative forcing) of the atmosphere. Fig. 20 (display A) shows the 2D field of zonally and diurnally averaged mean net radiative heating rates in the mesosphere and upper troposphere of Venus, that is, net heating rates $Q^{N}$ as functions of latitude and altitude that are referred to one Earth day. The results are based on atmospheric parameters that were retrieved from VIRTIS-M-IR measurements. This plot resembles the 2D field recently shown by Haus et al. (2015b) (Figure 36 in that paper), but many details are different, especially at altitudes between 60 and $70 \mathrm{~km}$. There is a narrow altitude range at $45-55 \mathrm{~km}$ where weak net heating 
occurs that results from a thermal heating of the atmosphere due to cloud influence. The maximum of about $0.5 \mathrm{~K} /$ day is located near the cloud base $(48 \mathrm{~km})$. This heating region has a minimum at mid latitudes. Almost zero net heating prevails in the deep atmosphere below $45 \mathrm{~km}$, that is, the troposphere of Venus is nearly in radiative energy balance.

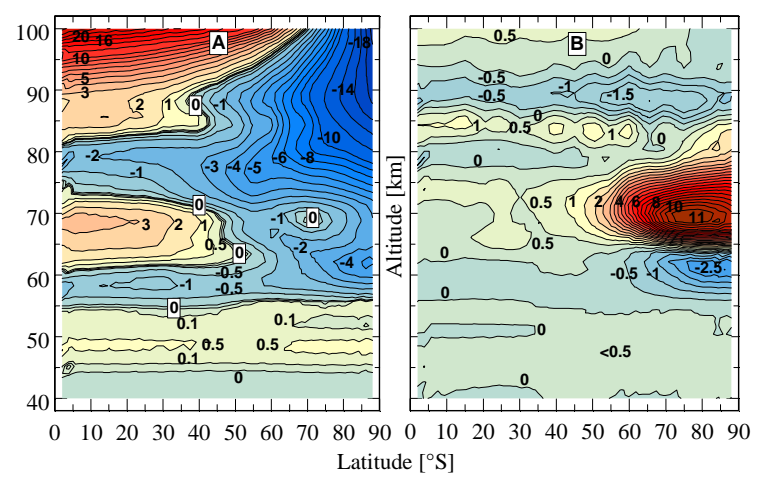

Fig. 20. A: Zonally and diurnally averaged mean net radiative heating rates as functions of latitude and altitude based on atmospheric parameters retrieved from VIRTIS measurements. B: Corresponding differences $\Delta Q^{N}$ (VIRTIS, VIRA-N). Positive $\Delta Q^{N}$ values indicate more net heating in case of VIRTIS. VIRA-N results neglect the change of cloud parameters and trace gas abundances with latitude. Net heating rates and differences are given in [K/day].

Net heating gradually decreases with increasing latitude above $55 \mathrm{~km}$, but a special shape compared with surrounding altitude regions is observed around $70 \mathrm{~km}$. This was not recognized in the earlier analyses (cf. display B). It is caused by two peculiarities in the atmosphere of Venus. The first (and most important) one is due to the presence of the unknown UV absorber that gives rise to strong additional solar heating of the atmosphere at just this altitude. The second one relates to the existence of the cold collar that extends between 55 and $75^{\circ} \mathrm{S}$ at altitudes between 60 and $70 \mathrm{~km}$ and slightly reduces thermal cooling in this domain due to lower atmospheric temperatures (especially at late night). As a consequence, net heating prevails at low and mid latitudes. Poleward of about $50^{\circ} \mathrm{S}$, enhanced UVA heating still occurs, but its efficiency decreases with increasing latitude due to generally smaller heating at high latitudes, and net cooling evolves. Due to the cold collar cooling minimum, a cell of nearly zero net heating may exist at $70 \mathrm{~km}$ and $70^{\circ} \mathrm{S}$.

Display B in Fig. 20 illustrates net heating rate differences between VIRTIS and VIRA$\mathrm{N}$ results. VIRA-N results neglect the change of cloud parameters (and trace gas abundances) with latitude. $\Delta \mathrm{Q}^{\mathrm{N}}$ (VIRTIS, VIRA-N) is calculated according to Eq. (3). Thus, positive $\Delta \mathrm{Q}^{\mathrm{N}}$ values indicate more net heating in case of VIRTIS data. Differences are largest poleward of $45^{\circ} \mathrm{S}$ and reach a maximum of $11 \mathrm{~K} /$ day at $70 \mathrm{~km}$ between 75 and $85^{\circ} \mathrm{S}$. These large differences prevented the detection of the net heating peculiarity as discussed above. Smaller net heating (that is, larger net cooling) based on VIRTIS data is detected between 57 and $63 \mathrm{~km}$ at these latitudes. Absolute values of $\Delta \mathrm{Q}^{\mathrm{N}}$ at low and mid latitudes are usually smaller than 0.5 $\mathrm{K} /$ day at all altitudes.

Two planet-wide layers with dominant net radiative cooling surround the $61-72 \mathrm{~km}$ region (display A). A rather narrow lower layer occurs at altitudes between 55 and 61 $\mathrm{km}$. Cooling is small $(0.5$ to $1.0 \mathrm{~K} /$ day $)$ equatorward of $60^{\circ} \mathrm{S}$, but increases up to 5 $\mathrm{K} /$ day at the pole at $62 \mathrm{~km}$. A second and broader $(\sim 10 \mathrm{~km})$ net cooling region is centered at $78 \mathrm{~km}$ where net cooling increases from $1 \mathrm{~K} /$ day at the equator to 9 $\mathrm{K} /$ day at the pole. Cooling already reaches a maximum of $13 \mathrm{~K} /$ day at the upper bound $(\sim 82 \mathrm{~km})$ of this cooling layer. Note again that minus signs in terms of cooling rates are only used per convention. At altitudes above $82 \mathrm{~km}$, net heating dominates the low and mid latitudes, while net cooling prevails at high latitudes. Net heating at $100 \mathrm{~km}$ reaches $23 \mathrm{~K} /$ day at the equator, and net cooling at the pole is in the same order of magnitude. The transition region between net heating and net cooling above $84 \mathrm{~km}$ moves with increasing altitude from $45^{\circ} \mathrm{S}$ to $70^{\circ} \mathrm{S}$.

It is instructive to compare the twodimensional net heating field shown in Fig. $20 \mathrm{~A}$ with the resulting latitude average. Globally (hemispherically) averaged radiative quantities are calculated according to 


$$
\bar{Y}(z)=\int_{0^{\circ}}^{90^{\circ}} \mathrm{Y}(\mathrm{z}, \varphi) \mathrm{W}(\varphi) \mathrm{d} \varphi
$$

where $\overline{\mathrm{Y}}$ and $\mathrm{Y}$ are used as synonyms for latitude-averaged and latitude-dependent fluxes, flux divergences, and temperature change rates, respectively. $\mathrm{W}(\varphi)$ is the latitudinal weight that equals to $\cos (\varphi)$ according to surface integration in spherical coordinates. Use of this weight reflects the fact that equatorial latitudes contribute much stronger to the globally averaged energy balance than polar latitudes do due to the larger relative equatorial area on the planet.

Fig. 21 illustrates altitude profiles of global averages of thermal cooling, solar heating, and net heating rates. Results that were previously obtained using VIRA-N temperature profiles and standard model cloud parameter and trace gas distributions (Haus et al., 2015b, Figure 23 in that work) are also shown. With respect to VIRTIS results and at $100 \mathrm{~km}$ altitude, globally averaged cooling $\mathrm{Q}^{\mathrm{CGA}}$ amounts to $32 \mathrm{~K} /$ day, while globally averaged heating $\mathrm{Q}^{\mathrm{HGA}}$ reaches $48 \mathrm{~K} /$ day leading to a net heating $\mathrm{Q}^{\mathrm{NGA}}$ of $16 \mathrm{~K} /$ day. Net heating of the atmosphere occurs down to $90 \mathrm{~km}$. Between 71 and $90 \mathrm{~km}$, negative net heating (net cooling) up to $3.5 \mathrm{~K} /$ day at $79 \mathrm{~km}$ is observed. The comparatively small net heating between 61 and $71 \mathrm{~km}$ and its local maximum of about $2 \mathrm{~K} /$ day at $70 \mathrm{~km}$ are forced by the presence of the unknown UV absorber (cf. Fig. 19). A weak net cooling region exists between 55 and $61 \mathrm{~km}$. Both heating and cooling (and consequently net heating, too) are very small at altitudes below $55 \mathrm{~km}$ mainly due to the strongly increasing air density and specific heat capacity with decreasing altitude. Inset A illustrates the above mentioned peculiarity of thermal fluxes near the cloud base at around $48-49 \mathrm{~km}$ that leads to net heating there (maximum $0.65 \mathrm{~K} /$ day). The deep atmosphere below $30 \mathrm{~km}$ is practically not heated by solar radiation (inset B). Thermal cooling rates are in the order of $0.005 \mathrm{~K} /$ day except for the lowest $1-2 \mathrm{~km}$ where the additional hot surface radiation $(\mathrm{T}=735 \mathrm{~K})$ causes a net cooling up to $0.02 \mathrm{~K} /$ day.

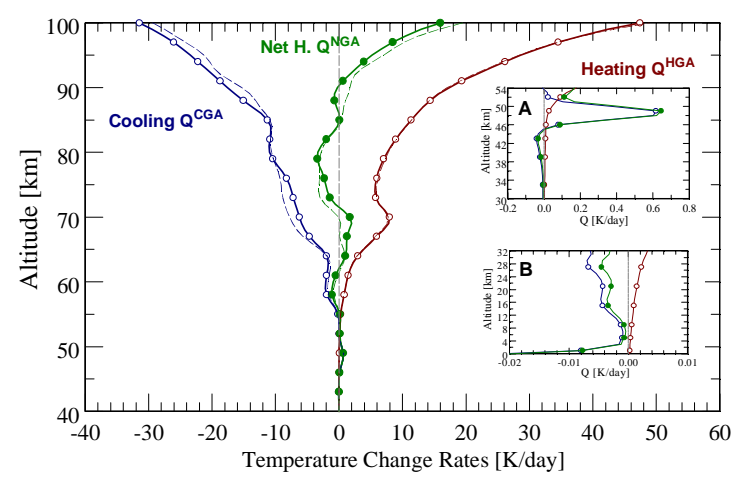

Fig. 21. Global averages of thermal cooling $\left(\mathrm{Q}^{\mathrm{CGA}}\right)$, solar heating $\left(\mathrm{Q}^{\mathrm{HGA}}\right)$, and net heating $\left(\mathrm{Q}^{\mathrm{NGA}}\right)$ rate altitude profiles. Solid lines with symbols: VIRTIS. Broken lines: VIRA-N for standard cloud model. The insets represent zooms of the VIRTIS curves near the cloud base (A) and near the surface (B).

The comparison of results obtained from VIRTIS and VIRA-N (broken lines) data shows only small differences for globally averaged heating rates (as can be expected from Figs. 16, 17, 18B) but quite large differences for globally averaged cooling rates mainly at around $70 \mathrm{~km}$ and above 85 $\mathrm{km}$. Weaker cooling in case of VIRTIS near $70 \mathrm{~km}$ is associated with the strong decrease of cooling due to consideration of retrieved cloud parameters (cf. Figs. 13 and Fig. 14B). Stronger cooling for VIRTIS above $85 \mathrm{~km}$ is due to slightly lower VIRTIS temperatures compared with VIRA-N (cf. Section 3.1). As it was discussed in the context of Fig. 12, small temperature changes at high altitudes may produce a quite strong cooling rate response. Slightly higher temperatures $\left(\mathrm{T}^{\text {mean }}+\mathrm{T}^{\text {std }}\right.$ in that example) generate less cooling and vice versa.

As it was already pointed out at the end of Section 5.1, local time dependent VIRTIS temperatures are not available for the dayside of the planet. Assuming the existence of a diurnal (wavenumber-1) thermal tide (that was at least observed at 65 and $80 \mathrm{~km}$ ) for present purposes, local time dependent cooling rates can be calculated for both night and day conditions. Solar heating rates only weakly respond to diurnal temperature changes (cf. inset Fig. 16) but nevertheless strongly depend on local time due to changing insolation conditions. Also recall the discussions performed in Section 
3.2 with respect to local time dependence of cloud parameters. Due to the lack of reliable quantities, retrieved zonal averages have to be used even when the variability of temperature change rates with local time is investigated.

Fig. 22 shows mean net radiative heating rates $Q^{N}$ as functions of local time and altitude at four different latitudes. $Q^{N}$ is always referred to a full Earth day. Apart from comparatively small changes due to cooling rate differences, the diagram for the full day would be symmetric, that's why it is only depicted for the first half of day. At the equator (display A) where solar insolation is strongest, net heating dominates net cooling from about 7:30 h until 16:30 $\mathrm{h}$ at altitudes between 60 and $70 \mathrm{~km}$, mainly forced by the presence of the unknown UV absorber. Net
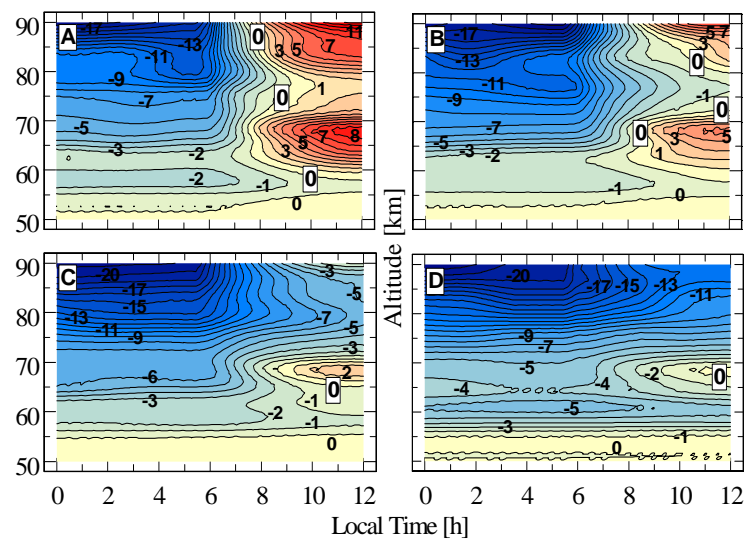

Fig. 22. Mean net radiative heating rates [K/day] as functions of local time and altitude at four latitudes (A: equator, B: $45^{\circ} \mathrm{S}, \mathrm{C}: 65^{\circ} \mathrm{S}, \mathrm{D}: 80^{\circ} \mathrm{S}$ ) based on atmospheric parameters retrieved from VIRTIS measurements.

heating from $70-80 \mathrm{~km}$ evolves somewhat later during the day $(09: 00 \mathrm{~h}$ at $75 \mathrm{~km})$ and shifts to earlier morning hours above $80 \mathrm{~km}$. At local noon (subsolar point at the equator), net heating at $68-70 \mathrm{~km}$ exceeds net cooling at midnight by about $12-13 \mathrm{~K} /$ day leading to a local time averaged value of $3 \mathrm{~K} /$ day (cf. Fig. 20A). Moving to mid latitudes at $45^{\circ} \mathrm{S}$ (display B), net heating in the UV absorber altitude domain evolves about one hour later $(08: 30 \mathrm{~h})$, but the $70-80 \mathrm{~km}$ region does no longer warm up during daylight hours. The situation dramatically changes at the cold collar (display C) and at polar latitudes (display D) where net heating is weak and almost disappears even between 60 and 70 $\mathrm{km}$ in case D. Near the pole, net cooling dominates at all altitudes in the course of day.

\section{Discussion}

\subsection{Influence of the UV absorber on planetary albedo and energy balance and a possible way of its quantification using VMC images}

For a planet in global radiative balance, the total outgoing radiation flux must compensate the incoming flux. According to Haus et al. (2015b), this equilibrium condition is described by Eq. (5),

$$
\frac{\mathrm{E}^{*}(1-\mathrm{A})}{4}=\sigma \mathrm{T}_{\mathrm{P}}{ }^{4} \text {. }
$$

$\mathrm{E}^{*}=2618.4 \mathrm{~W} / \mathrm{m}^{2}$ is the solar constant at mean Venus-Sun distance (0.723 AU) that is based on the synthetic solar irradiance model of Kurucz (2011) here. $\sigma$ is the StefanBoltzmann constant $\left(\sigma=5.6704 \times 10^{-8}\right.$ $\mathrm{W} /\left(\mathrm{m}^{2} \mathrm{~K}^{4}\right), \quad \mathrm{T}_{\mathrm{P}}$ is the effective planetary emission temperature. The quantity $\mathrm{A}$ is the Bond albedo of Venus (also denoted as spherical or global albedo) that defines the fraction of the total incident flux (total direct solar downward flux at TOA altitude) that is reflected back to space (total diffuse solar upward flux at TOA altitude) on global average,

$$
A=\frac{\int_{0}^{\infty} A_{\lambda} F_{\lambda}^{-H d i r} \mathrm{~d} \lambda}{\int_{0}^{\infty} F_{\lambda}^{-H d i r} \mathrm{~d} \lambda}=\frac{\int_{0}^{\infty} F_{\lambda}^{+H d i f} \mathrm{~d} \lambda}{\int_{0}^{\infty} F_{\lambda}^{-H d i r} \mathrm{~d} \lambda}=\frac{F^{+H}}{F^{-H}} .(6)
$$

The TOA as well as global average conditions are not explicitly written in Eq. (6). $A_{\lambda}$ is the spectral Bond albedo. The Bond albedo $\mathrm{A}$ can be also defined for a selected wavelength interval $\left(\lambda_{1}, \lambda_{2}\right)$ when explicit reference is given to this interval. Otherwise, integration has to be performed as described in Eq. (6).

Using the atmospheric models that were retrieved from VIRTIS-M-IR data (cf. Sections 3.1-3.3) and the nominal model 
developed for the unknown UV absorber (UVA-case 1, Section 4), the calculated Bond albedo is $A=0.761$. A value of 0.763 was determined earlier for atmospheric standard conditions together with global averages of solar flux deposited on the planet $\left(\mathrm{F}^{+}\right.$in Eq. (6)) and of outgoing thermal flux at TOA altitude $(140 \mathrm{~km})$ of 158.1 and 159.7 $\mathrm{W} / \mathrm{m}^{2}$, respectively (Haus et al., 2015b). The corresponding values based on atmospheric models resulting from VIRTIS data are 157.92 and $155.54 \mathrm{~W} / \mathrm{m}^{2}$. For comparison, Titov et al. (2007) derived $(157 \pm 6) \mathrm{W} / \mathrm{m}^{2}$ for the deposited solar flux and $\sim 160 \mathrm{~W} / \mathrm{m}^{2}$ for the outgoing thermal flux. The small net flux difference $\Delta \mathrm{F}^{\mathrm{n}}(\mathrm{TOA})=\left(\begin{array}{lll}157.92 & -155.54\end{array}\right)$ $\mathrm{W} / \mathrm{m}^{2}=2.38 \mathrm{~W} / \mathrm{m}^{2}$ around the mean value of $156.7 \mathrm{~W} / \mathrm{m}^{2}$ cannot be interpreted as an indication of global radiative imbalance. The difference is rather due to the uncertainties in both TOA values. Nevertheless, many numerical experiments have been performed to determine the conditions for exact planetary radiative equilibrium. There are different possible solutions with respect to variation of atmospheric parameters that affect radiative fluxes in the atmosphere. The simplest way is to modify the UVA model that is described in Section 4. This model permits an investigation of the absorbers' radiative effects regardless of its chemical composition, since it is not assumed to be an impurity of cloud mode 1 particles. By slightly reducing the altitude-independent case-1 standard model absorber factor (UVA-AF), which is 1.0 for standard definition, by $7.6 \%$, that is, using a factor of UVA-AF $=0.924$, the total solar flux deposited on the planet decreases from 157.92 to $155.54 \mathrm{~W} / \mathrm{m}^{2}$, which is exactly the determined value for the outgoing thermal flux. This modification only slightly changes the Bond albedo (that is a globally averaged value per definition). It attains a value of 0.764 instead of 0.761 obtained for UVA$\mathrm{AF}=1.0$. The smaller UVA column abundance reduces heating at $70 \mathrm{~km}$ by 0.29 $\mathrm{K} /$ day at $20^{\circ} \mathrm{S}$ and by $0.14 \mathrm{~K} /$ day at $80^{\circ} \mathrm{S}$. The effective planetary emission temperature according to Eq. (4) is $\mathrm{T}_{\mathrm{P}}=228.5 \mathrm{~K}$.
Fig 23 illustrates simulated changes of the spectral albedo at wavelengths between 0.2 and $1.0 \mu \mathrm{m}$ when only insolation conditions are considered that correspond to the equator at noon, that is, to the subsolar point on Venus in good approximation. Thus, the resulting albedo does not meet the global average condition and its notation should be distinguished from Bond albedo. It is denoted here as 'specific albedo $\mathrm{A}^{*}$ " and 'specific spectral albedo $A_{\lambda}{ }^{*}$, , respectively. The simulations are performed for different cases numbered from 1 to 11 that are described in Tables 5 and 6 . They consider different abundance factors for species that significantly influence radiation fluxes and hence albedo features. Line absorptions by atmospheric gases in the near IR and optical spectral range below $1 \mu \mathrm{m}$ play a minor role and can be safely neglected in the following discussion. Gaseous UV absorptions shortward of $0.4 \mu \mathrm{m}$ are dominated by $\mathrm{CO}_{2}$ and $\mathrm{SO}_{2}$ as shown by Haus et al. (2015b). Although being of minor importance, other UV absorbers like $\mathrm{H}_{2} \mathrm{O}$, OCS, and $\mathrm{HCl}$ are considered together with $\mathrm{CO}_{2}$ in a group called UVX here, $\mathrm{SO}_{2}$ is treated independently. Clouds and the still unknown additional absorbing agent, whose maximum influence resides at about $0.35 \mu \mathrm{m}$ according to Fig. 10B, are the other important species that contribute to fluxes and atmospheric heating rates shortward of $1 \mu \mathrm{m}$. Due to the

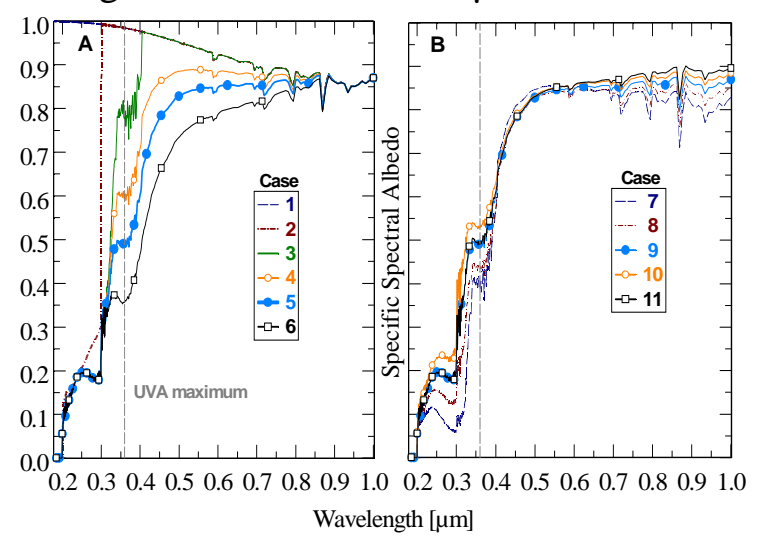

Fig. 23. Changes of the specific spectral albedo at wavelengths between 0.2 and $1.0 \mu \mathrm{m}$ due to different atmospheric parameters. For description of cases 1-11 see text and Tables 5 and 6. 
Table 5. Upward diffuse solar flux $\mathrm{F}^{+\mathrm{H}^{*}}$, solar net flux $\mathrm{F}^{\mathrm{n} \mathrm{H}^{*}}$, and specific albedo $\mathrm{A}^{*}$ in dependence on abundance factors AF of the unknown UV absorber (UVA-AF, nominal model), $\mathrm{SO}_{2} \mathrm{UV}$ absorption (UVSO2-AF), and other gas (X) UV absorption (UVX-AF). Fluxes are given in units of $\left[\mathrm{W} / \mathrm{m}^{2}\right]$. Spectral integration extends from 0.125 to $1.0 \mu \mathrm{m}\left(10000-80000 \mathrm{~cm}^{-1}\right)$.

\begin{tabular}{ccccccc}
\hline Case & UVA-AF & UVSO2-AF & UVX-AF & $\mathrm{F}^{+\mathrm{H}^{*}}$ & $\mathrm{~F}^{\mathrm{nH}}$ & $\mathrm{A}^{*}$ \\
\hline 1 & 0.0 & 0.0 & 0.0 & 842.1 & 70.8 & 0.922 \\
2 & 0.0 & 0.0 & 1.0 & 830.3 & 82.6 & 0.910 \\
3 & 0.0 & 1.0 & 1.0 & 802.0 & 110.9 & 0.879 \\
4 & 0.5 & 1.0 & 1.0 & 753.8 & 159.0 & 0.826 \\
5 & 1.0 & 1.0 & 1.0 & 716.3 & 196.6 & 0.785 \\
6 & 2.0 & 1.0 & 1.0 & 659.3 & 253.6 & 0.722 \\
\hline
\end{tabular}

Table 6. Upward diffuse solar flux $\mathrm{F}^{+\mathrm{H}^{*}}$, solar net flux $\mathrm{F}^{\mathrm{nH}}$, and specific albedo $\mathrm{A}^{*}$ in dependence on cloud mode abundance factors $\mathrm{MF}_{1,2}$ and $\mathrm{MF}_{3}$. The nominal UVA abundance model for UVA-AF=1.0 is used. Fluxes are given in units of $\left[\mathrm{W} / \mathrm{m}^{2}\right]$. Spectral integration extends from 0.125 to $1.0 \mu \mathrm{m}\left(10000-80000 \mathrm{~cm}^{-1}\right)$.

\begin{tabular}{cccccc}
\hline Case & $\mathrm{MF}_{1,2}$ & $\mathrm{MF}_{3}$ & $\mathrm{~F}^{+\mathrm{H}^{*}}$ & $\mathrm{~F}^{\mathrm{nH}^{*}}$ & $\mathrm{~A}^{*}$ \\
\hline 7 & 0.0 & 1.0 & 697.0 & 215.8 & 0.764 \\
9 & 0.5 & 1.0 & 701.4 & 211.4 & 0.768 \\
9 & 1.0 & 1.0 & 716.3 & 196.6 & 0.785 \\
10 & 1.5 & 1.0 & 730.3 & 182.6 & 0.800 \\
11 & 1.0 & 2.0 & 727.3 & 185.5 & 0.797 \\
\hline
\end{tabular}

neglect of gaseous line absorption, a constant $\mu \mathrm{m}$, and $\mathrm{UVSO}_{2}$ absorption rapidly spectral increment of $100 \mathrm{~cm}^{-1}$ in the decreases longward of $0.4 \mu \mathrm{m}$, spectral calculations is sufficient for present purposes. albedo curves $A_{\lambda}{ }^{*}$ sharply decrease at shorter Thus, the (monochromatic) wavelength step wavelengths. Additional consideration of the varies from about $0.2 \mathrm{~nm}$ near $0.125 \mu \mathrm{m}$ up to case-1 UVA model (cf. Fig. 10) yields the $10 \mathrm{~nm}$ at $1 \mu \mathrm{m}$. Spectral albedo fluctuations in other three curves in display A marked by Fig. 23 that mainly occur longward of $0.6 \mu \mathrm{m}$ symbols. $\mathrm{A}_{\lambda}{ }^{*}$ between 0.85 and $0.31 \mu \mathrm{m}$ and outside the gaseous UV absorber features decreases with increasing UVA abundance are due to signatures in the solar spectrum.

Display A in Fig. 23 describes $\mathrm{A}_{\lambda}{ }^{*}$ changes when vertical absorber amount distributions (or cumulative optical depths) of UVX, $\mathrm{UVSO}_{2}$, and UVA are varied by constant abundance factors AF according to Table 5 that considers the UVA nominal abundance model (cf. Sec. 4). This table also displays wavelength-integrated radiation characterristics at the top of atmosphere (TOA), the diffuse solar upward flux $\mathrm{F}^{+\mathrm{H}^{*}}$, the solar net flux $\mathrm{F}^{\mathrm{nH}}$, and the specific albedo $\mathrm{A}^{*}$. These quantities are calculated as wavelength integrals over the considered interval 0.125 $1.0 \mu \mathrm{m}$. The asterisks point to these specific parameter conditions (subsolar point, limited spectral range). Curves in display $A$ and numerical values in Table 5 are based on cloud mode factors $\mathrm{MF}_{\mathrm{i}}=1.0$. Case 1 neglects all UV absorbers, and the spectral albedo curve approaches unity shortward of $0.3 \mu \mathrm{m}$. Cases 2 and 3 consider UVX and UVX plus $\mathrm{UVSO}_{2}$ absorption, respectively. Since UVX absorptions abruptly stop longward of 0.3 factors. $\mathrm{UVSO}_{2}$ and UVX absorptions dominate at shorter wavelengths, and a further decrease due to larger UVA-AF is not observed there. Higher abundance of the unknown UV absorber reduces the TOA upward flux $\mathrm{F}^{+\mathrm{H}^{*}}$, since more radiation is absorbed in the atmosphere. Due to the definition of $\mathrm{A}\left(\mathrm{A}^{*}=\mathrm{F}^{+\mathrm{H}^{*}} / \mathrm{F}^{-\mathrm{H}^{*}}\right)$, and since $\mathrm{F}^{-}$ $\mathrm{H}^{*}$, the direct solar downward flux at TOA altitude, is independent of atmospheric parameter changes, the specific albedo $A^{*}$ also decreases with higher UVA abundances (as of course $\mathrm{A}_{\lambda}{ }^{*}$ does). But it is important to note that the solar net flux behaves in the opposite direction. It increases at the same time according to $\mathrm{F}^{\mathrm{nH}^{*}}=\mathrm{F}^{-\mathrm{H}^{*}}-\mathrm{F}^{+\mathrm{H}^{*}}$. Now it becomes clear that the intended reduction of the global averaged solar net flux to achieve radiative equilibrium of the planet as described above can be achieved with reduced amounts of the unknown UV absorber (UVA-AF <1).

Display B in Fig. 23 illustrates $\mathrm{A}_{\lambda}{ }^{*}$ changes when cloud cumulative optical depths 
(CODs) are varied by constant mode factors $\mathrm{MF}_{\mathrm{i}}$ according to cases 7-11 described in Table 6. This table also lists resulting TOA values of $\mathrm{F}^{+\mathrm{H}^{*}}, \mathrm{~F}^{\mathrm{nH}^{*}}$, and $\mathrm{A}^{*}$. Curves in display $\mathrm{B}$ and numerical values in Table 6 consider UV-AF factors of 1.0 and the UVA nominal abundance model (cf. Sec. 4). Note that cases 5 and 9 describe identical conditions. At wavelengths longward of 0.7 $\mu \mathrm{m}$, increasing cloud mode abundances intensify the TOA upward flux $\mathrm{F}^{+\mathrm{H}^{*}}$, since stronger scattering takes place that is almost conservative (cloud single scattering albedo of unity) in the investigated wavelength range (at least up to $1.5 \mu \mathrm{m}$ ). This is just the opposite effect compared with UV absorber forcing. Increasing TOA $\mathrm{F}^{+\mathrm{H}^{*}}$ fluxes enlarge the specific albedo but reduce the net flux $\mathrm{F}^{\mathrm{nH}}$. It is interesting to observe that spectral albedo responses to cloud mode factor increases are sometimes not unambiguous at visible wavelengths. Recall that spectral albedos resulting from different absorber distributions but from the same UVA absorption cross-section spectrum are not the same, since interferences with other atmospheric constituents shortward of about 700-800 nm (mainly clouds) may cause different vertical flux profiles. Nevertheless, wavelength-integrated quantities finally show the just described trends, since the range $0.6-1.0 \mu \mathrm{m}$ dominates the integrals. Thus, reduction of the globally averaged solar net flux to achieve radiative equilibrium of the planet as described above would require consideration of enhanced cloud abundances $\left(\mathrm{MF}_{\mathrm{i}}>1\right)$.

The clouds of Venus and especially the morphology of the cloud tops were investigated by the Venus Monitoring Camera (VMC) aboard the Venus Express mission. This experiment provided a significant improvement in Venus imaging as compared to the capabilities of earlier missions (Titov et al., 2008, 2012). VMC has acquired images in four narrow-band filters centered at 365, 513, 965 and $1010 \mathrm{~nm}$. The ultraviolet channel at $365 \mathrm{~nm}$ (bandwidth of about $40 \mathrm{~nm}$ ) was especially sensitive to abundance variations of the unknown UV absorber. Changes in atmospheric structure and dynamics due to the non-uniform UVA distribution (variations with respect to either geographic coordinates or altitude, or possibly both) were described as the cause of observed ultraviolet markings in the clouds of Venus (Titov et al., 2008). At most visible and infrared wavelengths, the planet on the dayside appears as a bright uniform disk due to conservative radiation scattering by the clouds. Observed global cloud patterns with relatively dark clouds at low latitudes that often have mottled and fragmented appearance, more streaky clouds at mid latitudes, and the almost featureless bright polar hood poleward of about $60^{\circ} \mathrm{S}$, which is sometimes crossed by dark spiral or circular structures, can change on time scales of a few days (Titov et al., 2012). Brightness contrasts in the UV images of more than $50 \%$ were sometimes identified.

Brightness can be considered as proxy of albedo (Titov et al., 2012). Brighter UV features may hint at lower UVA abundances (and/or thicker clouds), dark signatures may indicate higher UVA concentrations (and/or thinner clouds). It should be possible to relate these local time and latitude-dependent features $\left(\mathrm{B}^{\mathrm{VMC}}(\mathrm{LT}, \varphi)\right)$ to an average value $\left(\mathrm{B}^{\mathrm{VMC}-\mathrm{Av}}\right)$ that could be constructed from single images in the UV channel along an observation session, that is, to calculate ratios in the form $\mathrm{R}^{\text {meas }}=\mathrm{B}^{\mathrm{VMC}}(\mathrm{LT}, \varphi) / \mathrm{B}^{\mathrm{VMC}-}$ $\mathrm{Av}^{\mathrm{v}}$. Ratios of synthetic specific spectral albedo values that are determined at $0.36 \mu \mathrm{m}$ from calculated spectral albedos for different abundance factors AF of the unknown absorber and choosing $\mathrm{AF}=1.0$ as reference, that is, $\mathrm{R}_{\lambda}{ }^{\mathrm{sim}}=\mathrm{A}_{\lambda}{ }^{*}(\mathrm{AF}) / \mathrm{A}_{\lambda}{ }^{*}(\mathrm{AF}=1)$ provide a possible tool to interpret observed VMC ratios with respect to UV absorber abundance. The synthetic spectral albedo ratios, however, also depend on latitude and local time. Table 7 shows two examples of how the synthetic ratios $\mathrm{R}_{\lambda}{ }^{\text {sim }}$ look like at the subsolar point (noon at the equator) and at $65^{\circ} \mathrm{S}$ at 15:00 h. This table relies on the presently used standard model of cloud mode abundance distribution (Fig. 4) and cloud parameters that were retrieved from VIRTISM-IR measurements (zonally averaged mean cloud mode factors according to Fig. 5 and 
Table 4, latitude-dependent mode 2 characteristics according to Table 3). Possible cloud mode factor $\mathrm{MF}_{3}$ variations do not influence spectral albedos and their ratios at $0.36 \mu \mathrm{m}$ by more than $1 \%$ (cf. Fig. 23B, case 9 vs. 11). $\mathrm{MF}_{1,2}$ may alter the ratios stronger. The globally averaged standard deviation $\sigma_{\mathrm{MF} 1,2}$ is 0.23 , resulting in about 5\% albedo ratio changes $(\sim 0.05)$ for the two investigated cases. According to Table 7, this would permit to interpret spectral albedo changes and possibly observed VMC brightness changes of more than about $10 \%$ to be caused by abundance variations of the unknown UV absorber in the order of $25 \%$ or more.

Table 7. Specific spectral albedo $\mathrm{A}_{\lambda}{ }^{*}$ at $0.36 \mu \mathrm{m}(\mathrm{A} 1, \mathrm{~A} 2)$ and albedo ratio $\mathrm{R}_{\lambda}{ }^{\text {sim }}$ (R1, R2) in dependence on abundance factors AF of the unknown UV absorber (nominal model). Ratios refer to $\mathrm{AF}=1.0 . \mathrm{A} 1, \mathrm{R} 1$ : Latitude $0^{\circ} \mathrm{S}$, noon (subsolar point). A2, R2: Latitude $65^{\circ} \mathrm{S}, 15: 00 \mathrm{~h}$.

\begin{tabular}{cccccccccc}
\hline AF & 0.25 & 0.50 & 0.75 & 1.00 & 1.25 & 1.50 & 1.75 & 2.0 & 4.0 \\
\hline A1 & 0.671 & 0.593 & 0.532 & 0.483 & 0.443 & 0.410 & 0.381 & 0.357 & 0.241 \\
R1 & 1.389 & 1.227 & 1.101 & 1.000 & 0.917 & 0.849 & 0.789 & 0.739 & 0.499 \\
A2 & 0.752 & 0.665 & 0.595 & 0.537 & 0.489 & 0.449 & 0.415 & 0.385 & 0.250 \\
R2 & 1.400 & 1.238 & 1.108 & 1.000 & 0.911 & 0.836 & 0.773 & 0.717 & 0.466 \\
\hline
\end{tabular}

\subsection{Variability of zonally averaged temperature change rates determined from VIRTIS data}

It is an important aim of the present study to investigate temperature change rate (Q) responses to temperature profile $\mathrm{T}(\mathrm{z})$ and cloud mode factor $\mathrm{MF}_{\mathrm{i}}$ variability, that is, to define reasonable variability bounds of mean $\mathrm{Q}$ profiles. This is an urgently required prerequisite to investigate parameterization approaches for the calculation of atmospheric temperature change rates that can be used in Global Circulation Models (GCMs). Q parameterization studies will be a topic of a follow-up paper, however.

Some figures in Section 5 have already illustrated Q changes when selected mean parameters are replaced by added or subtracted standard deviations std, for example Fig. 12 for $\mathrm{T}^{\text {mean }}$ and $\mathrm{T}^{\text {mean+std }}$, Fig. 13 and Fig. 17 for $\mathrm{MF}_{\mathrm{i}}^{\text {mean }}, \mathrm{MF}_{\mathrm{i}}^{\text {mean } \pm \text { std }}$. There are no convincing arguments, however, that standard deviations of different parameters $\left(\sigma_{\mathrm{T}}, \sigma_{\mathrm{MF} 1,2}, \sigma_{\mathrm{MF} 3}\right.$, cf. Fig. 2B and Fig. 5) are related in a consistent way. When for example all available data on standard deviations of cloud mode factors $\mathrm{MF}_{1,2}$ and $\mathrm{MF}_{3}$ are compared, $\mathrm{MF}_{3}$ at some latitudes slightly decreases with increasing $\mathrm{MF}_{1,2}$, but at other latitudes it increases. Comparing differences of retrieved zonally averaged temperature profiles at different latitudes when simultaneous cloud parameter retrievals are considered or neglected in the procedures, Haus et al. (2014) have concluded that the overall influence of cloud parameter changes on the retrieved mesospheric zonally averaged temperature structure can be rated as moderate. Temperature variations associated with observed cloud parameter changes typically did not exceed 2-3 $\mathrm{K}$ at altitudes between 60 and $75 \mathrm{~km}$ and were much smaller outside of this altitude interval. Different patterns of temperature change with reduced cloud top altitude were observed at different latitudes.

Based on these arguments, studies of temperature change rate variability should consider retrieved standard deviations of atmospheric parameters that may principally act in different directions and not only in the same direction as done so far. This gives rise to eight cases, 'Case A' $\left(+\sigma_{\mathrm{T}},+\sigma_{\mathrm{MF} 1,2}\right.$, $\left.+\sigma_{\mathrm{MF} 3}\right)$, 'B' $\left(+\sigma_{\mathrm{T}},-\sigma_{\mathrm{MF} 1,2},-\sigma_{\mathrm{MF} 3}\right)$, 'C' $\left(+\sigma_{\mathrm{T}}\right.$, $\left.+\sigma_{\mathrm{MF} 1,2},-\sigma_{\mathrm{MF} 3}\right),{ }^{\prime} \mathrm{D}$ ' $\left(+\sigma_{\mathrm{T}},-\sigma_{\mathrm{MF} 1,2},+\sigma_{\mathrm{MF} 3}\right)$, ' $\mathrm{E}$ ' $\left(-\sigma_{\mathrm{T}},+\sigma_{\mathrm{MF} 1,2},+\sigma_{\mathrm{MF} 3}\right), \quad$ 'F' $\left(-\sigma_{\mathrm{T}}, \quad-\sigma_{\mathrm{MF} 1,2}, \quad-\right.$ $\left.\sigma_{M F 3}\right)$, 'G' $\left(-\sigma_{T},+\sigma_{M F 1,2},-\sigma_{M F 3}\right)$, and 'H' $\left(-\sigma_{T}\right.$, $\left.-\sigma_{M F 1,2},+\sigma_{M F 3}\right)$. Cloud mode factors $M_{1,2}$ and latitude-dependent mode 2 parameter changes together with the standard model of cloud mode abundances at each latitude determine actual cloud top altitudes. The influence of trace gas variations is very small and can be neglected in the following discussion. Variability of the unknown UV 
absorber is not included at this point, since standard deviations of the abundance factor are not available. Basic responses of heating rates to UVA abundance changes have already been discussed in the context of Fig. 19. Future analyses will of course include estimated UV absorber variability.

Fig. 24 illustrates thermal cooling rate altitude profiles obtained for the eight cases ' $A$ '- ' $\mathrm{H}$ ' described above. Latitude $65^{\circ} \mathrm{S}$ is exemplarily selected. The two additional broken lines depict the cases $\mathrm{T}^{\text {mean } \pm \text { std }}$ (cases ' $\mathrm{I}$ ' and ' $\mathrm{J}$ ') where mean values of $\mathrm{MF}_{\mathrm{i}}$ are used. The mean cooling profile (all standard deviations are set to zero) is described by the thick solid line. $\mathrm{Q}^{\mathrm{C}}$ variability above $80 \mathrm{~km}$ is mainly induced by temperature and resulting pressure changes, while $\mathrm{Q}^{\mathrm{C}}$ changes below about $75 \mathrm{~km}$ are mainly forced by cloud influence. The eleven curves are now used to determine the maximum deviations of cases A-J from the mean profile at each altitude and latitude, that is, the two envelopes as exemplarily shown in Fig. 25 for the two latitudes $20^{\circ} \mathrm{S}$ (display $\mathrm{A}$ ) and $65^{\circ} \mathrm{S}$ (display B). Discrimination between the two envelopes is performed by the notations 'minimum' and 'maximum' where 'minimum' denotes the envelope for weaker cooling rates. It is clear that the two envelope cooling profiles do no longer characterize specific input data sets. They shall serve to define the possible variability of cooling rates based on a mean state of atmospheric parameters that was derived

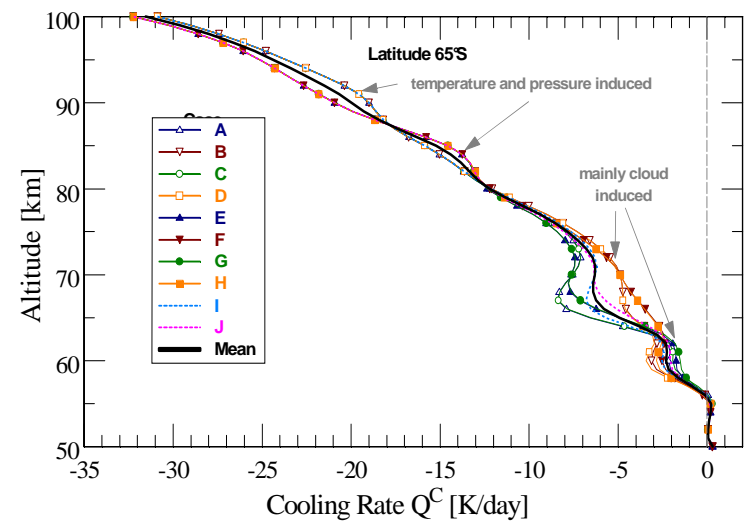

Fig. 24. Variability of thermal cooling rate altitude profiles based on retrieved standard deviations of atmospheric parameters. For description of the different cases see text.

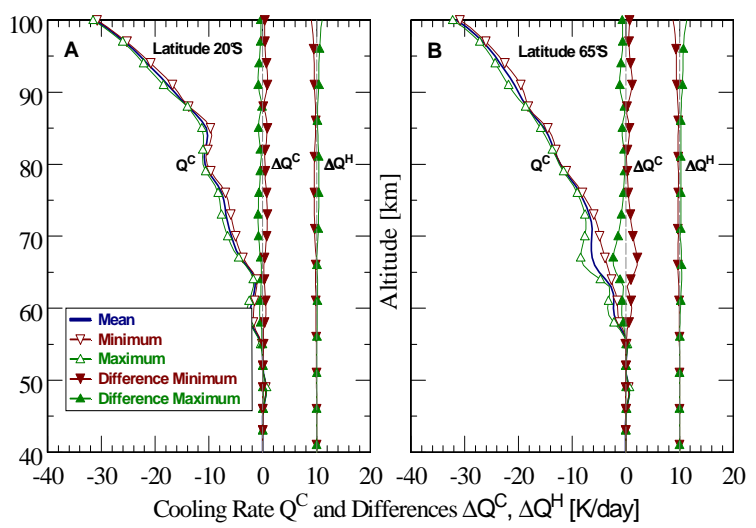

Fig. 25. Mean, minimum, and maximum cooling rate $\mathrm{Q}^{\mathrm{C}}$ altitude profiles and differences $\Delta \mathrm{Q}^{\mathrm{C}}$ (Y, Mean), $\Delta \mathrm{Q}^{\mathrm{H}}$ (Y, Mean) from the mean profile at $20^{\circ} \mathrm{S}(\mathrm{A})$ and $65^{\circ} \mathrm{S}(\mathrm{B})$. Y stands for either minimum or maximum $\mathrm{Q}^{\mathrm{C}}$. Positive $\Delta \mathrm{Q}^{\mathrm{C}}$ and $\Delta \mathrm{Q}^{\mathrm{H}}$ values indicate less $\mathrm{Y}$ cooling and more $\mathrm{Y}$ heating, respectively. $\Delta \mathrm{Q}^{\mathrm{H}}$ has an offset of $10 \mathrm{~K} /$ day for better representation.

together with corresponding parameter standard deviations from VIRTIS-M-IR measurements. Differences $\Delta \mathrm{Q}^{\mathrm{C}}$ (Y, Mean) are calculated according to Eq. (3) where $\mathrm{Y}$ is used as synonym for either minimum and maximum cooling profiles $\mathrm{Q}^{\mathrm{C}}$. Differences $\Delta \mathrm{Q}^{\mathrm{H}}$ (Y, Mean) have an analogous meaning. Positive $\Delta \mathrm{Q}^{\mathrm{C}}$ and $\Delta \mathrm{Q}^{\mathrm{H}}$ values hint on less $\mathrm{Y}$ cooling and more $\mathrm{Y}$ heating, respectively. Differences both for cooling and heating rates are almost symmetrically distributed around their respective mean. The sensitivity of heating rates to parameter changes is much smaller than that of cooling rates as already discussed before. The three heating rate profiles $\mathrm{Q}^{\mathrm{H}}$ are not shown, therefore.

Based on the graphs in Fig. 25, it is admissible to assume $\Delta \mathrm{Q}^{\mathrm{C}}$ and $\Delta \mathrm{Q}^{\mathrm{H}}$ symmetries of the two envelopes at each altitude and at each latitude, which can be motivated by the approximate linearity of responses to small parameter perturbations. Fig. 26 then provides a $2 \mathrm{D}$ picture of cooling rate (display A) and heating rate (display B) overall variability based on zonally averaged mean values and corresponding standard deviations $(1 \sigma)$ of atmospheric parameters that were retrieved from VIRTIS-M-IR measurements. Note that overall fluctuation ranges are depicted. Thus, lower and upper bounds of temperature change rates can be calculated using plotted data from Fig. 14A and Fig. 18A, respectively, and adding or 
subtracting half the plotted values from Fig. 26A and Fig. 26B, respectively. Maximum cooling rate deviations are identified at mid latitudes at altitudes above $80 \mathrm{~km}$ and at mid and high latitudes between 60 and $75 \mathrm{~km}$. Absolute values of cooling rates at altitudes above $80 \mathrm{~km}$ are always larger than $10 \mathrm{~K} /$ day (cf. Fig. 14), and maximum (half) deviations of $1.5 \mathrm{~K} /$ day at mid latitudes would correspond to $15 \%$ (with respect to 10 $\mathrm{K} /$ day). Mid latitude absolute cooling at 65$70 \mathrm{~km}$ is about $6-8 \mathrm{~K} /$ day. Half deviations in the order of $2 \mathrm{~K} /$ day would produce less or more cooling up to $30 \%$. Maximum (half) deviations of heating rates do not exceed 0.5 $\mathrm{K} /$ day at altitudes below $90 \mathrm{~km}$. This is just the type of information required for parameterization approaches.

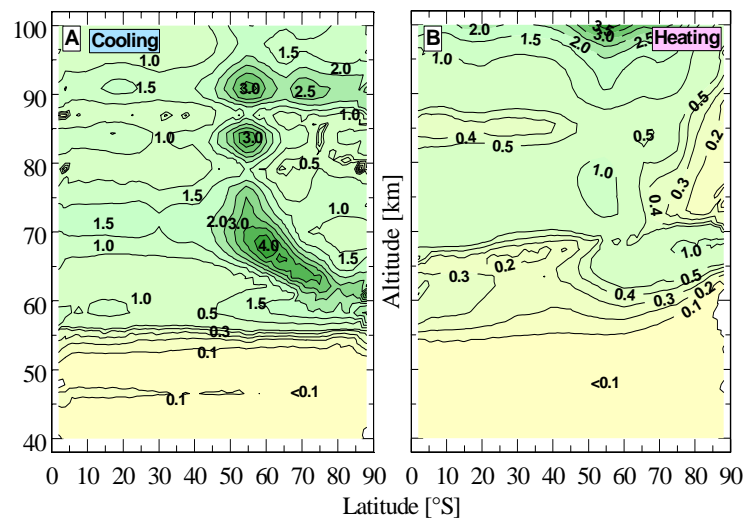

Fig. 26. Overall variability of cooling (A) and heating (B) rates as function of latitude and altitude based on zonally averaged mean values and corresponding standard deviations of atmospheric parameters retrieved from VIRTIS measurements. Variability is given in [K/day].

\subsection{Comparison of radiative forcing based on VIRTIS and VeRa temperature data}

The Venus Express (VEX) radio science experiment (VeRa, Häusler et al., 2006) performed radio occultation measurements of Venus' atmosphere in the closed loop receiver mode. Vertical profiles of the neutral atmospheric molecular number density were obtained from measured refractivity profiles. Assuming hydrostatic equilibrium, altitude profiles of temperature and pressure were derived from these data. The usable altitude range extends from about
$45-90 \mathrm{~km}$. The upper bound is determined by assumptions on the boundary temperature at $100 \mathrm{~km}$ that may strongly affect the retrieval results down to $80-90 \mathrm{~km}$. The actual lower bound is due to the observation geometry ("grazing occultations") that limited sounding to altitudes between about $47 \mathrm{~km}$ at equatorial and $42 \mathrm{~km}$ at polar latitudes (Tellmann et al., 2009, 2012). The VEX orbital configuration allowed for covering each latitude at different local times and illumination conditions during the same occultation season. Thus, day and night time temperature altitude profiles as functions of latitude and local time could be retrieved from VeRa data. Present investigations use nightside data that were initially averaged over local time and $5^{\circ}$ latitude bins (e.g. 40$45^{\circ}, 75-80^{\circ}$ ) and over both hemispheres. Averaging equatorward of $30^{\circ}$ extended over $10^{\circ}$ bins. These data were further processed to obtain averaged values at selected latitudes (e.g. $20^{\circ}, 65^{\circ}$ ). VeRa temperature standard deviations $\sigma_{\mathrm{T}}$ (not shown here) at altitudes between 60 and $85 \mathrm{~km}$ are usually in the order of 4-8 K. Largest values $(8 \mathrm{~K}$ ) are observed at $65 \mathrm{~km}$ at latitudes poleward of $40^{\circ}$ and at $83 \mathrm{~km}$ at equatorial latitudes. At $90 \mathrm{~km}$, standard deviations poleward of $40^{\circ}$ may reach $12 \mathrm{~K}$, however. $90 \mathrm{~km}$ is the upper altitude boundary for derived VeRa temperature profiles. $\sigma_{\mathrm{T}}$ decreases at altitudes below $60 \mathrm{~km}$, and minimum values of $2 \mathrm{~K}$ occur at $48 \mathrm{~km}$. The measurement error quickly drops from the upper bound (up to $10 \%)$ to the lower bound $(\sim 0.2 \mathrm{~K})$.

Retrieval results obtained at regions close to measurement sensitivity bounds are especially prone to possible errors and should be always used with care. This holds true for both VeRa and VIRTIS data. Thus, it should be stated at this point that calculated temperature change rates based on temperature retrieval results from VIRTIS and VeRa data at altitudes above $90 \mathrm{~km}$ (where lacking retrieval data are substituted in the way described below) and comparison of results are less reliable than for lower altitudes (but above $58 \mathrm{~km}$ ). 
Fig. 27 shows a comparison of zonally averaged mean VIRTIS, VeRa, VIRA-N, and VIRA-1 atmospheric model temperature profiles at $20,45,65$ and $80^{\circ}$. VIRTIS temperatures are primarily valid for the southern hemisphere, while VIRA and VeRa data result from observations over both hemispheres. High similarities between northern and southern hemisphere temperature fields as retrieved by Haus et al. (2013) indicate global N-S axial symmetry of atmospheric temperature structure, however. The horizontal broken lines in each display marked with $a, b, c$, and d have the following meaning. Line a: Above $90 \mathrm{~km}$, both VIRTIS and VeRa temperatures that are used for radiative energy balance calculations are linear interpolations between different $\mathrm{T}(90 \mathrm{~km})$ values and a fixed temperature $\mathrm{T}(100 \mathrm{~km})=165 \mathrm{~K}$, thus more resembling night time than day time profiles in this altitude domain. Line b: Above 84 $\mathrm{km}$, linear interpolations connect retrieved VIRTIS temperatures at $84 \mathrm{~km}$ with VIRA-N values at $90 \mathrm{~km}$. This step is required, since VIRTIS retrievals above $84 \mathrm{~km}$ are not very reliable due to instrumental noise in the main center of the $4.3 \mu \mathrm{m} \mathrm{CO} \mathrm{CO}_{2}$ band where temperature profiles were retrieved from. Line c: Below $58 \mathrm{~km}$, VIRTIS temperatures tend to follow the initial temperature model used in the retrieval procedures (VIRA-N). Line d: Below $48 \mathrm{~km}$, linear interpolations connect VeRa temperatures at $48 \mathrm{~km}$ with the VIRA-N value at $32 \mathrm{~km}$, which is identical for VIRA-N, VIRA-1, and VIRTIS.

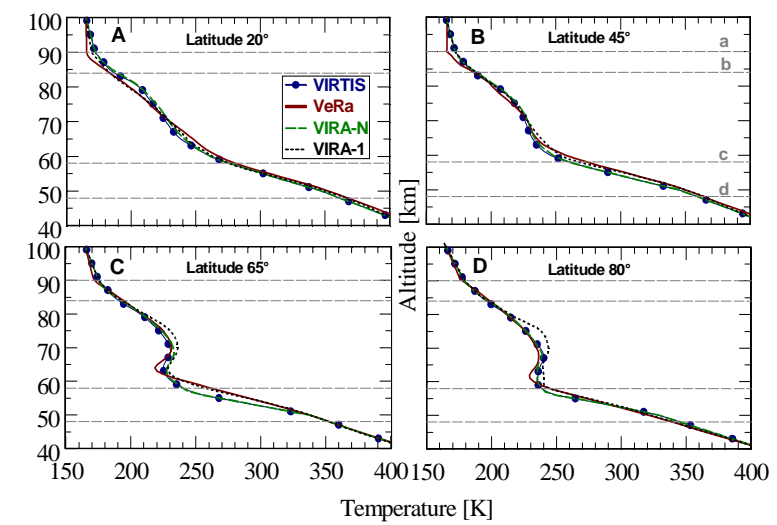

Fig. 27. Comparison of mean zonally averaged VIRTIS, VeRa, VIRA-N, and VIRA-1 atmospheric model temperature profiles at four latitudes. For explanations of horizontal broken lines a-d see text.
Fig. 28 (display A) provides a more comprehensive picture of VeRa temperature results. It shows the retrieved zonally averaged mean VeRa temperature field as function of latitude and altitude. Display B illustrates differences between VeRa and VIRTIS temperature retrievals, $\Delta \mathrm{T}=\mathrm{T}(\mathrm{VeRa})-\mathrm{T}(\mathrm{VIRTIS})$. Positive values correspond to lower VIRTIS temperatures.

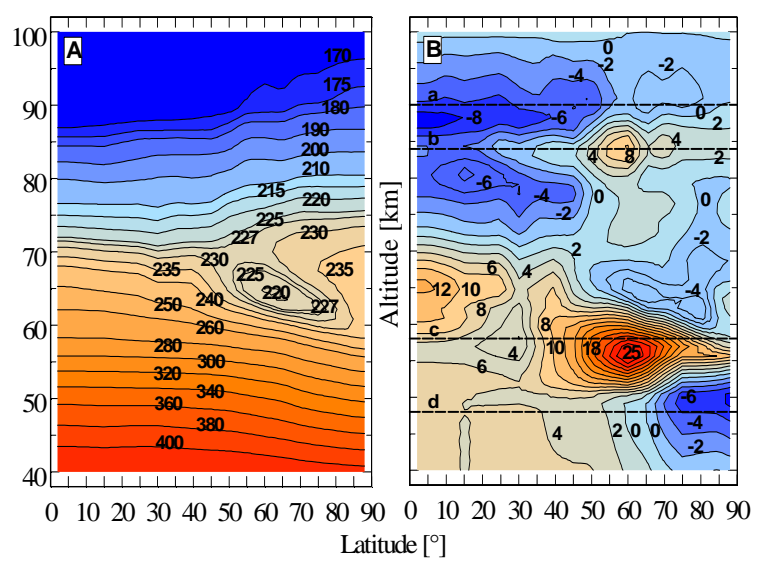

Fig. 28. A: Zonally averaged mean nightside temperature field as function of latitude and altitude based on retrieved values from $\mathrm{VeRa}$ nightside measurements. B: Temperature differences between VeRa and VIRTIS retrievals, $\Delta \mathrm{T}=\mathrm{T}(\mathrm{VeRa})$ T(VIRTIS). Temperatures and differences are given in $[\mathrm{K}]$. For explanations of horizontal broken lines a-d see text related to Fig. 27.

The calculated $\Delta \mathrm{T}$ field should be quite reliable due to the observed global N-S axial symmetry of atmospheric temperature structure. Recall that retrieved temperatures based on VIRTIS measurements are primarily valid for the southern hemisphere, while retrieved VeRa temperature fields use observations over both hemispheres. Similar plots like Fig. 28 (not shown here) have been generated for VIRA-1 and VIRA-N temperature fields, too. Figs. 27 and 28 reveal that VIRA, VIRTIS and VeRa temperatures at low and mid latitudes up to about $45^{\circ}$ usually agree within $10 \mathrm{~K}$. At altitudes above $75 \mathrm{~km}$, VeRa temperatures are mostly lower than VIRTIS values. The differences reach $-8 \mathrm{~K}$ at $88 \mathrm{~km}$ near the equator. A cell of warmer air $(\Delta \mathrm{T}=+8 \mathrm{~K})$ centered at $85 \mathrm{~km}$ and $60^{\circ}$ is observed by VeRa. Partly large temperature differences occur at altitudes between 52 and $60 \mathrm{~km}$ where VIRTIS and VIRA-N results near 55 $\mathrm{km}$ and $60^{\circ}$ are 20-25 $\mathrm{K}$ lower than VeRa 
and VIRA-1 results. Recall that VIRTIS temperatures below 58-60 km (broken line c in display B, cf. Fig. 27) approach VIRA-N data. Compared with VIRA-1, other profiles also differ by up to $10 \mathrm{~K}$ between 65 and 75 $\mathrm{km}$. Note that maximum and minimum temperature differences between $\mathrm{VeRa}$ and VIRTIS on the one hand, and between VeRa and VIRA-1 on the other hand (not shown here) are often located in different regions both with respect to altitude and latitude indicating quite large differences even between VeRa and VIRA-1 profiles. The comparatively small temperature differences near $100 \mathrm{~km}$ and below $45 \mathrm{~km}$ are due to use of the above described linear temperature profile interpolations to fixed boundary values at 100 and $32 \mathrm{~km}$, although VeRa profiles near $40 \mathrm{~km}$ still deviate from VIRA (and thus VIRTIS) profiles by up to $4 \mathrm{~K}$.

Retrieved VIRTIS temperatures often seem to closely follow the VIRA-N models that were used as initial models in the retrieval procedures. This is certainly the case at altitudes above $85 \mathrm{~km}$ and below 58-60 km due to the lack of appropriate weighting functions in those altitude domains. At altitudes between 60 and $85 \mathrm{~km}$, however, VIRTIS temperature retrieval results are not strongly forced by the initial model. This was demonstrated in great detail by Haus et al. (2013). The authors used synthetic VIRTIS measurements generated for very different atmospheric temperature profiles and cloud parameters and added Gaussian noise. The multi-window retrieval technique (MWR) was then applied to recover the model parameters (not only temperature profiles but also cloud parameters) whereupon the synthetic spectra were based.

Having collected and discussed the different temperature models, it is now a very interesting question how the calculated temperature change rates $\mathrm{Q}$ respond to them. This cannot be fully assessed in advance due to the complex character of radiative transfer through different atmospheric layers. Comparisons of $\mathrm{Q}^{\mathrm{C}}$ and $\mathrm{Q}^{\mathrm{H}}$ with respect to VIRTIS and VIRA-N temperature differences have been discussed in detail already in Section 5. But note that for the comparisons shown below, all calculations now consider cloud and trace gas parameters as retrieved from VIRTIS-M-IR data.

Fig. 29 illustrates atmospheric cooling rate altitude profiles $\mathrm{Q}^{\mathrm{C}}(\mathrm{z})$ at $20,45,65$ and $80^{\circ}$ (displays A-D) that are based on zonally averaged mean VIRTIS, VeRa, VIRA-N, and VIRA-1 temperature profiles shown in Fig. 27. $\mathrm{Q}^{\mathrm{C}}$ profiles well reflect the varying temperature conditions at different latitudes. Largest cooling rate changes are observed at altitudes between 75 and $95 \mathrm{~km}$ at all latitudes. Smaller VeRa temperatures between 70 and $90 \mathrm{~km}$ at low latitudes, for example, result in smaller $\mathrm{Q}^{\mathrm{C}}$ values. Recall again that real cooling rates are mostly positive, and the minus sign is only used per convention. The VeRa temperature between 60 and $65 \mathrm{~km}$ at high latitudes is lower than that of other temperature models, and the VeRa cooling rate has consequently also a local minimum there.

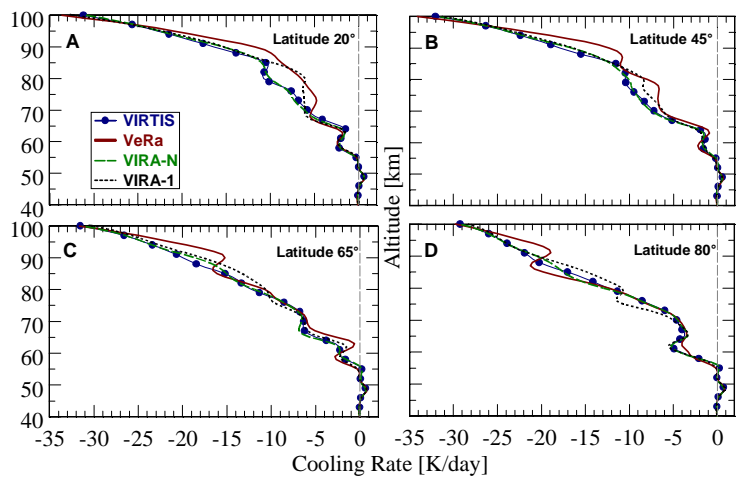

Fig. 29. Zonally averaged mean VIRTIS, VeRa, VIRA-N, and VIRA-1 cooling rate altitude profiles at four latitudes.

Fig. 30 (display A) shows the 2D field of zonally and diurnally averaged mean net radiative heating rates in the mesosphere and upper troposphere of Venus, that is, heating rates $\mathrm{Q}^{\mathrm{N}}$ as functions of latitude and altitude. The results are based on atmospheric parameters that were retrieved from both VeRa (thermal profiles) and VIRTIS-M-IR (cloud mode abundances and cloud top altitudes, trace gas abundances) measurements. Display B illustrates zonally and diurnally averaged mean net heating rate differences between VeRa and VIRTIS comparing Fig. $30 \mathrm{~A}$ with Fig 20A. $\Delta \mathrm{Q}^{\mathrm{N}}$ 
(VeRa, VIRTIS) is calculated according to Eq. (3). Since heating rate profiles $Q^{\mathrm{H}}(\mathrm{z})$ based on the different temperature models (not shown here) are very similar, these net heating rate differences are almost exclusively determined by cooling rate differences. Thus, positive values in display $\mathrm{B}$ indicate less cooling in case of $\mathrm{VeRa}$, that is, stronger net heating of the atmosphere. Compared with VIRTIS and in agreement with Fig. 29, a planet-wide net heating excess is observed in case of $\mathrm{VeRa}$ temperature data at altitudes around $90 \mathrm{~km}$.

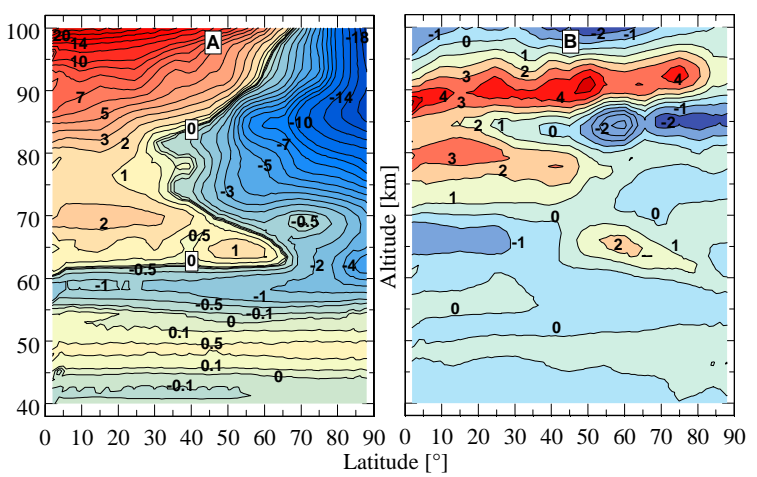

Fig. 30. A: Zonally and diurnally averaged mean net radiative heating rates as functions of latitude and altitude based on atmospheric parameters retrieved from $\mathrm{VeRa}$ (temperature) and VIRTIS (clouds) measurements. B: Corresponding differences $\Delta Q^{N}$ (VeRa, VIRTIS). Positive values indicate more net heating in case of VeRa. Net heating rates and differences are given in [K/day].

VeRa net heating is also larger around $80 \mathrm{~km}$ at equatorial and mid latitudes. Slightly smaller net heating takes place at equatorial latitudes around $65 \mathrm{~km}$, while the cold collar region experiences a slightly stronger radiative forcing. These changes cause the loss of the broad, planet-wide net cooling region that is obtained for VIRTIS temperatures between 72 and $82 \mathrm{~km}$ (cf. Fig. 20A). Low latitudes at these altitudes are now characterized by a small net heating, but the strong increase of net cooling toward the pole (up to $13 \mathrm{~K} /$ day) is maintained. The zero-isoline between 60 and $70 \mathrm{~km}$ and between 80 and $90 \mathrm{~km}$ shifts towards the pole by about $10-15^{\circ}$. Note that the net heating peculiarity found from VIRTIS data near $68 \mathrm{~km}$ and $70^{\circ} \mathrm{S}$ is preserved. This is not surprising, however, since the same UV absorber model is used in both cases and cold collar cooling features are also very similar.

Fig. 31 shows altitude profiles of global averages (GA) of thermal cooling, solar heating, and net heating rates according to Eq. (4) obtained for different temperature profiles. The meaning of the thick broken line will be explained in Section 6.4. Compared with VIRTIS, VeRa net cooling between 70 and $85 \mathrm{~km}$ is weaker, while net heating increases between 85 and $96 \mathrm{~km}$ and slightly deceases at altitudes between 65 and $70 \mathrm{~km}$.

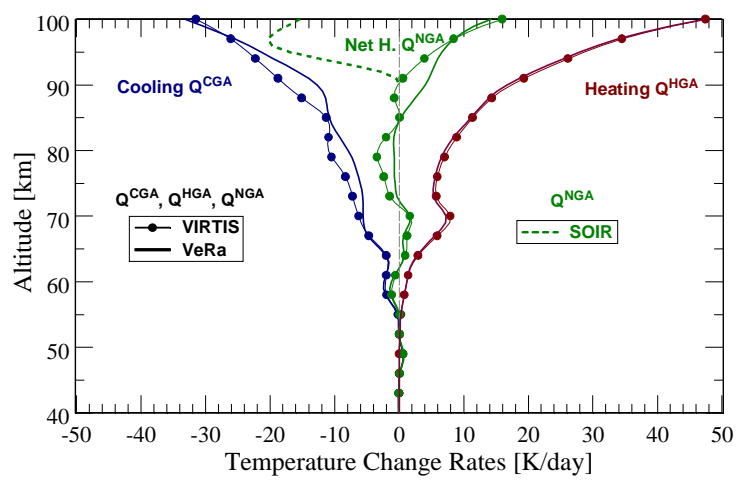

Fig. 31. Global averages of thermal cooling, solar heating, and net heating rate altitude profiles. Comparison of results obtained for different temperature profiles.

The global averages of deposited solar flux and outgoing thermal flux at TOA altitude for the atmospheric models retrieved from VIRTIS data are 157.92 and $155.54 \mathrm{~W} / \mathrm{m}^{2}$ (cf. Section 6.1). Using VeRa temperatures, the corresponding values are 158.76 and $165.71 \mathrm{~W} / \mathrm{m}^{2}$, respectively. The calculated Bond albedo in case of $\mathrm{VeRa}$ is $\mathrm{A}=0.759$ (0.761 for VIRTIS). Since the thermal flux component is larger than the solar component in case of VeRa, an unknown UV absorber abundance factor of about 1.2 (cf. Section 6.1) would be required to achieve exact TOA radiative equilibrium, thereby producing a planetary Bond albedo of 0.750 .

With respect to the intended search for parameterization approaches for the calculation of atmospheric temperature change rates, the observed $Q$ changes due to temperature fields retrieved from different experiments will be taken into account. But 
this is beyond the scope of present investigations.

\subsection{Comparison of radiative forcing based on VIRTIS and SPICAV/SOIR temperature data}

Not only the VIRTIS and VeRa instruments on VEX but also SPICAV/SOIR have measured atmospheric temperature profiles. The SPICAV (Spectroscopy for the investigation of the characteristics of the atmosphere of Venus) instrument provided $\mathrm{CO}_{2}$ density and temperature vertical profiles of the upper atmosphere (90-140 km) measuring in the stellar occultation mode and at ultraviolet wavelengths $(118-320 \mathrm{~nm})$. Observations covered all latitudes and local times on the nightside. A very warm nightside layer at altitudes $90-120 \mathrm{~km}$ was detected by SPICAV that peaks around 100 $\mathrm{km}$ and exhibits a large temperature excess $(30-70 \quad \mathrm{~K})$ compared with previous measurements (Bertaux et al., 2007). Following these authors, the altitude range $100-150 \mathrm{~km}$ has largely been unexplored up to now. The upper limit for infrared soundings and radio occultation is $100 \mathrm{~km}$, descent probes have so far measured only below this range, and atmospheric drag measurements were performed only above $150 \mathrm{~km}$. Largest temperature maxima at 100 $\mathrm{km}$ were detected for solar zenith angles near $170^{\circ}$, that is, near to the antisolar point. The authors have interpreted this newly found temperature peak to be caused by adiabatic heating during air subsidence near the antisolar point, as the end result of the solarantisolar circulation pattern suspected to exist in the thermosphere $(100-200 \mathrm{~km})$ from the dayside to the nightside. They also suggested that it should be further investigated whether the new hot profiles are sporadic and patchy, or whether they are permanent and large-scale features of the upper mesosphere and thermosphere. Similar results with respect to a warm atmospheric nightside layer above $90 \mathrm{~km}$ were found by the SOIR (Solar Occultation in the IR) instrument that also measured $\mathrm{CO}_{2}$ density and temperature vertical profiles usually above $85 \mathrm{~km}$ but exclusively at the terminators using the solar occultation technique in the infrared $(2.2-4.3 \mu \mathrm{m})$ (Mahieux et al., 2012, 2015).

Since the lower boundary of usable altitude range for temperature sounding is placed near $90 \mathrm{~km}$ for both SPICAV and SOIR, these measurements do not cover the main target range of present studies. With respect to VIRTIS and VeRa data, the upper boundary of retrieved temperature profiles is rather 90 than $100 \mathrm{~km}$. As it was already pointed out in Section 6.3, results obtained for regions close to measurement sensitivity bounds are especially prone to possible errors and should be always used with care. Temperature profiles above $90 \mathrm{~km}$ are constructed for present investigations in the way that latitude-dependent values at $90 \mathrm{~km}$ are linearly interpolated to an assumed fixed value of $165 \mathrm{~K}$ at $100 \mathrm{~km}$. A latitudeindependent linear nightside profile then extends to $140 \mathrm{~K}$ at $140 \mathrm{~km}$ altitude.

A significantly higher temperature at altitudes above $90 \mathrm{~km}$ would seriously influence calculated cooling rates, while changes of heating rates can be expected to be small. To estimate the changes of thermal cooling rates due to the observed warm layer above $90 \mathrm{~km}$, a nightside profile is constructed that considers the mean hydrostatic profile described by Mahieux et al. (2015). Characteristic temperatures are $184 \mathrm{~K}$ at $95 \mathrm{~km}, 200 \mathrm{~K}$ at $100 \mathrm{~km}, 180$ at 110 $\mathrm{km}$, and $120 \mathrm{~K}$ at $125 \mathrm{~km}$. To emulate a nightside temperature profile that is different from the one used so far, latitude-dependent VIRTIS (or VIRA) profiles are linearly interpolated from their values at $90 \mathrm{~km}$ to $\mathrm{T}(100 \mathrm{~km})=200 \mathrm{~K}$, then follow the Mahieux profile up to $110 \mathrm{~km}$, and then result from linear interpolation from $\mathrm{T}(110 \mathrm{~km})=180 \mathrm{~K}$ to $\mathrm{T}(140 \mathrm{~km})=140 \mathrm{~K}$ (as before).

Resulting cooling rates $\mathrm{Q}^{\mathrm{C}}$ based on the higher temperatures especially around 100 $\mathrm{km}$ are much larger above $90 \mathrm{~km}$ compared with VIRTIS. At $100 \mathrm{~km}$ and $20^{\circ} \mathrm{S}$, $\mathrm{Q}^{\mathrm{C}}$ (SOIR) is larger than $\mathrm{Q}^{\mathrm{C}}$ (VIRTIS) by a factor of two, that is, it reaches $62 \mathrm{~K} /$ day. 
Since radiative heating does not change by more than $1 \mathrm{~K} /$ day as expected, cooling in case of SOIR would dominate net radiative heating at $100 \mathrm{~km}$ at all latitudes in contrast with Figs. 20 and 30. The resulting globally averaged net heating altitude profile above $90 \mathrm{~km}$ is shown as thick broken line in Fig. 31. Net heating is much smaller compared to VIRTIS and VeRa results. Strong net cooling takes place in fact. It is far away from radiative equilibrium.

Present results on the radiative energy balance of Venus at altitudes above $90 \mathrm{~km}$ are mainly based on VIRA temperature data. Recall that neither VIRTIS nor VeRa was sensitive to temperature variations in this altitude domain. Until the hot nightside profiles as measured by SPICAV/SOIR are not verified by future experiments to be permanent and large-scale features of the upper mesosphere and thermosphere, it is very difficult (or even impossible) to assess the reliability of cooling rates that are calculated based on either VIRA or SPICAV/SOIR profiles above $90 \mathrm{~km}$. These results should be used with great care, therefore. Note that recent simulations using the Venus Thermospheric General Circulation Model (VTGCM, Bougher et al., 2015) did not reproduce the high SOIR temperatures for the bottom of the warm layer near $100 \mathrm{~km}$.

\subsection{Comparison of present and literature results on radiative forcing}

The present paper investigates atmospheric radiation fluxes $(\mathrm{F})$ and temperature change rates $(\mathrm{Q})$ that are based on improved threedimensional atmospheric models (altitudelatitude-local time) retrieved from VIRTISM-IR as well as VeRa data. F and Q including their variability in dependence on atmospheric (and also spectroscopic) model parameters were also analyzed in the recently published precursor work of Haus et al. (2015b). Contrary to the present work, these previous analyses were based on initial atmospheric standard models (temperature and trace gas altitude profiles, cloud parameters). It is one of the most important result of present investigations that radiative cooling of the atmosphere at altitudes between 65 and $80 \mathrm{~km}$ and poleward of about $50^{\circ} \mathrm{S}$ is significantly weaker (up to 9 $\mathrm{K} /$ day, $30 \%$, cf. Fig. 14) than predicted in the precursor study where cloud parameter changes were neglected. Heating rates are less sensitive to the cloud structure, but when retrieved parameters are used, the $65-90 \mathrm{~km}$ altitude region near $70^{\circ} \mathrm{S}$ nevertheless exhibits Q changes up to $1.6 \mathrm{~K} /$ day (30-40\%, cf. Fig. 18). Thus, consideration of retrieved zonal variations of cloud parameters seriously improves the general view to radiative forcing in the atmosphere of Venus.

Haus et al. (2015b, Figure 35 in that paper) have compared globally averaged cooling and heating rates obtained for VIRA-N temperature profile and cloud standard model conditions with earlier results from the literature (Tomasko et al., 1985; Crisp, 1986; Crisp, 1989; Haus and Goering, 1990; Lee and Richardson, 2011). Partly large differences were identified. These investigations used different atmospheric and spectroscopic model parameters. The spectral ranges that were taken into account, the used solar irradiance spectra, and the definition of TOA altitude also differed. It was not always clear from the given information whether global averages were generated by use of latitude weighting or not. Replacing the former results of Haus et al. (2015b) by the curves from Fig. 21 (this work), which are marked by open circles, would change nothing with respect to the heating rate comparison, but would move the cooling rate profile above $65 \mathrm{~km}$ closer to the profiles reported by other authors.

The only other recent two-dimensional analysis (altitude-latitude) of both radiative cooling and radiative heating in the atmosphere of Venus that considers atmospheric parameters retrieved from VEX instrument data (VeRa temperatures, VIRTIS-M-IR cloud parameters) was performed by Lee et al. (2015). Fig. 32 compares differences of zonally and diurnally averaged mean cooling rates 
(display A), heating rates (display B), and net heating rates (display $\mathrm{C}$ ) as functions of latitude and altitude $(\mathrm{H}$ : Haus et al., this work, L: Lee et al., 2015). Differences are shown in the form $\Delta \mathrm{Q}^{\mathrm{Y}}(\mathrm{L}, \mathrm{H})$ and are calculated according to Eq. (3). Y stands for either cooling or heating or net heating. Display D illustrates corresponding differences for global averages.

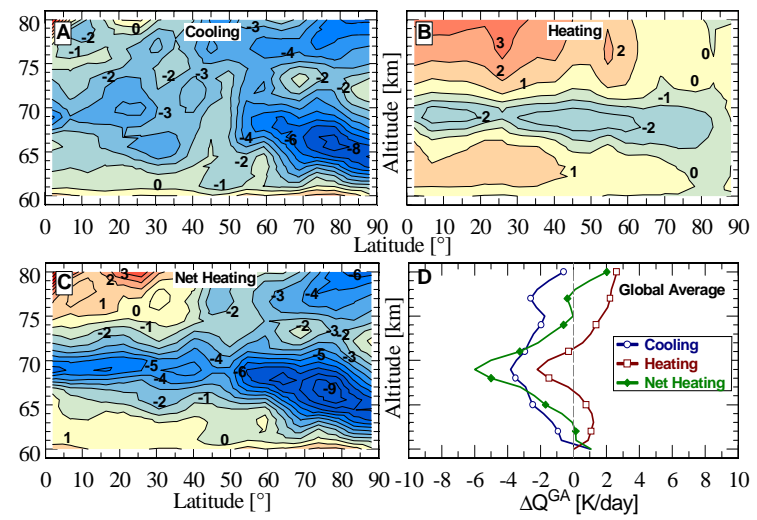

Fig. 32. A-C: Differences $\Delta \mathrm{Q}^{\mathrm{Y}}(\mathrm{L}, \mathrm{H})$ of zonally and diurnally averaged mean cooling rates (A), heating rates $(\mathrm{B})$, and net heating rates $(\mathrm{C})$ shown as functions of latitude and altitude. Negative values in (A): More cooling in case of L. Negative values in $(B, C)$ : Less heating/net heating in case of L. (D): Corresponding differences for global averages. H: Haus et al. (this work), L: Lee et al. (2015). VeRa temperature profiles and the latitude-dependent cloud model of $\mathrm{H}$ are always used. Temperature change rates are given in [K/day].

Lee et al. (2015) have limited their study to the altitude range $55-80 \mathrm{~km}$. The lowest 5 $\mathrm{km}$ are excluded from the comparison however, since the authors have stated that some unrealistic discontinuities appeared in their results at these altitudes. $\mathrm{Q}^{\mathrm{Y}}$ results are based on VeRa temperatures in both cases $\mathrm{L}$ and $\mathrm{H}$. $\mathrm{H}$ uses cloud parameters that are determined by the standard model shown in Fig. 4 and latitude-dependent modifications of this model as retrieved from VIRTIS measurements for modes 1, 2 and 3 (cf. Section 3.2). The cloud model of $\mathrm{L}$ significantly differs from the present one. The only cloud particles that were assumed to exist at altitudes above $60 \mathrm{~km}$ belong to mode 2 particles. Their altitude distribution of number density peaks at $60 \mathrm{~km}$ with varying peak concentrations with latitude. Thus, neither upper haze and higher altitude mode 1 particles nor mode 2' particles above $60 \mathrm{~km}$ were considered. The three modes 1 ,
2', and 3 were addressed as latitudeindependent cloud constituents at altitudes below $60 \mathrm{~km}$. Latitude-dependent changes of mode 2 upper scale heights $\left(\mathrm{H}_{\text {up }}(2)\right)$ of particle altitude distribution and cloud top altitude $\left(\mathrm{z}_{\mathrm{t}}(2)\right)$ were retrieved by comparing synthetic spectra, which were generated for different sets of these two parameters, with VIRTIS spectral radiance measurements in the 4.4-5.0 $\mu \mathrm{m}$ range. $\mathrm{L}$ did not attempt to perform simultaneous and self-consistent cloud parameter and temperature profile retrievals from VIRTIS data as done by the present authors. L have modeled the UV absorber by reducing the single scattering albedo of mode 2 particles. Thus, its vertical distribution is determined by the upper cloud structure. Details with respect to consideration of gaseous absorption also differ between $\mathrm{H}$ and $\mathrm{L}$.

The overall differences between the two modeling results $\mathrm{H}$ and $\mathrm{L}$ are quite large. Cooling rates (display A of Fig. 32) of L are larger (indicated by a minus sign) by 2-3 $\mathrm{K} /$ day at low and mid latitudes between 65 and $75 \mathrm{~km}$, but larger up to $8 \mathrm{~K} /$ day at polar latitudes near $65 \mathrm{~km}$. Heating rates usually agree within $\pm 2 \mathrm{~K} /$ day being larger above 70 $\mathrm{km}$ and below $65 \mathrm{~km}$ in case of L compared with $\mathrm{H}$, but smaller in the intermediate range. Reduced heating at $65-70 \mathrm{~km}$ may be due to the different consideration of the UV absorber that follows the upper cloud structure in the L model and is thus placed at lower altitudes compared with the $\mathrm{H}$ model. Due to overall smaller heating rate differences than cooling rate differences, net heating differences $\Delta \mathrm{Q}^{\mathrm{N}}$ are mainly determined by $\Delta \mathrm{Q}^{\mathrm{C}}$. Net heating in case $\mathrm{L}$ is smaller at altitudes around $70 \mathrm{~km}$ by about 5 $\mathrm{K} /$ day at all latitudes. The maximum difference occurs at $67 \mathrm{~km}$ and $75-80^{\circ}$ where net heating found by $\mathrm{L}$ is smaller by $9 \mathrm{~K} /$ day compared with present results.

It is very likely that the observed differences are mainly due to the very different cloud models used by the two authors, since the temperature profiles are similar. Recall that the neglect of latitudinal variations of cloud parameters as visualized in Fig. 20B for net 
radiative heating has produced a net heating drop of up to $11 \mathrm{~K} /$ day at $70 \mathrm{~km}$ and polar latitudes. Now, in Fig. 32C, a net heating decrease for $\mathrm{L}$ data in a comparable order of magnitude is observed, since there are considerably less clouds at this altitude compared with the cloud model of $\mathrm{H}$. Maximum cloud abundances assumed to exist at $60 \mathrm{~km}$ and the neglect of latitudinal variations of cloud mode 3 abundances in the $\mathrm{L}$ model support the above hypothesis on cloud model responsibility for observed temperature change rate differences. The globally averaged net heating result of Haus et al. (this work) for VeRa temperature profiles is much closer to radiative equilibrium conditions at altitudes between 60 and $80 \mathrm{~km} \mathrm{(cf.} \mathrm{Fig.} \mathrm{31),} \mathrm{but} \mathrm{this}$ observation alone is not a conclusive indicator of the results' reliabilities.

\section{Summary and conclusions}

The radiative transfer simulation model described by Haus et al. (2015b) is applied to calculate fluxes and temperature change rates in the atmosphere of Venus at altitudes between 0 and $100 \mathrm{~km}$. The calculations are performed separately for thermal (1.67-1000 $\mu \mathrm{m})$ and solar $(0.125-1000 \mu \mathrm{m})$ flux components. Improved models of atmospheric parameters are utilized that have been retrieved mainly from VIRTIS-M-IR (VEX) measurements. This concerns nightside temperature altitude profiles as well as cloud mode abundances and cloud top altitudes (Haus et al., 2013, 2014), (Figs. 1-3, Figs. 4-5, Fig. 7 in the present work) and trace gas abundances (Haus et al., 2015a), (Figs. 8-9 in the present work). Retrieved atmospheric temperatures based on VeRa data (Tellmann et al., 2009) (Figs. 27-28) are also considered.

The solar irradiance spectrum of Kurucz (2011) is selected as insolation model. Gaseous absorptions at infrared and visible wavelengths are calculated applying a high spectral resolution line-by-line procedure. UV absorptions by $\mathrm{CO}_{2}, \mathrm{H}_{2} \mathrm{O}$, OCS, and $\mathrm{HCl}$ shortward of $0.4 \mu \mathrm{m}$ as well as molecular
Rayleigh scattering are considered. The standard cloud model facilitates analytical descriptions of four-modal particle altitude distributions (Fig. 4) where all modes are assumed to consist of spherical $\mathrm{H}_{2} \mathrm{SO}_{4}$ aerosols at 75 weight- $\%$ solution. Mie scattering theory is applied to derive wavelength-dependent microphysical parameters of each mode. Standard cloud model results are modified according to retrieved latitude-dependent cloud parameters (mode abundances, mode 2 upper scale height and peak concentration altitude, Fig. 6, Tables 1-4). The standard model of the unknown UV absorber (Fig. 10) is not directly linked to any cloud mode and permits an investigation of radiative effects regardless of its chemical composition by modifying the basic altitude distribution by an altitude-independent factor.

On global average, the solar flux deposited on the planet is $157.9 \mathrm{~W} / \mathrm{m}^{2}$, and the outgoing thermal net flux is $155.5 \mathrm{~W} / \mathrm{m}^{2}$ for VIRTIS data. The mean value of 156.7 $\mathrm{W} / \mathrm{m}^{2}$ very well corresponds to the value of $(157 \pm 6) \mathrm{W} / \mathrm{m}^{2}$ reported by Titov et al. (2007). Exact TOA global radiative equilibrium referenced to the outgoing thermal net flux can be easily achieved by reducing the default unknown UV absorber abundance by $7.6 \%$. This provides a globally averaged Bond albedo of 0.764 and an effective planetary emission temperature of $228.5 \mathrm{~K}$.

Ratios of synthetic specific spectral albedo values that are determined at $0.36 \mu \mathrm{m}$ from calculated albedos for different abundance factors of the unknown absorber provide a possible tool to interpret VMC data with respect to actual UV absorber abundances (Fig. 22). This would require relating local time and latitude-dependent observations performed by the VEX Venus Monitoring Camera (VMC) to an averaged value that has to be constructed from single images along an observation session.

Cooling rates may heavily respond to variations of atmospheric thermal structure and cloud parameter changes. Pure 
temperature effects on zonally averaged cooling rates $\mathrm{Q}^{\mathrm{C}}$ are strongest pronounced at altitudes between 60 and $90 \mathrm{~km}$ where $Q^{C}$ usually increases with increasing temperature (Fig. 11). Cloud influences may additionally seriously alter these results between 55 and $80 \mathrm{~km}$ where $\mathrm{Q}^{\mathrm{C}}$ usually increases with increasing cloud abundance (Fig. 13). There is little response of $Q^{C}$ to abundance changes of mode 1 particles, but strong response to changes of mode 2 parameters that mainly determine the cloud top altitude. It is an important result of present investigations that radiative cooling of the atmosphere at altitudes between 65 and $80 \mathrm{~km}$ and poleward of about $50^{\circ} \mathrm{S}$ is significantly weaker (up to $9 \mathrm{~K} /$ day, $30 \%$ ) than predicted in the precursor study (Haus et al., 2015b) where cloud parameter changes were neglected (Figs. 13-14). Slightly larger cooling, however, is observed near $60 \mathrm{~km}$ and poleward of $60^{\circ} \mathrm{S}$ mainly due to mode 3 influence. The development of the cold collar over the course of night at altitudes between 60 and $70 \mathrm{~km}$ and at $65^{\circ} \mathrm{S}$ where the atmosphere is warmer at early night and colder at late night by about $10 \mathrm{~K}$ is well reflected in terms of cooling rates that decrease with local time (Fig. 15). The observed change of $1.7 \mathrm{~K} /$ day is rather small, however. Larger temporal variability (6 $\mathrm{K} /$ day) occurs at $80 \mathrm{~km}$.

Heating rates $Q^{\mathrm{H}}$ strongly depend on latitude due to decreasing solar insolation with increasing distance from equator resulting in much smaller heating rates at high latitudes. This effect however declines with decreasing altitude due to the strong absorption of solar radiation by gaseous and particulate constituents. Heating rates generally respond much weaker to temperature and cloud parameter changes than cooling rates do (Figs. 16-18). They are almost insensitive to small temperature changes. Cloud influence may become stronger at altitudes between 60 and $85 \mathrm{~km}$, but maximum $\mathrm{Q}^{\mathrm{H}}$ changes (less heating between 70 and $85 \mathrm{~km}$, more heating between 60 and $70 \mathrm{~km}$ ) do not exceed 1.5 $\mathrm{K} /$ day at high latitudes and are much smaller toward the equator. Variations of the unknown UV absorber abundance may significantly alter $\mathrm{Q}^{\mathrm{H}}$ profiles (Fig. 19). The nominal model doubles heating at $70 \mathrm{~km}$ and low latitudes compared with a neglect of this opacity source.

Atmospheric net heating dominates the low and mid latitudes above $82 \mathrm{~km}$, while net cooling prevails at high latitudes (Fig. 20). A similar but much smaller meridional gradient is also observed at altitudes between 61 and $72 \mathrm{~km}$ where the unknown UV absorber provides additional heating. Together with reduced cooling in the cold collar region, it causes a peculiarity of the net heating field near $70 \mathrm{~km}$ and $70^{\circ} \mathrm{S}$ (almost zero net heating). Based on VIRTIS temperature data, the intermediate altitude range between 72 and $82 \mathrm{~km}$ is characterized by general net cooling but maintaining the strong equator to pole gradient. Another narrow and much weaker net cooling layer exists at altitudes between 55 and $61 \mathrm{~km}$. Below about $53 \mathrm{~km}$, very weak net heating occurs at all latitudes that results from thermal heating of the atmosphere near the cloud base $(48 \mathrm{~km})$. Nearly zero net heating prevails in the deep atmosphere below $44 \mathrm{~km}$ where the troposphere of Venus is almost in radiative equilibrium. Assuming the existence of a diurnal thermal tide, mean net heating at the equator dominates mean net cooling from about $7: 30 \mathrm{~h}$ until $16: 30 \mathrm{~h}$ local time at altitudes between 60 and $70 \mathrm{~km}$, mainly forced by the presence of the unknown UV absorber (Fig. 22).

The possible variability of temperature change rates based on a mean state of atmospheric parameters and on corresponding parameter standard deviations $\sigma$ (all retrieved from VIRTIS-M-IR measurements) is studied in great detail (Figs. 24-26). Maximum Q deviations from the mean value at each altitude and latitude (within $\pm \sigma$ ) are calculated neglecting so far possible UV absorber variations. These profiles may serve as important prerequisites to investigate parameterization approaches for the calculation of atmospheric temperature change rates that can be used in Global Circulation Models (GCMs, Lebonnois et al., 2010). Both cooling and 
heating rate deviations are usually below \pm 5 $10 \%$. $Q^{C}$ deviations may reach $\pm 30 \%$ near $60^{\circ} \mathrm{S}$ at $65-70 \mathrm{~km}$.

Responses of atmospheric temperature change rates to different atmospheric temperature models are investigated, especially the case when VIRTIS temperature fields are replaced by temperature data retrieved from measurements of the Venus Express (VEX) radio science experiment (VeRa, Tellmann et al., 2009), (Figs. 27-28 in this work). Compared with VIRTIS temperatures, a planet-wide net heating excess is observed in case of $\mathrm{VeRa}$ temperatures at altitudes around $90 \mathrm{~km}$ (Figs. 29-31). VeRa net heating is also larger around $80 \mathrm{~km}$ at equatorial and mid latitudes. This causes the loss of the broad, planet-wide net cooling region between 72 and $82 \mathrm{~km}$ obtained for VIRTIS temperatures. Low latitudes at these altitudes are now characterized by a small net heating. On global average and compared with VIRTIS, VeRa net cooling between 70 and $85 \mathrm{~km}$ is weaker by up to $2 \mathrm{~K} /$ day, while net heating increases between 85 and $96 \mathrm{~km}$.

When the warm nightside layer at altitudes $90-120 \mathrm{~km}$ (peaking around $100 \mathrm{~km}$ ) that was detected by SPICAV/SOIR (and that could be a permanent feature, but possibly might also be just of sporadic nature) is considered, much stronger cooling occurs at altitudes above $90 \mathrm{~km}$. Globally averaged net radiative heating at $95 \mathrm{~km}$ is in the order of $20 \mathrm{~K} /$ day that is far away from radiative equilibrium. Taking into account the existing large differences between observed temperature profiles at altitudes above $90 \mathrm{~km}$ and in view of the large response of calculated cooling rates to these uncertainties, a general conclusion can be drawn, which is valid for any study on radiative energy balance of Venus. Results obtained at altitudes between 90 and $100 \mathrm{~km}$ are less reliable compared with the bulk of the atmosphere below $90 \mathrm{~km}$ and should be used with care.

Comparison of present data with recent findings of Lee et al. (2015) with respect to radiative cooling, heating and net heating rates at altitudes between 60 and $80 \mathrm{~km}$ indicate that different models applied to describe the clouds of Venus may have a strong influence on the results. Much stronger cooling and less net radiative heating were reported by Lee et al.

Present investigations that are based on very detailed and comparative analyses of possible influence quantities confirm the earlier observed strong sensitivity of the radiative energy balance of Venus to atmospheric parameter variations, especially to changes of atmospheric temperature structure and cloud distribution with altitude and latitude. Neglect of zonal cloud parameter variations and neglect of the radiative properties of the still unknown UV absorber seriously distorts the general view to radiative forcing. When retrieved atmospheric parameters obtained from both VIRTIS-M-IR and VeRa measurements aboard the Venus Express mission are taken into account, the entire atmosphere of Venus at altitudes between 0 and $90 \mathrm{~km}$ is found to be not far away from radiative equilibrium (usually within $\pm 2 \mathrm{~K} /$ day). Nevertheless, cooling and net heating rate changes for different atmospheric models are still large enough to conclude that future experiments are urgently required to improve knowledge of atmospheric thermal structure and composition.

The observed atmospheric thermal structure in the upper mesosphere used to calculate the net radiative forcing field is characterized by increasing temperatures with latitude with maxima near the pole. This structure can only be maintained by dynamical processes. A possible mechanism would involve a meridional circulation characterized by rising motion at low latitudes, poleward heat flow (being especially strong near the mesopause), and subsidence at high latitudes (Crisp, 1989).

Present results on radiative energy balance analyses will serve as reference for ongoing investigations and provide a profound data base to improve the understanding of 
radiative forcing of atmospheric dynamical processes. The development of parameterization approaches for the calculation of atmospheric temperature change rates that are applicable in GCMs of Venus' atmosphere will mainly constitute the follow-up segment of work.

\section{Acknowledgments}

R.H. is funded by the German Research Foundation under grant number HA 2887/22. We acknowledge the work of the VIRTIS/VEX and VeRa/VEX teams and also the entire Venus Express team of ESA and Astrium, who made the measurement data available that were used in this study.

\section{References}

Arney, G., Meadows, V.S., Crisp, D., Schmidt, S.J., Bailey, J., Robinson, T.D., 2014. Spatially resolved measurements of $\mathrm{H} 2 \mathrm{O}, \mathrm{HCl}, \mathrm{CO}, \mathrm{OCS}, \mathrm{SO} 2$, cloud opacity, and acid concentration in the Venus nearinfrared spectral windows. J. Geophys. Res. 119(8), 1860-1891, http://dx.doi.org/10.1002/2014JE004662.

Arnold, G., Haus, R., Kappel, D., Piccioni, G., Drossart, P., 2012. VIRTIS/VEX observations of Venus: Overview of selected scientific results. J. Appl. Remote Sensing 6, 20 pp.,

http://dx.doi.org/10.1117/1.JRS.6.063580.

ASTM Standard E490-00a, 2006. Solar constant and zero air mass solar spectral irradiance tables, http://rredc.nrel.gov/solar/spectra/am0/.

Bertaux, J.L., Vandaele, A.C., Korablev, O., Villard, E., Fedorova, A. et al., 2007. A warm layer in Venus' cryosphere and high-altitude measurements of $\mathrm{HF}$, $\mathrm{HCl}$, $\mathrm{H} 2 \mathrm{O}$ and HDO. Nature 450, 646-649, http://dx.doi.org/10.1038/nature05974.

Bézard, B., Tsang, C.C.C, Carlson, R.W., Piccioni, G., Marcq, E., Drossart, P., 2009. Water vapor abundance near the surface of Venus from Venus Express / VIRTIS observations. J. Geophys. Res. 114(E00B39),

http://dx.doi.org/10.1029/2008JE003251.

Bougher, S.W., Brecht, A.S., Schulte, R., Fischer, J., Parkinson, C.D. et al., 2015. Upper atmosphere temperature structure at the Venusian terminators: A comparison of SOIR and VTGCM results. Planet. Space Sci. 113-114, 336-346,

http://dx.doi.org/10.1016/j.pss.2015.01.012.
Carlson, R.W. and Anderson, M.S., 2011. Absorption properties of sulfuric acid in Venus' infrared spectral window region. EPSC Abstracts 6, EPSC-DPS20111171 .

Cottini, V., Ignatiev, N.I., Piccioni, G., Drossart, P., Grassi, D., and Markiewicz, W.J., 2012. Water vapor near the cloud tops of Venus from Venus Express / VIRTIS dayside data. Icarus 217(2), 561-569, http://dx.doi.org/10.1016/j.icarus.2011.06.018.

Crisp, D., 1986. Radiative forcing of the Venus mesosphere: I. Solar fluxes and heating rates. Icarus 67(3), 484-514,

http://dx.doi.org/10.1016/0019-1035(86)90126-0.

Crisp, D., 1989. Radiative forcing of the Venus mesosphere: II. Thermal fluxes, cooling rates, and radiative equilibrium temperatures. Icarus $77(2), 391-$ 413,

http://dx.doi.org/10.1016/0019-1035(89)90096-1.

Crisp, D. and Titov, D.V., 1997. The thermal balance of the Venus atmosphere. In Venus-II: Geology, Geophysics, Atmosphere, and Solar Wind Environment, Bougher, S.W., Hunten, D.M., Phillips, R.J. (Eds.), 353-384, Univ. of Ariz. Press, Tucson. ISBN-13: 978-0816518302.

de Bergh, C., Bézard, B., Owen, T., Crisp, D., Maillard, J.P., Lutz, B.L., 1991. Deuterium on Venus: Observations from Earth. Science 251(4993), 547549, http://dx.doi.org/10.1126/science.251.4993.547.

Drossart, P., Piccioni, G., Adriani, A., Angrilli, F., Arnold, G. et al., 2007. Scientific goals for the observation of Venus by VIRTIS on ESA/Venus express mission. Planet. Space Sci. 55(12), 16531672, http://dx.doi.org/10.1016/j.pss.2007.01.003.

Grassi, D., Migliorini, A., Montabone, L., Lebonnois, S., Cardesin-Moinelo et al., 2010. Thermal structure of Venusian nighttime mesosphere as observed by VIRTIS-Venus Express. J. Geophys. Res. 115 (E09007), 11 pp.,

http://dx.doi.org/10.1029/2009JE003553.

Grassi, D., Politi, R., Ignatiev, N.I., Plainaki, C., Lebonnois, S. et al., 2014. The Venus nighttime atmosphere as observed by the VIRTIS-M instrument. Average fields from the complete infrared data set. J. Geophys. Res. 119(4), 837-849, http://dx.doi.org/10.1002/2013JE004586.

Grinspoon, D.H., Pollack, J.B., Sitton, B.R., Carlson, R.W., Kamp, L.W. et al., 1993. Probing Venus's cloud structure with Galileo NIMS. Planet. Space Sci. 41(7), 515-542, http://dx.doi.org/10.1016/0032-0633(93)90034-Y. 
Haus, R. and Goering, H., 1990. Radiative energy balance in the Venus mesosphere. Icarus 84(1), 6282, http://dx.doi.org/10.1016/0019-1035(72)90009-7.

Haus, R., Kappel, D., Arnold, G., 2013. Selfconsistent retrieval of temperature profiles and cloud structure in the northern hemisphere of Venus using VIRTIS/VEX and PMV/VENERA-15 radiation measurements. Planet. Space Sci. 89, 77-101, http://dx.doi.org/10.1016/j.pss.2013.09.020.

Haus, R., Kappel, D., Arnold, G., 2014. Atmospheric thermal structure and cloud features in the southern hemisphere of Venus as retrieved from VIRTIS/VEX radiation measurements. Icarus 232C, 232-248, http://dx.doi.org/10.1016/j.icarus.2014.01.020.

Haus, R., Kappel, D., Arnold, G., 2015a. Lower atmosphere minor gas abundances as retrieved from Venus Express VIRTIS-M-IR data at $2.3 \mu \mathrm{m}$. Planet. Space Sci. 105, 159-174, http://dx.doi.org/10.1016/j.pss.2014.11.020.

Haus, R., Kappel, D., Arnold, G., 2015b. Radiative heating and cooling in the middle and lower atmosphere of Venus and responses to atmospheric and spectroscopic parameter variations. Planet. Space Sci. 117, 262-294,

http://dx.doi.org/10.1016/j.pss.2015.06.024.

Häusler, B., Pätzold, M., Tyler, G.L., Simpson, R.A., Bird, M.K. et al., 2006. Radio science investigations by VeRa anboard the Venus Express spacecraft. Planet. Space Sci. 54(13-14), 1315-1335, http://dx.doi.org/10.1016/j.pss.2006.04.032.

Ignatiev, N.I., Titov, D.V., Piccioni, G., Drossart, P., Markiewicz, W.J. et al., 2009. Altimetry of the Venus cloud tops from the Venus Express observations. J. Geophys. Res. 114(E00B43), 10 pp., http://dx.doi.org/10.1029/2008JE003320.

Jones, A.D., 1976. Optical constants of sulphuric acid in the far infrared. J. Quant. Spectrosc. Radiat. Transfer 16(12), 1017-1019, http://dx.doi.org/10.1016/0022-4073(76)90130-8.

Kappel, D., Haus, R., Arnold, G., 2015. Error analysis for retrieval of Venus' IR surface emissivity from VIRTIS/VEX measurements. Planet. Space Sci. 113$114,49-65$,

http://dx.doi.org/10.1016/j.pss.2015.01.014.

Kappel, D., Arnold, G., Haus, R., 2016. Multispectrum retrieval of Venus IR surface emissivity maps from VIRTIS/VEX nightside measurements of Themis Regio. Icarus 265, 42-62,

http://dx.doi.org/10.1016/j.icarus.2015.10.014.

Keating, G.M., Bertaux, J.L., Bougher, S.W., Cravens, T.E., Dickinson, R.E. et al., 1985. Models of Venus neutral upper atmosphere: Structure and composition. In: The Venus International Reference Atmosphere, Kliore, A. J., Moroz, V.I., Keating, G.M. (Eds.), Adv. Space Res. 5(11), 117-171 (1985), http://dx.doi.org/10.1016/0273-1177(85)90200-5.

Kurucz, R.L., 2011. http://kurucz.harvard.edu/sun/.

Lebonnois, S., Hourdin, F., Eymet, V., Crespin, A., Fournier, R., Forget, F., 2010. Superrotation of Venus' atmosphere analysed with a full general circulation model. J. Geophys. Res. 115(E06006),

http://dx.doi.org/10.1029/2009JE003458.

Lee, C. and Richardson, M.I., 2011. A discrete ordinate, multiple scattering, radiative transfer model of the Venus atmosphere from 0.1 to $260 \mu \mathrm{m}$. J. Atmos. Sci. 68, 13223-1339,

http://dx.doi.org/10.1175/2011JAS3703.1.

Lee, Y.J., Titov, D.V., Tellmann, S., Piccialli, A., Ignatiev, N. et al., 2012. Vertical structure of the Venus cloud top from the VeRa and VIRTIS observations onboard Venus Express. Icarus 217(2), 599-609, http://dx.doi.org/10.1016/j.icarus.2011.07.001.

Lee, Y.L., Titov, D.V., Ignatiev, N.I., Tellmann, S., Pätzold, M., Piccioni, G., 2015. The radiative forcing variability caused by changes of the upper cloud vertical structure in the Venus mesosphere. Planet. Space Sci. 113-114, 298-308,

http://dx.doi.org/10.1016/j.pss.2014.12.006.

Mahieux, A., Vandaele, A.C., Robert, S., Wilquet, V., Drummond, R. et al., 2012. Densities and temperatures in the Venus mesosphere and lower thermosphere retrieved from SOIR on board Venus Express. Carbon dioxide measurements at the Venus terminator. J. Geophys. Res. 117(E7), http://dx.doi.org/10.1029/2012/JE004058.

Mahieux, A., Vandaele, A.C., Robert, S., Wilquet, V., Drummond, R. et al., 2015. Rotational temperatures of Venus upper atmosphere as measured by SOIR on board Venus Express. Planet. Space Sci. 113-114, 347-358, http://dx.doi.org/10.1016/j.pss.2014.12.020.

Marcq, E., Bézard, B., Drossart, P., Piccioni, G., Reess, J.M., Henry, F., 2008. A latitudinal survey of $\mathrm{CO}$, OCS, $\mathrm{H}_{2} \mathrm{O}$, and $\mathrm{SO}_{2}$ in the lower atmosphere of Venus: Spectroscopic studies using VIRTIS-H. J. Geophys. Res. 113(E00B07), http://dx.doi.org/10.1029/2008JE003074.

Moroz, V.I., 1981. The albedo of Venus in the range 0.2-4.0 microns (in Russian). Kosm. Issled. 19(4), 591-598.

Moroz, V.I., Ekonomov, A.P., Moshkin, B.E., Revercomb, H.E., Sromovsky, L.A. et al., 1985. Solar and thermal radiation in the Venus atmosphere. Adv. Space Res. 5(11), 197-232. In: The Venus International 
Reference Atmosphere, Kliore, A. J., Moroz, V.I., Keating, G.M. (Eds.), Adv. Space Res. 5(11), 197-232 (1985), http://dx.doi.org/10.1016/0273-1177(85)902029.

Moroz, V.I., Zasova, L., 1997. VIRA-2: A review of inputs for updating the Venus International Reference Atmosphere. Adv. Space Res. 19(8), 1191-1201, http://dx.doi.org/10.1016/S0273-1177(97)00270-6.

Palmer, K.F. and Williams, D., 1975. Optical constants of sulphuric acid: Application to the clouds of Venus. Appl. Opt. 14(1), 208-219,

http://dx.doi.org/10.1364/AO.14.000208.

Piccialli, A., Montmessin, F., Belyaev, D., Mahieux, A., Wilquet, V. et al., 2014. Thermal structure of Venus' nightside upper atmosphere measured by SPICAV UV on Venus Express. EPSC Abstracts 9, EPSC2014-408.

Piccioni, G., Drossart, P., Suetta, E., Cosi, M., Ammannito, E. et al., 2007a. VIRTIS: The Visible and Infrared Thermal Imaging Spectrometer. ESA Spec. Publ. SP-1295, pp. 1-27, European Space Agency, Paris.

Piccioni, G., Drossart, P., Sanches-Lavega, A., Hueso, R., Taylor, F.W. et al., 2007b. South-polar features on Venus similar to those near the north pole. Nature 450, 637-640, http://dx.doi.org/10.1038/nature06209.

Pollack, J.B., Toon, O.B., Whitten, R.C., Boese, R., Ragent, B. et al., 1980. Distribution and source of the UV absorption in Venus' atmosphere. J. Geophys. Res. 85(A13), 8141-8150, http://dx.doi.org/10.1029/JA085iA13p08141.

Pollack, J.B., Dalton, J.B., Grinspoon, D., Wattson, R.B., Freedman, R. et al., 1993. Near-infrared light from Venus' nightside: A spectroscopic analysis. Icarus 103(1), 1-42,

http://dx.doi.org/10.1006/icar.1993.1055.

Rothman, L.S., Gordon, I.E., Barbe, A., Chris Benner, D., Bernath, P.F., et al., 2009. The HITRAN 2008 molecular spectroscopic database. J. Quant. Spectrosc. Radiative Transfer 110 (9-10), 533-572, http://dx.doi.org/10.1016/j.jqsrt.2009.02.013.

Rothman, L.S., Gordon, I.E., Barber, R.J., Dothe, H., Gamache, R.R., et al., 2010. HITEMP, the hightemperature molecular spectroscopic database. J. Quant. Spectrosc. Radiat. Transfer 111(15), 21392150, http://dx.doi.org/10.1016/j.jqsrt.2010.05.001.

Schofield, J.T. and Taylor, F.W., 1982. Net global thermal emission from the Venusian atmosphere. Icarus 52(2), 245-262, http://dx.doi.org/10.1016/0019-1035(82)90111-7.
Schofield, J.T. and Taylor, F.W., 1983. Measurements of the mean, solar-fixed temperature and cloud structure of the middle atmosphere of Venus. Q. J. Roy. Meteorol. Soc. 109, 57-80, http://dx.doi.org/10.1002/qj.49710945904.

Seiff, A. and Kirk, D.B., 1982. Structure of the Venus mesosphere and lower thermosphere from measurements during entry of the Pioneer Venus probes. Icarus 49(1), 49-70, http://dx.doi.org/10.1016/0019-1035(82)90056-2.

Seiff, A., Schofield, J.T., Kliore, A.J., Taylor, F.W., Limaye, S.S. et 5 al., 1985. Models of the structure of the middle atmosphere of Venus from the surface to 100 kilometers altitude. In: The Venus International Reference Atmosphere, Kliore, A. J., Moroz, V.I., Keating, G.M. (Eds.), Adv. Space Res. 5(11), 3-58 (1985),

http://dx.doi.org/10.1016/0273-1177(85)90197-8.

Smith, W.L., 1970. Iterative solution of the radiative transfer equation for the temperature and absorbing gas profile of an atmosphere. Appl. Opt. 9(9), 19931999 ,

http://dx.doi.org/10.1364/AO.9.001993.

Stamnes, K., Tsay, S.C., Wiscombe, W. and Jayaweera, K., 1988. Numerically stable algorithm for discrete-ordinate-method radiative transfer in multiple scattering and emitting layered media. Appl. Opt. 27(12), 2502-2509,

http://dx.doi.org/10.1364/AO.27.002502.

Taylor, F.W., Beer, R., Chahine, M.T., Diner, D.J., Elson, L.S. et al., 1980. Structure and meteorology of the middle atmosphere of Venus: Infrared remote sensing from the Pioneer orbiter. J. Geophys. Res. 85(A13), 7963-8006,

http://dx.doi.org/10.1029/JA085iA13p07963.

Taylor, F.W., 2006. Venus before Venus Express. Planet. Space Sci. 54(13-14), 1249-1262, http://dx.doi.org/10.1016/j.pss.2006.04.031

Tellmann, S., Pätzold, M., Häusler, B., Bird, M.K., Tyler, G.L., 2009. Structure of the Venus neutral atmosphere as observed by the Radio Science experiment VeRa on Venus Express. J. Geophys. Res. 114(E00B36), 354-372,

http://dx.doi.org/10.1029/2008JE003204.

Tellmann, S., Häusler, B., Hinson, D.P., Tyler, G.L., Andert, T.P. et al., 2012. Small-scale temperature fluctuations seen by the VeRa Radio Science Experiment on Venus Express. Icarus 221(2), 471480, http://dx.doi.org/10.1016/j.icarus.2012.08.023.

Titov, D.V., 1995. Radiative balance in the mesosphere of Venus from the Venera-15 infrared spectrometer results. Adv. Space Res. 15(4), 73-77, http://dx.doi.org/10.1016/0273-1177(94)00066-A. 
Titov, D.V., Svedhem, H., Taylor, F.W., 2006. The atmosphere of Venus: Current knowledge and future investigations. In Solar System Update, Blondel, P., and Mason, J.W. (Eds.), pp. 87-110, Springer Praxis Publishing, Chichester, UK, http://dx.doi.org/10.1007/3-540-37683-6_3.

Titov, D.V., Bullock, M.A., Crisp, D., Renno, N.O., Taylor, F.W., Zasova, L.V., 2007. Radiation in the Atmosphere of Venus. In Exploring Venus as a Terrestrial Planet, Esposito, L.W., Stofan, E.R., and Cravens, T.E. (Eds.), AGU Geophysical Monograph Series 176, 121-138, http://dx.doi.org/10.1029/176GM08.

Titov, D.V., Taylor, F.W., Svedhem, H., 2008a. Introduction to the special section on Venus Express: Results of the Nominal Mission, J. Geophys. Res. 113(E00B19),

http://dx.doi.org/10.1029/2008JE003202.

Titov, D.V., Taylor, F.W., Svedhem, H., Ignatiev, N.I., Markiewicz, W.J., Piccioni, G., and Drossart, P., 2008b. Atmospheric structure and dynamics as the cause of ultraviolet markings in the clouds of Venus. Nature 450, 620-623,

http://dx.doi.org/10.1038/nature07466.

Titov, D.V., Markiewicz, W.J., Ignatiev, N.I., Song, L., Limaye, S.S. et al., 2012. Morphology of the cloud tops as observed by the Venus Express Monitoring Camera. Icarus 217, 682-701, http://dx.doi.org/10.1016/j.icarus.2011.06.020.

Titov, D.V., Piccioni, G., Drossart, P., Markiewicz, W.J., 2013. Radiative energy balance in the Venus atmosphere. In Towards Understanding the Climate of Venus, Bengtsson, L., Bonnet, R.M., Grinspoon, D., Koumoutsaris, S., Lebonnois, S, Titov, D. (Eds.), ISSI Scientific Report Series 11, 23-53, http://dx.doi.org/10.1007/978-1-4614-5064-1_4.

Tomasko, M.G., Doose, L.R., Smith, P.H., 1985. The absorption of solar energy and the heating rate in the atmosphere of Venus. Adv. Space Res. 5(9), 71-79, http://dx.doi.org/10.1016/0273-1177(85)90272-8.

Tsang, C.C.C., Irwin, P.G.J., Wilson, C.F., Taylor, F.W., Lee, C. et al., 2008. Tropospheric carbon monoxide concentrations and variability on Venus from Venus Express/VIRTIS-M observations. J. Geophys. Res. 113(E00B08), 13pp., http://dx.doi.org/10.1029/2008JE003089.

Tsang, C.C.C., Taylor, F.W., Wilson, C.F., Liddell, S.J., Irwin, P.G.J. et al., 2009. Variability of CO concentrations in the Venus troposphere from Venus Express/VIRTIS using a Band Ratio Technique. Icarus 201(2), 432-443, http://dx.doi.org/10.1016/j.icarus.2009.01.001.
Tsang, C.C.C, Wilson, C.F., Barstow, J.K., Irwin, P.G.J. et al., 2010. Correlations between cloud thickness and sub-cloud water abundance on Venus. Geophys. Res. Letters 37(L02202), http://dx.doi.org/10.1029/2009GL041770.

Wilson, C.F., Guerlet, S., Irwin, P.G.J., Tsang, C.C.C., Taylor, F.W., et 3 al., 2008. Evidence for anomalous cloud particles at the poles of Venus. J. Geophys. Res. 113(E00B13), 373-384, http://dx.doi.org/10.1029/2008JE003108.

Wiscombe, W.J., 1980. Improved Mie scattering algorithms. Appl. Opt. 19(9), 1505-1509, http://dx.doi.org/10.1364/AO.19.001505.

Zasova, L.V., Moroz, V.I., Linkin, V.M., Khatuntsev, I.V., Maiorov, B.S., 2006. Structure of the Venusian atmosphere from surface up to $100 \mathrm{~km}$. Cosmic Res. 44(4), 364-383,

http://dx.doi.org/10.1134/S0010952506040095.

Zasova, L.V., Ignatiev, N.I., Khatuntsev, I., Linkin, V., 2007. Structure of the Venus atmosphere. Planet. Space Sci. 55(12), 1712-1728, http://dx.doi.org/10.1016/j.pss.2007.01.011. 